UNIVERSIDADE DE SÃO PAULO

ESCOLA DE ENGENHARIA DE SÃO CARLOS

DEPARTAMENTO DE ENGENHARIA ELÉTRICA E DE COMPUTAÇÃO

PROGRAMA DE PÓS-GRADUAÇÃO EM ENGENHARIA ELÉTRICA

ROSVANDO MARQUES GONZAGA JUNIOR

\title{
PLATAFORMA EMBARCADA PARA MONITORAMENTO DESCENTRALIZADO DE SISTEMAS DE DISTRIBUIÇÃO UTILIZANDO CONCEITOS DE INTERNET DAS COISAS
}

SÃO CARLOS 

ROSVANDO MARQUES GONZAGA JUNIOR

\section{PLATAFORMA EMBARCADA PARA MONITORAMENTO DESCENTRALIZADO DE SISTEMAS DE DISTRIBUIÇÃO UTILIZANDO CONCEITOS DE INTERNET DAS COISAS}

Dissertação de Mestrado apresentada à Escola de Engenharia de São Carlos, da Universidade de São Paulo, como parte dos requisitos para obtenção do Título de Mestre em Ciências, programa em Engenharia Elétrica.

Área de Concentração: Sistemas Elétricos de Potência Orientador: Prof. Dr. João Bosco Augusto London Jr.

Trata-se da versão corrigida dessa dissertação. A versão original se encontra disponível na EESC/USP que aloja o Programa de PósGraduação de Engenharia Elétrica. 

AUTORIZO A REPRODUÇÃO TOTAL OU PARCIAL DESTE TRABALHO, POR QUALQUER MEIO COONVENCIONAL OU ELETRO̊NICO, PARA FINS DE ESTUDO E PESQUISA, DESDE QUE CITADA A FONTE.

Ficha catalográfica elaborada pela Biblioteca Prof. Dr. Sérgio Rodrigues Fontes da EESC/USP com os dados inseridos pelo(a) autor(a).

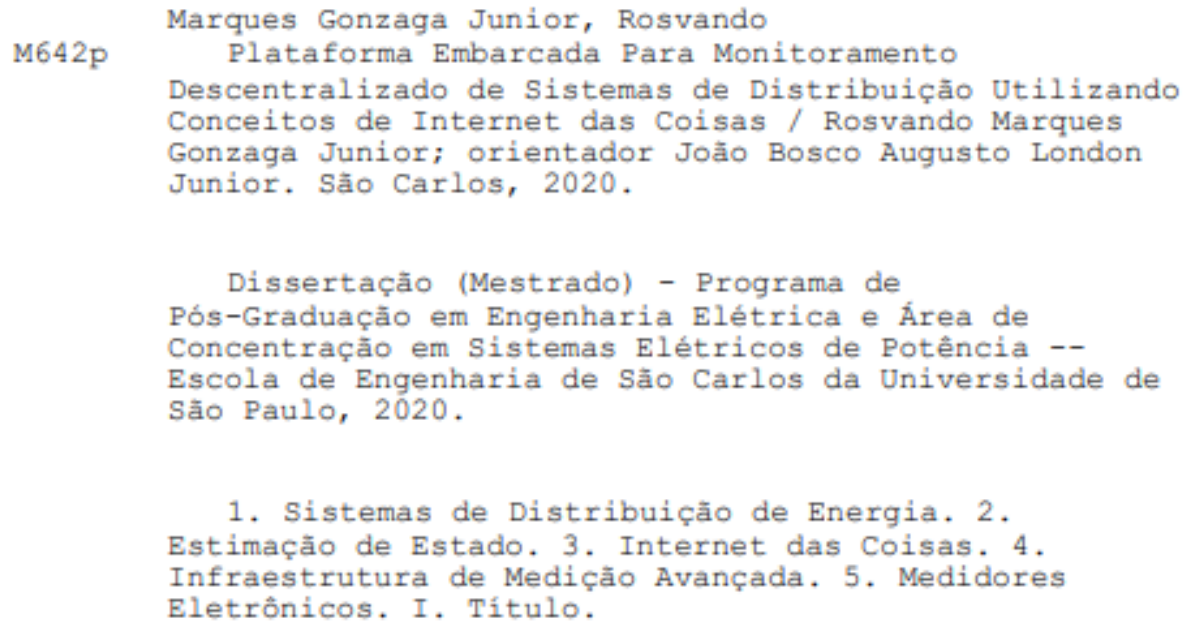

Eduardo Graziosi Silva - CRB - 8/8907 



\section{FOLHA DE JULGAMENTO}

Candidato: Engenheiro ROSVANDO MARQUES GONZAGA JUNIOR.

Título da dissertação: "Plataforma embarcada para monitoramento descentralizado de sistemas de distribuição utilizando conceitos de Internet das Coisas".

Data da defesa: 20/10/2020

Comissão Julgadora:

$\underline{\text { Resultado }}$

Prof. Associado João Bosco Augusto London Junior

Aprovado

(Orientador)

(Escola de Engenharia de São Carlos - EESC/USP)

Prof. Dr. Madson Cortes de Almeida

$\underline{\text { Aprovado }}$

(Universidade Estadual de Campinas/UNICAMP)

Prof. Dr. Edson da Costa Bortoni

Aprovado

(Universidade Federal de Itajubá/UNIFEI)

Coordenador do Programa de Pós-Graduação em Engenharia Elétrica:

Prof. Titular Ivan Nunes da Silva

Presidente da Comissão de Pós-Graduação:

Prof. Titular Murilo Araujo Romero 

Aos meus pais e minha família, com amor. 



\section{AGRADECIMENTOS}

A Deus por permitir que coisas extraordinárias ocorram em minha vida, pela minha família e amigos de longa data.

Aos meus pais, e irmãs pela compreensão e ajuda durante a realização deste trabalho.

À minha namorada pelo suporte, amor e carinho em todas as horas de dificuldade.

Ao Professor Dr. João Bosco Augusto London Junior, pela orientação, confiança no meu trabalho, muitas das vezes realizado a distância, atenção e incentivo na elaboração deste trabalho.

Ao Professor Dr. Rodrigo Maximiano Antunes de Almeida, do IESTI da Universidade Federal de Itajubá, pelo apoio durante o desenvolvimento desta pesquisa.

Ao Professor Dr. Juan Manoel Corchado Rodríguez do Departamento de Informática y Automática da Universidad de Salamanca, pela orientação durante o período de estadia na Espanha.

Aos professores e amigos do Laboratório de Análise Computacional em Sistemas Elétricos de Potência - LACOSEP, pela recepção, contribuição com meu desenvolvimento pessoal, ensinamentos e amizade durante todo este período.

A todos os amigos da pós-graduação pelas conversas, risadas, cafés da Vera, cafés do ICMC e inúmeros almoços e jantares no restaurante universitário da USP.

Aos amigos do Futebol CAASO pela recepção, amizade, jogos, campeonatos, viagens e churrascos que ajudaram e muito na adaptação a cidade de São Carlos -SP.

Aos amigos da Universidad de Salamanca, em especial aos do BISITE, pelo apoio e amizade no período em que estive na Espanha.

A todos os integrantes do Projeto de P\&D (ANEEL 2866-0504/2018) da Companhia Paranaense de Energia - COPEL DISTRIBUIÇÃO S.A.

A todos os funcionários e professores do Departamento de Engenharia Elétrica e Computação da Escola de Engenharia de São Carlos da Universidade de São Paulo.

À FUNAPE pelo apoio financeiro. 

"Quando algo é importante o suficiente, você realiza mesmo que as chances não estejam a seu favor"

(Elon Musk) 



\section{Sumário}

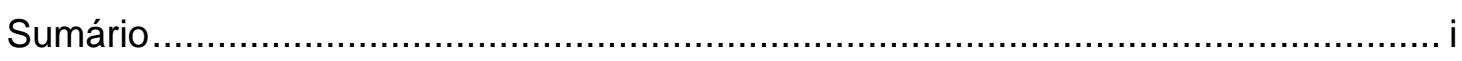

Resumo

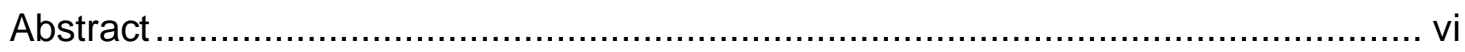

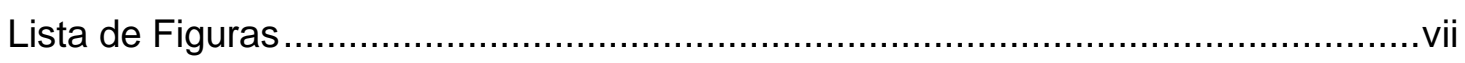

Lista de Tabelas ............................................................................................ viii

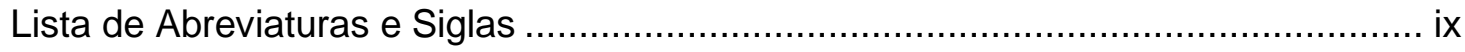

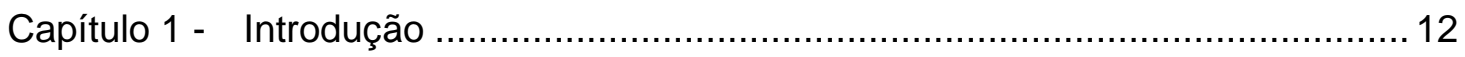

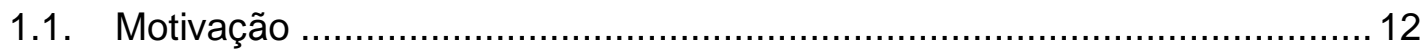

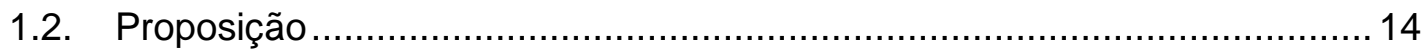

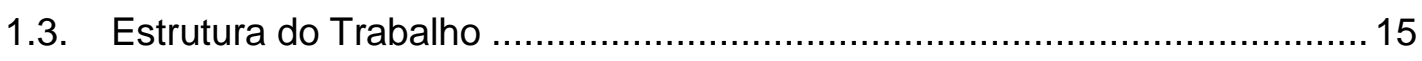

Capítulo 2 - Monitoramento em Tempo Real de Sistemas de Distribuição .............. 17

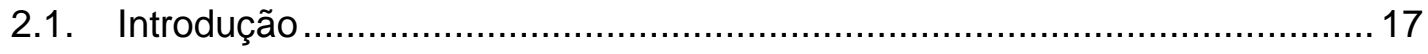

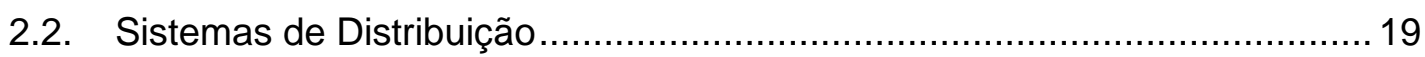

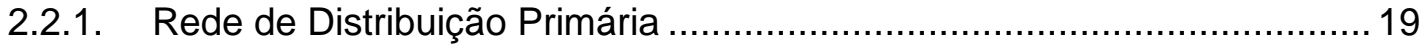

2.2.2. Rede de Distribuição Secundária .................................................... 20

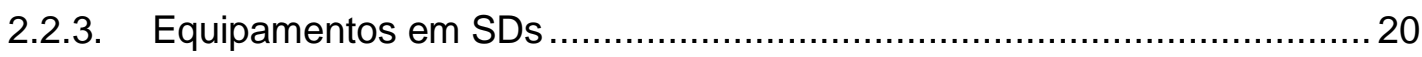

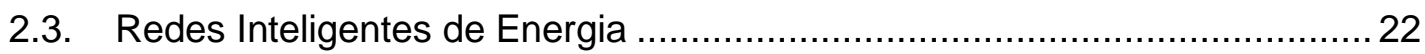

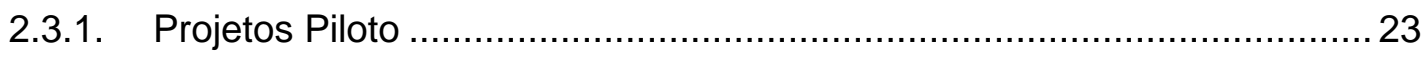

2.4. Estimação de Estado ..................................................................... 24

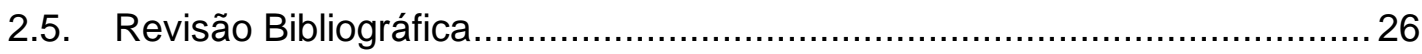

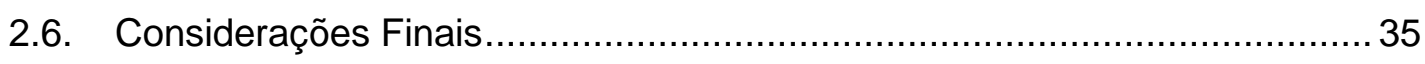

Capítulo 3 - Redes e Protocolos de Comunicação ............................................... 37

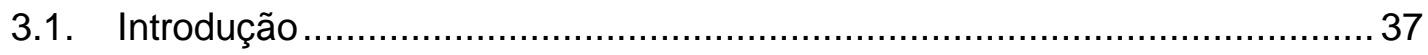

3.2. Tecnologias de Comunicação por Rádio Frequência ............................... 37

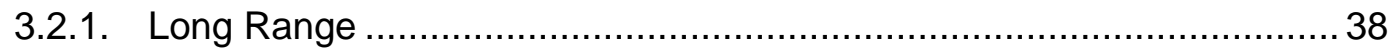

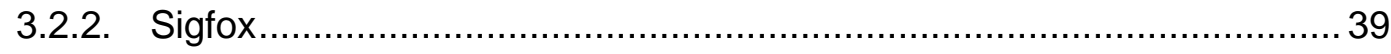


3.2.3. Zigbee.

3.3. Tecnologias de Comunicação Celular ................................................. 40

3.3.1. Long Term Evolution .................................................................. 41

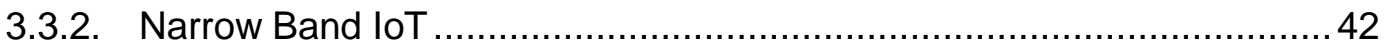

3.4. Comunicação pela rede elétrica ....................................................... 42

3.5. Protocolos de Rede e de Comunicação Para Aplicações de Internet das Coisas $\quad 43$

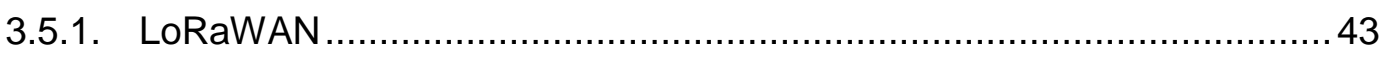

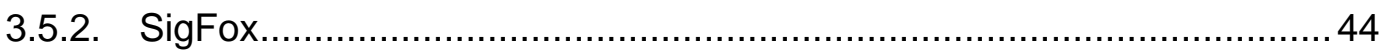

3.5.3. Message Queuing Telemetry Transport (MQTT) ............................... 45

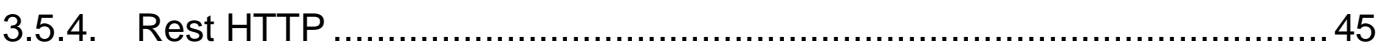

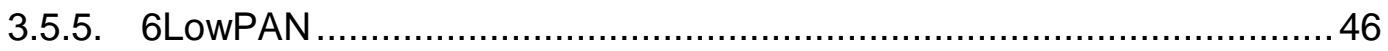

3.6. Faixas de Frequência e Possibilidade de Interferência...............................46

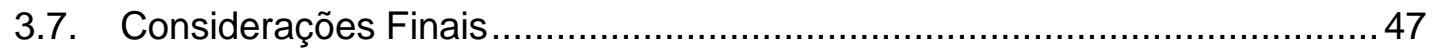

Capítulo 4 - Plataforma Embarcada Para Monitoramento Descentralizado de Redes Inteligentes de Energia

4.1. Introdução . 49

4.2. Arquiteturas Descentralizadas para Alocação de Módulos Eletrônicos para Monitoramento de SDs.

4.3. Comparando as Arquiteturas Descentralizas Propostas Com Uma Centralizada em Um SD Real 52

4.3.1. Rede de Distribuição da Cidade de Londrina-PR .............................52

4.3.2. Requerimentos Computacionais do EEE Proposto …...........................53

4.3.3. Avaliação dos Requisitos de Volume de Dados .................................55

4.3.4. Redução do Volume de Dados Utilizando o Estimado de Estado Embarcado 55

4.4. Metodologia de Implementação da Plataforma Embarcada.........................57

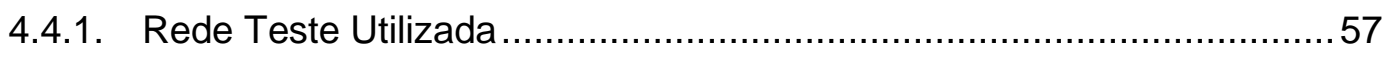

4.4.2. Requerimentos de Hardwares .......................................................... 59

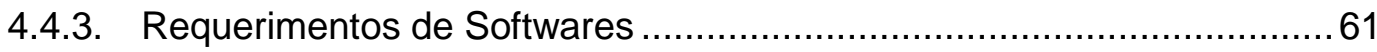




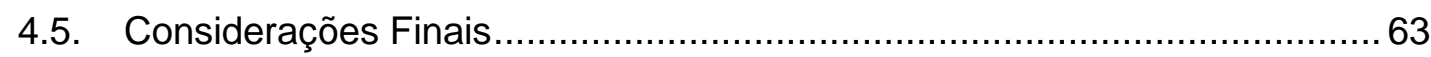

Capítulo 5 - Testes e Análises dos Resultados ................................................6 65

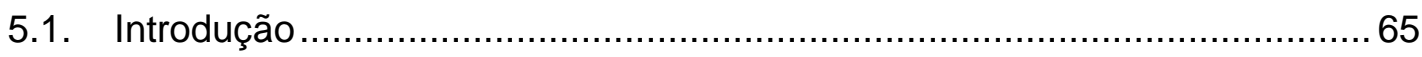

5.2. Detalhamento da Implementação da Plataforma Embarcada......................65

5.3. Sistemática de Avaliação do EEE ................................................. 72

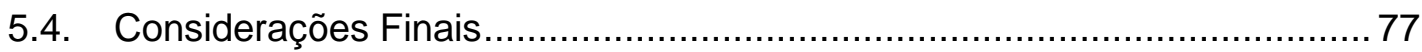

Capítulo 6 - Conclusões e Perspectivas Futuras................................................. 79

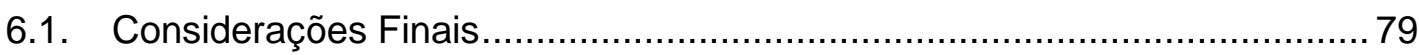

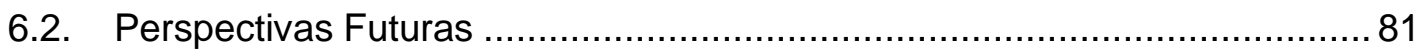

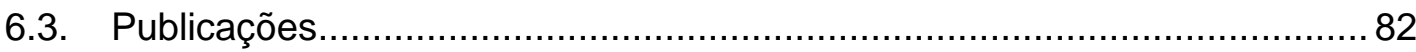

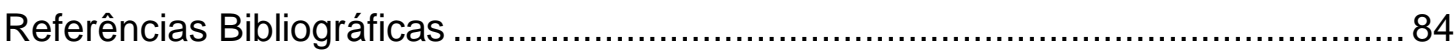

Apêndice A - Resultados do processo de estimação para a rede completa.............. 89

Apêndice B - Resultados do processo de estimação para a rede do transformador 1370 106

Apêndice $C$ - Resultados do processo de estimação para a rede primária com os valores de $\mathrm{P}$ e $\mathrm{Q}$ de cada transformador recebidos da plataforma embarcada. 110 


\section{Resumo}

GONZAGA JUNIOR, R. M. Plataforma Embarcada Para Monitoramento Descentralizado de Sistemas de Distribuição Utilizando Conceitos de Internet das Coisas. 2020. Pg. Dissertação de Mestrado - Escola de Engenharia de São Carlos, Universidade de São Paulo, São Carlos, 2020.

O objetivo principal desta dissertação de mestrado é demonstrar as vantagens e viabilidade do monitoramento descentralizado de Sistemas de Distribuição (SDs). Para isso propõe: (i) Arquiteturas descentralizadas para alocação de módulos eletrônicos de processamento para monitoramento de SDs; (ii) Comparação dessas arquiteturas com uma estratégia centralizada para monitoramento de SDs; (iii) Desenvolvimento e implantação, em bancada, de uma Infraestrutura de Medição Avançada (IMA), fazendo uso de módulos de comunicação que permitem o desenvolvimento de redes wireless para o envio e recebimento de mensagens em tempo real, utilizando conceitos de Internet das Coisas e Edge Computing. Essa infraestrutura possibilita a simulação de uma rede inteligente de energia, no que se refere ao tráfego de informações existentes entre os medidores eletrônicos inteligentes e os centros de operação de sistemas de distribuição; e (iv) desenvolvimento e implantação de um estimador de estado por mínimos quadrados ponderados em um módulo eletrônico (embarcado), a partir da utilização de placas de desenvolvimento eletrônico dotadas de processadores de alta performance, com sistema operacional Linux para possibilitar análises matriciais referentes ao processo de estimação de estado. Os estudos referentes às propostas (i) e (ii) foram desenvolvidos com base no SD real da Companhia Paranaense de Energia (COPEL). Os desenvolvimentos eletrônicos (propostas (iii) e (iv)) foram realizados com apoio do Laboratório de Eletrônica do Grupo de Investigación en Bioinformática, Sistemas Informáticos Inteligentes y Tecnología Educativa (BISITE) da Universidad de Salamanca, na Espanha. Para validação do estimador de estado embarcado em módulos eletrônicos fez-se uso de um sistema de distribuição de energia real, com 114 barras de média tensão, 5 transformadores de distribuição conectados às suas respectivas unidades consumidoras, totalizando 208 barras. Os resultados obtidos têm demonstrado que o uso da arquitetura descentralizada proposta para monitoramento de SDs, que considera a instalação de módulos eletrônicos no secundário dos transformadores de distribuição com estimadores de estado embarcados, reduz consideravelmente a quantidade de dados que transitam pela rede de comunicação sem perda de precisão, assim como os requisitos computacionais para executar o monitoramento em tempo real de SDs.

Palavras-chave - Sistemas de Distribuição de Energia, Internet das Coisas, Infraestrutura de Medição Avançada, Estimação de Estado, Medidores Eletrônicos. 



\section{Abstract}

GONZAGA JUNIOR, R. M. Embedded Platform for Decentralized Monitoring of Distribution Systems Using Internet of Things Concepts. 2020. Pg. MsC Degree Dissertation - Escola de Engenharia de São Carlos, Universidade de São Paulo, São Carlos, 2020.

The main objective of this master's thesis is to demonstrate the advantages and feasibility of decentralized monitoring of Distribution Systems (DSs). For this, it proposes: (i) Decentralized architectures for the allocation of electronic processing modules for DS monitoring; (ii) Comparison of these architectures with a centralized strategy for monitoring of DSs; (iii) Development and implementation, in the bench, of an Advanced Measurement Infrastructure (AMI), making use of communication modules that allow the development of wireless networks for sending and receiving messages in real time, using concepts of Internet of Things (IOT) and Edge Computing. This infrastructure enables the simulation of a smart grid, with regard to the information traffic existing between smart meters and distribution operation centers; and (iv) development and implementation of a state estimator by Weighted Least Squares (WLS) in an electronic module (embedded), from the use of electronic development boards equipped with high performance processors, with Linux operating system to enable matrix analysis related to the state estimation process. The studies related to the proposals (i) and (ii) were developed based on the real DS of Companhia Paranaense de Energia (COPEL). The electronic developments (proposals (iii) and (iv)) were carried out with the support of the Electronics Laboratory of the Research Group in Bioinformatics, Intelligent Systems and Educational Technology (BISITE) of the Universidad de Salamanca in Spain. To validate the estimator and embedded state in electronic modules, a real energy DS was used, with 114 medium voltage bars, 5 distribution transformers connected to their respective consumer units, totaling 208 bars. The results obtained have shown that the use of the decentralized architecture proposed for monitoring DSs, which considers the installation of electronic modules in the secondary of distribution transformers with embedded state estimators, considerably reduces the amount of data that transits through the communication network without loss of precision, as well as the computational requirements to perform real-time monitoring of DSs.

Keywords - Distribution Systems, Smart Meters, Advanced Measurement Infrastructure, State Estimation, Embedded Systems, Internet of Things. 


\section{Lista de Figuras}

Figura 2.1: Componentes de um sistema elétrico de potência. 19

Figura 2.2: Abordagem da penetração de novas tecnologias nas rede de distribuição.

Figura 2.3: Projeto de implementação de redes inteligentes na cidade de Jaguariúna SP

Figura 2.4:Metodologia de estimação de estado sequencial por WLS (do inglês Weighted Least Squares) proposta em (SOUSA et al., 2018). 30

Figura 3.1: Taxa de dados vs alcance da tecnologia. 44

Figura 4.1: Parâmetros de entrada e saída do estimador embarcado. 50

Figura 4.2: Ilustração da implementação da primeira arquitetura proposta. 51

Figura 4.3: Sistema de distribuição em larga escala da cidade de Londrina-PR . 52

Figura 4.4: Quantidade de dados processados pelo EEE em cada transformador de distribuição no período de um dia. 56

Figura 4.5: Rede teste utilizada para implementação. ........................................ 58

Figura 4.6: Especificações Técnicas Jetson Nano.............................................. 61

Figura 4.7: Esquemático de desenvolvimento. .................................................63

Figura 5.1: Conexão entre a Raspberry PI e o módulo LoRa Ra-01.........................65

Figura 5.2: Conexão física do gateway de processamento...................................6 66

Figura 5.3: Dashboard desenvolvido na plataforma Things Board.........................6 67

Figura 5.4: Plataforma completa em funcionamento.......................................... 68

Figura 5.5: Estrutura de funcionamento da rede de comunicação. ...........................69

Figura 5.6: Implementação da arquitetura proposta.............................................. 70

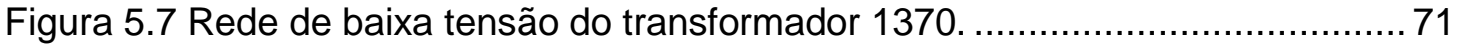

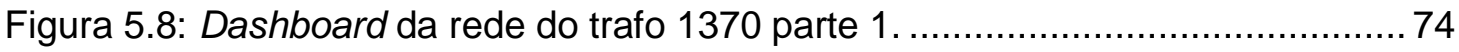

Figura 5.9: Dashboard da rede do trafo 1370 parte 2. ...................................... 74

Figura 5.10: Dashboard da rede do trafo 1370 parte 3 ....................................... 75

Figura 5.11:Dashboard da rede do trafo 1370 parte 4 .......................................... 75 


\section{Lista de Tabelas}

Tabela 3.1- Requisitos de comunicação de diferentes tipos de redes.......................37

Tabela 3.2: Dados utlizados pela rede Sigfox (OSMAN; ABBAS, 2018)...................39

Tabela 4.1- Quantidade de EEEs e média de UCs por EEE de cada uma das Arquiteturas Descentralizadas Propostas - Com base no SD Real da COPEL....................53

Tabela 4.2: Custo e tempo computacional para executar a estimação de estados para as arquiteturas definidas.

Tabela 4.3: Quantização de dados processados por cada estimador embarcado nas arquiteturas descentralizadas propostas. .56

Tabela 4.4: Quantidade de UCs por transformador. 59

Tabela 5.1: Valores utilizados para a inserção de ruídos. 73

Tabela 5.2: Comparativo entre os resultados dos EE executados para a rede completa e para rede primária. 76

Tabela 5.3: Tempo de execução do EE para as redes definidas. 77 


\section{Lista de Abreviaturas e Siglas}

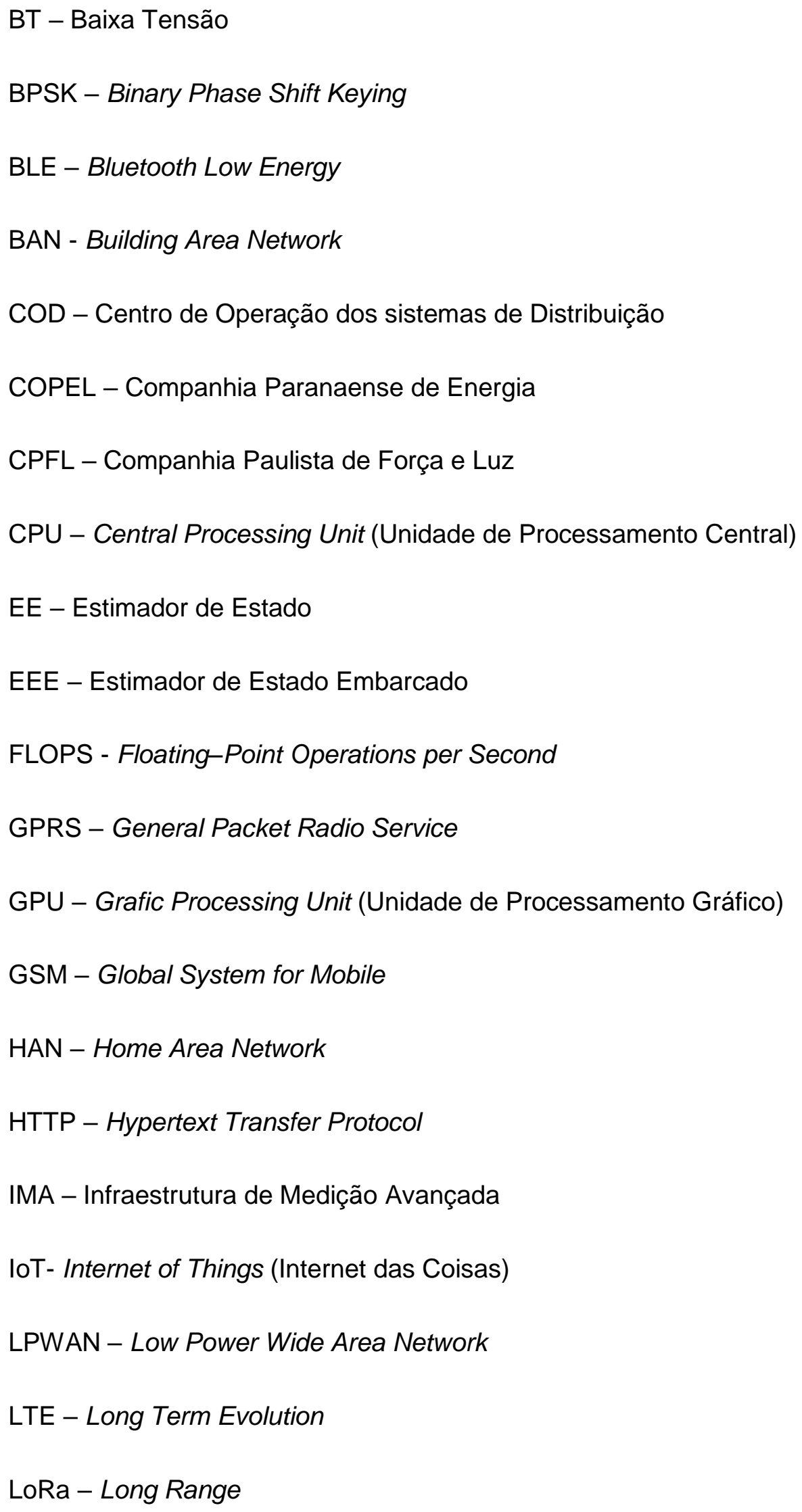


MT - Média Tensão

MQP - Mínimos Quadrados Ponderados

MQTT - Message Queuing Telemetry Transport

M2M - Machine-to-Machine (Máquina a Máquina)

NAN - Neighborhood Area Network

NB - Narrow Band

OFDMA - Orthogonal Frequency Division Multiple

PSO - Particle Swarm Optimization (Otimização por Enxame de Partículas)

PMU - Pashor Measurement Units (Unidade de Medição Fasorial)

PLC - Power Line Communication

QoS - Quality of Service (Qualidade de Serviço)

REST - Representational State Transfer

RF - Rádio Frequência

RNA - Redes Neurais Artificiais

SD - Sistema de Distribuição

SE - Subestação de Distribuição

SEP - Sistema Elétrico de Potência

SCADA - Supervisory Control and Data Acquisition (Sistema Supervisório de Controle e Aquisição de Dados)

SG - Smart Grids

SoC - System on a Chip

UNB - Ultra Narrow Band

UC - Unidades Consumidoras 
WAN - Wide Area Network

3Gpp - $3^{r d}$ Generation Partnership Project

6LowPAN - IPv6 over Low-Power Wireless Personal Area Networks 


\section{Capítulo 1 - Introdução}

\subsection{Motivação}

Diversos fatores relacionados ao conceito de redes inteligentes (do inglês, Smart Grids) têm contribuído para aumentar a complexidade da operação dos Sistemas de Distribuição (SDs), tais como: novas arquiteturas de redes elétricas com capacidade de operar autonomamente; penetração de novas fontes de energia renováveis (nas redes de distribuição primária e secundária); o advento dos Veículos Elétricos; armazenamento de energia; etc. Dessa forma, nos últimos anos vem aumentando o interesse pelo desenvolvimento e implantação de ferramentas para monitoramento em tempo real de SDs. Ou seja, de ferramentas que possibilitem a aferição, em tempo real, da condição operacional dos SDs, pois a partir dessa informação ações de controle podem ser tomadas para corrigir falhas e garantir um estado operativo seguro.

A ferramenta fundamental para monitoramento em tempo real de redes elétricas é o Estimador de Estado (EE), que tem a função de determinar, em tempo real, as variáveis de estado da rede (usualmente as tensões complexas nodais), através do processamento de um conjunto redundante de medidas com ruído. Mediante a análise dessas variáveis de estado verifica-se a condição operacional da rede elétrica. Porém, historicamente, a quantidade limitada de medidas existentes nos SDs inviabilizou a implantação de EEs nessas redes. Entretanto, acontecimentos recentes, também relacionados ao conceito de redes inteligentes, vêm propiciando um aumento significativo na quantidade de medidas disponíveis nos SDs, motivando o desenvolvimento e implantação de EEs específicos para esses sistemas. Dentre esses acontecimentos destacam-se a instalação de Medidores Eletrônicos Inteligentes (MEI) na rede secundária e o desenvolvimento das chamadas micro PMUs (do inglês, Phasor Measurement Units) (PRIMADIANTO; LU, 2017), que permitem a medição de grandezas fasoriais nos SDs.

O aumento da quantidade de informações disponíveis nos SDs contribui para o desenvolvimento e implantação de EEs nesses sistemas, mas, por outro lado, traz à tona algumas questões que devem ser analisadas no desenvolvimento desses EEs. Isto em razão do aumento da quantidade de dados que passarão a ser transmitidos para os Centros de Operação dos sistemas de Distribuição (CODs) e da dimensão da rede elétrica que terá que ser considerada pelo EE (RAFAEL S. SILVA, FELIPE M. LABURU, 2017). Pois as redes primárias de distribuição já acarretam em redes de larga escala, geralmente compostas por dezenas de milhares de barras, e a adição dos modelos das redes secundárias de distribuição, 
onde os MEls estão sendo instalados, deve elevar essa escala para centenas de milhares de barras. Dessa forma, duas características se sobressaem como necessárias para a estimação de estado em SDs: capacidade de lidar com sistemas de larga escala e desempenho computacional para tratar as peculiaridades das redes de distribuição.

Face ao exposto, devido à dimensão e subdivisão dos SDs em diversos alimentadores, uma alternativa que se apresenta como interessante para a operação dos SDs, é a utilização de uma abordagem multiáreas (M.V.; H.A.; ANANTHAPADMANABHA, 2015). Desde o início do desenvolvimento dos EEs, considerou-se a ideia de operar os sistemas elétricos através de subdivisões em áreas e de maneira descentralizada (VAN CUTSEM; RIBBENS-PAVELLA, 1983), isto em função de o setor elétrico ser divido em regiões e possuírem operadores distintos, e também de forma a melhorar a eficiência computacional e confiabilidade dos EEs. Desse modo, ao longo dos anos diversos EEs foram propostos, para sistemas de transmissão, utilizando o conceitos de decomposição em multiáreas e abordagens descentralizadas (GÓMEZ-EXPOSITO et al., 2011).

Com o advento da eletrônica e das redes de telecomunicações, cada vez mais é possível realizar o monitoramento em tempo real de dispositivos conectados à rede de energia. Assim, utilizando conceitos e tecnologias criados para atender demandas oriundas dessas novas aplicações, destacam-se as novas redes de comunicação desenvolvidas para o ecossistema de Internet das Coisas (do inglês - loT - Internet of Things), são elas: Sigfox, Narrow Band IoT, LoRa, entre outras, que permitem a conexão de vários dispositivos com longo alcance e baixo consumo de energia. Da mesma forma, os avanços da capacidade de processamento dos dispositivos eletrônicos embarcados permitem que operações, antes confiadas aos CODs, sejam prontamente executadas de forma independente por módulos embarcados fazendo o uso do conceito de computação na borda (do inglês - Edge Computing). As redes inteligentes visam modificar a rede de energia para um poderoso sistema confiável incorporando vários modos de controle e funções automatizadas. A implantação das Infraestruturas de Medição Avançadas (IMA) é um fator chave para o desenvolvimento das redes inteligentes (KHEAKSONG; LEE, 2014). A IMA é uma infraestrutura conectada que inclui $\mathrm{MEl}$, redes de comunicação em diferentes níveis hierárquicos, como sistemas de gerenciamento de dados provenientes dos MEls, e os própios CODs das concessionárias para integralizar os dados (ELAKSHUMI; PONRAJ, 2017).

Nesse contexto, aparecem como promissoras as propostas vislumbrando a realização da estimação de estado descentralizada em SDs, diferentemente dos EEs convencionais centralizados usualmente proposto para essas redes elétricas. 


\subsection{Proposição}

Devido às incessantes atualizações tecnológicas ocorridas nos últimos tempos, sejam no campo das telecomunicações ou da eletrônica, esta dissertação de mestrado visa demonstrar as vantagens e viabilidade do monitoramento descentralizado de SDs. Importa recordar, mais uma vez, que tradicionalmente os CODs fazem uso de estratégias centralizadas para monitoramento de SDs.

Para atingir o objetivo em mira, propõe-se:

1. Arquiteturas descentralizadas para alocação de módulos eletrônicos de processamento para monitoramento de SDs, cada um deles contando com um estimador de estado (embarcado) por mínimos quadrados ponderados;

2. Comparação das arquiteturas descentralizadas propostas com uma estratégia centralizada para monitoramento de SDs;

3. Desenvolvimento e implantação, em bancada, de uma IMA, fazendo uso de módulos de comunicação que permitem o desenvolvimento de redes wireless para o envio e recebimento de mensagens em tempo real, utilizando conceitos de Internet das Coisas e Edge Computing. Essa infraestrutura deverá possibilitar a simulação de uma rede inteligente de energia, no que se refere ao tráfego de informações existente entre os MEls e os CODs;

4. Desenvolvimento e implantação de um estimador de estado por mínimos quadrados ponderados em um módulo eletrônico (embarcado), a partir da utilização de placas de desenvolvimento eletrônico dotadas de processadores de alta performance, com sistema operacional Linux para possibilitar análises matriciais referentes ao processo de estimação de estado.

Para desenvolvimento das propostas (i) e (ii) será utilizado como referência um SD real da COPEL. Importa destacar que os desenvolvimentos eletrônicos (propostas (iii) e (iv)) foram realizados com apoio do Laboratório de Eletrônica do Grupo de Investigación en Bioinformática, Sistemas Informáticos Inteligentes y Tecnología Educativa (BISITE) da Universidad de Salamanca na Espanha1. Para validação do EE embarcado em cada módulo eletrônico, utilizar-se-á um sistema de distribuição de energia real, com 114 barras de média tensão, 5 transformadores de distribuição conectados às suas respectivas unidades consumidoras, totalizando 208 barras.

1 Convênio de Mobilidade Internacional firmado entre a Universidade de São Paulo e a Universidad de Salamanca para alunos e docentes dos programas de pós-graduação. 
Vale ressaltar que este trabalho não tem como objetivo o estudo de EEs descentralizados, como apresentado nos trabalhos de (M.V.; H.A.; ANANTHAPADMANABHA, 2015) e (VAN CUTSEM; RIBBENS-PAVELLA, 1983). Destacase que esse estudo está sendo realizado em uma pesquisa de doutorado em desenvolvimento no Laboratório de Análises Computacionais em Sistemas Elétricos de Potência, da Escola de Engenharia de São Carlos, da Universidade de São Paulo (LACOSEP EESC/USP), grupo de pesquisa em que este trabalho de mestrado foi realizado. Destaca-se também que para este trabalho não foi realizada a análise econômica de implementação dos módulos em um sistema real, devido ao curto prazo para o desenvolvimento do trabalho proposto.

Os resultados obtidos de simulações computacionais e da utilização da plataforma desenvolvida têm demonstrado as vantagens e viabilidade de arquiteturas descentralizadas para monitoramento de SDs, em especial, da arquitetura considerando a instalação de módulos eletrônicos no secundário dos transformares de distribuição, com estimadores de estado embarcados. Isto em razão de essa arquitetura ter possibilitado uma redução considerável da quantidade de dados que transitam pela rede de comunicação, assim como os requisitos computacionais para executar o monitoramento em tempo real de SDs.

\subsection{Estrutura do Trabalho}

Este documento encontra-se dividido em 6 capítulos, onde a introdução corresponde ao primeiro. Todos possuem Introdução e Considerações Finais para manter a coesão entre as ideias apresentadas em cada capítulo.

O capítulo 2, intitulado "Monitoramento em tempo real de SDs", traz a definição do processo de estimação de estado em SDs e apresenta uma revisão bibliográfica, destacando diversos trabalhos relevantes apresentados na literatura especializada.

No capítulo 3 apresentam-se tecnologias de comunicação sem fio utilizadas em aplicações para redes inteligentes, assim como protocolos de comunicação empregados em projetos de Internet das Coisas.

No capítulo 4 encontra-se o estudo sobre a quantidade de dados que passarão a ser trocados entre o COD e os MEls, com base em uma rede real de distribuição de energia situada na cidade de Londrina- PR, pertencente a Companhia Paranaense de Energia (COPEL). Em seguida, é apresentada a metodologia de implementação da plataforma embarcada desenvolvida.

No capítulo 5 apresentam-se os testes e análises dos resultados obtidos a partir da metodologia proposta. 
As considerações finais deste trabalho de dissertação de mestrado, bem como as perspectivas futuras, são apresentadas no capítulo 6 . 


\section{Capítulo 2 - Monitoramento em Tempo Real de Sistemas de Distribuição}

\subsection{Introdução}

Nos últimos anos, os SDs foram afetados por muitas mudanças significativas. Entre elas as novas regulamentarizações do mercado de energia, que permitem e auxiliam o aumento da penetração de geração distribuída, principalmente fontes renováveis de energia, e novos recursos energéticos distribuídos, como veículos elétricos, que transformaram a rede passiva em uma rede ativa altamente complexa. Em função desses aspectos, bem como dos requisitos sempre mais rigorosos para qualidade de energia e confiabilidade do sistema, fazse necessário um melhor gerenciamento e controle efetivo da rede. Para atender a essa necessidade, uma nova filosofia para rede de distribuição foi criada, conhecida como redes inteligentes (DELLA GIUSTINA et al., 2014).

Com o avanço das tecnologias de medição e de comunicação de dados, cada vez mais é possível se ter dispositivos telecomandados onde seja factível a repartição da rede de energia em pequenas redes independentes dentro do SD, sendo essas pequenas redes chamadas de micro-redes.

Tais micro-redes estarão a maior parte do tempo operando sincronizadas com a rede elétrica ao redor, mas também serão capazes de se separar durante os períodos de contingência devido à tempestades ou perturbações temporárias, como falhas da rede local (JOOS et al., 2017). Porém, ainda com esses avanços as iniciativas para implementação e utilização de redes equipadas com dispositivos que permitam tal operação, tem pouca aderência ao mercado de energia elétrica nacional.

A operação em tempo real é de fundamental importância para automatização dos SDs. A estipulação da condição operacional dos alimentadores de distribuição de energia elétrica com precisão aceitável é o primeiro passo para o desenvolvimento de inúmeras funções automatizadas, como, por exemplo, o restabelecimento de energia das redes de distribuição após a ocorrência de faltas permanentes.

A gestão e operação de redes de baixa tensão (BT) podem ser bastante desafiadoras, considerando sua extensão e o número de ativos a serem controlados, quando comparados a níveis de tensão mais altos. Além disso, algumas dessas redes podem ter várias décadas de tempo de vida e, portanto, os recursos de monitoramento na rede de BT são tipicamente reduzidos (CAMPOS et al., 2017). 
Conforme já mencionado neste texto, para realizar a operação em tempo real de redes elétricas o primeiro passo é a determinação do estado operativo corrente. Para isso, o estimador de estado desempenha um papel fundamental, pois através do estimador as medidas obtidas em tempo real (que estão sujeitas à ruídos inerentes do processo de tele medição) são processadas para obtenção das variáveis de estado (usualmente tensões complexas nodais), através das quais determina-se o estado de operação.

No entanto, diversos fatores característicos de redes de distribuição não contribuem de forma positiva para a estimação de estado em SDs, são eles (DELLA GIUSTINA et al., 2014):

- Usualmente os SDs são compostos por alimentadores radiais, com ramais que podem ser monofásicos, bifásicos (cargas residenciais) ou trifásicos (cargas comerciais e industriais);

- Os SDs são compostos por redes não-transpostas, desbalanceadas por natureza (em virtude da impossibilidade de distribuir uniformemente as cargas nos alimentadores) e com alta relação resistência/reatância;

- São diversas as possibilidades de conexão dos transformadores e das cargas dos SDs;

- A dimensão do problema é elevada, pois, mesmo para uma cidade de pequeno porte (de até 50 mil habitantes), o SD pode conter milhares de barras bifásicas e trifásicas;

- A maioria dos alimentadores possuem medidas de magnitude de corrente ao invés de medidas de potência, que representam um problema para utilização de estimadores convencionais (problemas de ordem numérica);

- Normalmente os status de dispositivos seccionadores e de banco de capacitores, bem como a posição de taps de transformadores, não são monitorados de forma direta;

- Reduzido número de medidas, em relação aos sistemas de transmissão. Dessa forma, para possibilitar a execução de EEs em SDs torna-se necessário a utilização de pseudo-medidas de carga, obtidas usualmente a partir dos chamados estimadores de demanda (AUGUSTO et al., 2018).

Nas próximas seções deste capítulo serão abordados temas sobre as redes de distribuição, equipamentos que fazem parte de um SD e as atualizações tecnológicas que vem adentrando os sistemas primários e secundários de distribuição de energia. Da mesma maneira, tem como objetivo apresentar o desenvolvimento tecnológico a respeito de 
estimação de estado em SDs, assim como a revisão bibliográfica desta linha de pesquisa. Com isto revela-se a importância do monitoramento em tempo real dos SDs e da necessidade de métodos de análises específicos para as informações provenientes das redes de distribuição de energia.

\subsection{Sistemas de Distribuição}

\subsubsection{Rede de Distribuição Primária}

O SD normalmente começa com a subestação de distribuição (SE) que é alimentada por uma ou mais linhas de sub transmissão. Em alguns casos, a SE é alimentada diretamente a partir de uma linha de transmissão de alta tensão, caso em que, muito provavelmente, não há um sistema de sub transmissão. No entanto, isso varia de empresa para empresa. Cada SE servirá um ou mais alimentadores primários. Com raras exceções, os alimentadores são radiais, o que significa que existe apenas um caminho para a energia fluir da SE para o usuário (KERSTING, 2011).

Os níveis de tensão geralmente utilizados na rede de distribuição primária variam de 11 a $23 \mathrm{kV}$, dependendo da localidade e das empresas responsáveis pela operação do SD, sendo a tensão de distribuição em $13.8 \mathrm{kV}$ a mais utilizada no Brasil. Os principais componentes e etapas que a energia elétrica percorre em um Sistema Elétrico de Potência (SEP) podem ser observados na Figura 2.1.

Figura 2.1: Componentes de um sistema elétrico de potência.

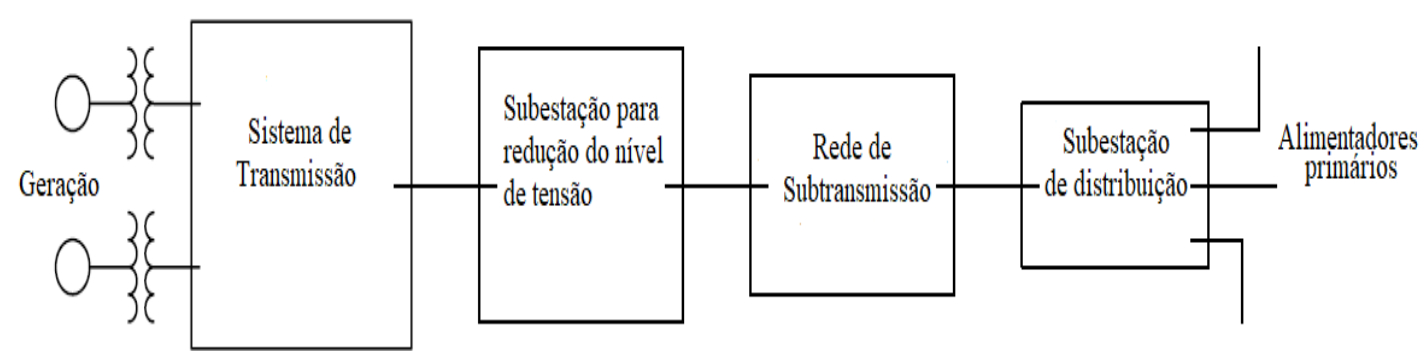

Fonte : Adaptado de (KERSTING, 2011).

Os SDs, sejam eles aéreos ou subterrâneos, são configurados para operar de maneira radial em sua enorme maioria, de forma a favorecer fatores inerentes à proteção, tendo como exemplo: coordenação e atenuação de correntes de curto-circuito pretendendo diminuir custos com equipamentos. Via de regra, esses sistemas apresentam possibilidades de alteração da topologia, através de controle de abertura e fechamento das chaves 
seccionadoras presentes em pontos de interconexões (MANTOVANI; CASARI; ROMERO, 2000).

\subsubsection{Rede de Distribuição Secundária}

A rede de distribuição secundária tem seu ponto de início a partir dos transformadores de distribuição. Tais equipamentos fazem a conexão da rede de distribuição primária com a rede de distribuição secundária. O nível de tensão proveniente dos alimentadores de Média Tensão (MT), ou do sistema (ou rede) de distribuição primária, passa por uma regulação nos transformadores de distribuição e a partir de então se tornam adequados para os sistemas (ou redes) de distribuição secundários, ou também conhecidos como BT. No Brasil geralmente os circuitos secundários operam com tensões de 220/127V ou 380/220V. Assim como as redes primárias, as redes secundárias também podem ser aéreas ou subterrâneas, predominando no Brasil as redes aéreas, com topologias de redes radiais ou em malha (KAGAN; OLIVEIRA; ROBBA, 2005).

Como exposto anteriormente, as redes de distribuição acarretam sistemas de grande ordem e com relevante complexidade na sua operação, necessitando dessa forma de equipamentos que permitam o funcionamento do SD de forma continua e segura. Além disso, são de fundamental importância, para a operação de um SD, informações sobre o estado operativo corrente da rede de distribuição, sendo este obtido através dos medidores de grandezas elétricas instalados ao longo do SD.

\subsubsection{Equipamentos em SDs}

Os principais equipamentos para compor uma rede de distribuição, seja ela primária ou secundária, quando se trata de uma análise estática, seja pelo fluxo de potência ou mesmo no contexto de estimação de estado de monitoramento em tempo real, são:

(i) Transformadores de Distribuição: tem a função de conectar a MT com a BT;

(ii) Ramal de Ligação: trata-se do conjunto de condutores que ligam a rede de distribuição secundária até as unidades consumidoras (UCs). Os cabos dos alimentadores secundários geralmente possuem bitolas maiores, pois devem suportar correntes altas;

(iii) Medidores de Energia: geralmente são instalados dentro das caixas de medição e tem como principal função medir e registrar o consumo de energia elétrica ativa ou reativa do consumidor em questão;

(iv) Chaves Seccionadoras ou Chaves Faca: são dispositivos que fazem parte do $\mathrm{SD}$, e que tem como principal objetivo propiciar manobras na rede, para eventuais 
manutenções, reformas, ou falhas em geral. Geralmente estas manobras se dão através do fechamento ou abertura de um componente similar a uma barra metálica;

(v) Chaves Fusíveis: são dispositivos que procuram proteger o alimentador secundário, isolando eletricamente e automaticamente a parte da rede faltosa do sistema no menor tempo possível. Seu princípio de funcionamento é baseado na temperatura, através do sobreaquecimento de um elo condutor fusível quando o limite é atingido;

(vi) Unidades Consumidoras: são também chamados de clientes. É o destino final da energia elétrica, ou seja, é caracterizado pela entrega de energia elétrica em um ponto com o equipamento de medição individualizado.

As novas redes de distribuição de energia se apresentam desafiadoras nos quesitos de monitoramento e gestão das novas tecnologias como os MEls, geração distribuída, veículos elétricos, armazenadores de energia, entre outras. Desse modo, as novas funcionalidades oriundas destas tecnologias, que vem adentrando rapidamente o panorama das distribuidoras no Brasil e no mundo, aumentam a complexidade do gerenciamento e operação de um SD. A Figura 2.2 traz uma abordagem onde estas novas tecnologias estão presentes nas redes secundárias. 
Figura 2.2: Abordagem da penetração de novas tecnologias nas rede de distribuição.

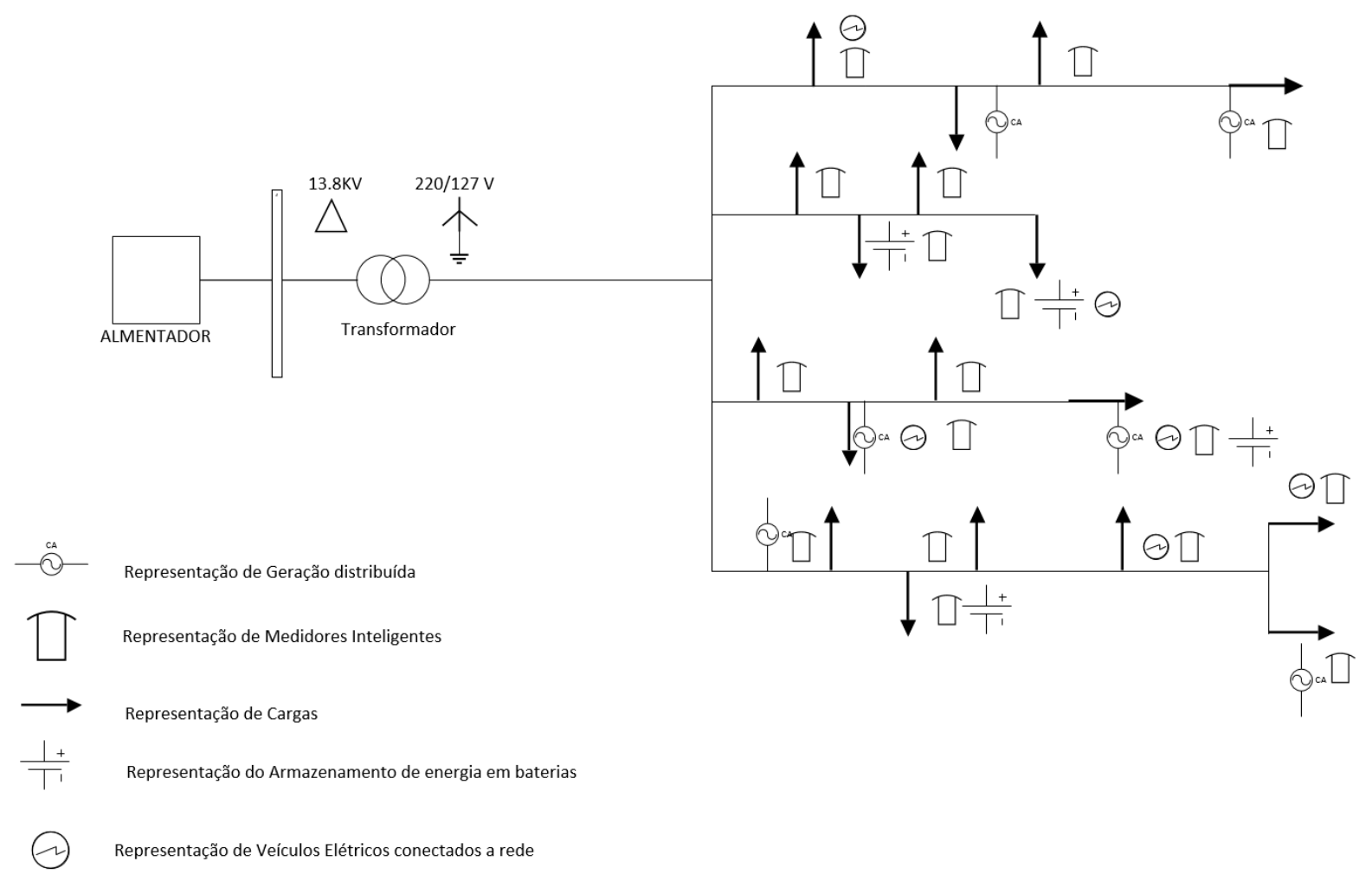

Fonte: Elaborada pelo autor.

\subsection{Redes Inteligentes de Energia}

Uma rede inteligente de energia envolve aplicativos baseados em informações disponibilizadas pelo aumento da automação e da infra-estrutura de comunicação. Entre os componentes presentes nas futuras redes de energia estão MEls, dispositivos de armazenamento de energia e aparelhos inteligentes e infra-estrutura de software tais como padrões de interoperabilidade e protocolos de segurança cibernética. As motivações para o desenvolvimento dessas aplicações são a resiliência da rede, o desempenho e as eficiências operacionais geradas com a automatização dos SDs (LEFEBVRE; PREVOST; LENOIR, 2014).

As redes inteligentes visam modificar a rede de energia para um poderoso sistema confiável incorporando vários modos de controle e funções automatizadas. A implantação das AMls é um fator chave para o desenvolvimento das redes inteligentes (KHEAKSONG; LEE, 2014). A IMA é uma infraestrutura conectada que inclui MEls, redes de comunicação em diferentes níveis hierárquicos, como sistemas de gerenciamento de dados provenientes dos MEls, e os própios CODs das concessionárias para integralizar os dados (ELAKSHUMI; PONRAJ, 2017). 
Os MEls são usados para registrar o consumo de energia e outras informações relacionadas, como indicadores de qualidade de energia. Os medidores enviam mensagens a montante em resposta a solicitações. Também pode receber sinais de preços ou mesmo algum nível de controle pode ser incorporado aos MEls. Além disso, eles podem também estabelecer um caminho de comunicação com os medidores mais próximos (SHIOBARA; PALENSKY; NISHI, 2015).

\subsubsection{Projetos Piloto}

A Companhia Paulista de Força e Luz (CPFL) com sede na cidade de Campinas - SP, pretende transformar a rede distribuição da cidade de Jaguariúna - SP em uma rede inteligente, substituindo a tradicional leitura manual de consumo de energia por um sistema eletrônico, conectado e mais inteligente. Dessa forma os clientes, residenciais, rurais e comerciais de pequeno porte, receberão os novos MEls. Essa tecnologia permite detectar falhas, armazenar energia, acionar mecanismos para evitar interrupções e, ainda, a gestão do consumo de energia. Segundo a CPFL, a digitalização das redes elétricas é o futuro do setor e modernizar cada vez mais as redes de energia, traz uma grande melhora na eficiência operacional e na qualidade do serviço (ENERGIA, 2017).

O projeto visa a instalação de mais de 20 mil MEls na rede de distribuição de BT da cidade de Jaguariúna -SP. Com um investimento de $R \$ 26$ milhões, serão testados MEls com diferentes tecnologias de comunicação, afim de averiguar o melhor comportamento de cada tecnologia (CPFL ENERGIA, 2019). A Figura 2.3 apresenta mais detalhes sobre o projeto da CPFL. 
Figura 2.3: Projeto de implementação de redes inteligentes na cidade de Jaguariúna -SP.

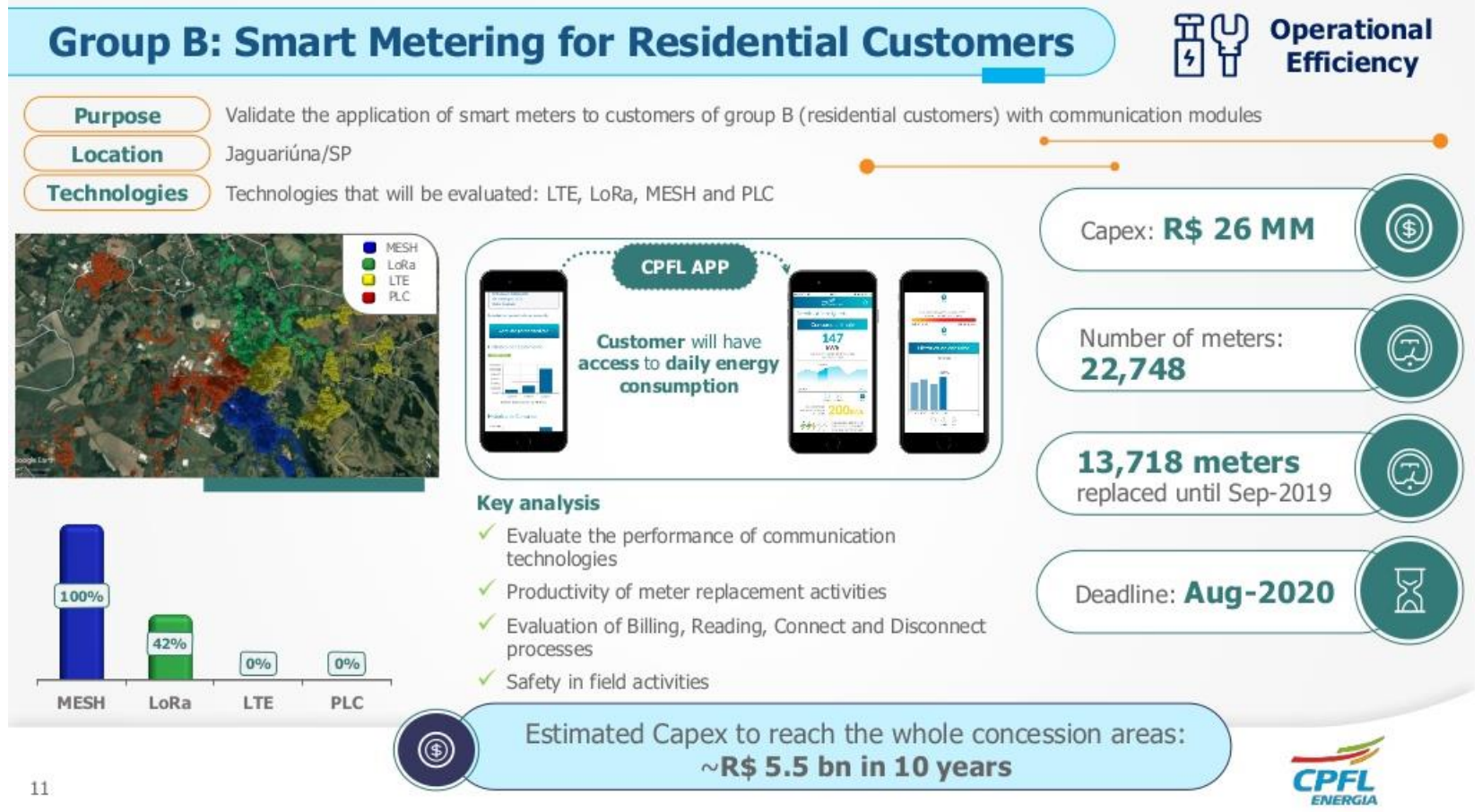

Fonte: Retirado de (CPFL ENERGIA, 2019) .

Outra companhia de energia a investir em projetos de cidades inteligentes é a LIGHT Serviços de Eletricidade S.A na cidade do Rio de Janeiro - RJ. O projeto busca a criação de uma IMA para mais de 400 mil UCs, 100 SEs e 2200 alimentadores na cidade. O plano visa automatizar cortes e religamentos, câmaras de transformadores e além da troca da leitura de consumo, antes realizada de forma manual, para um sistema com MEls, onde a medição é realizada de forma eletrônica enviando os dados via redes de comunicação. As tecnologias de transferência de dados, por Rádio Frequência (RF), General Packet Radio Service (GPRS) e Power Line Communication (PLC), tecnologias essas que serão discutidas no Capitulo 3 deste trabalho. Em um plano de 5 anos, o projeto visa a expansão da IMA criada para atender mais de 1.4 milhão de UCs (CRUZ, 2017).

Diversas outras concessionárias de energia elétrica no Brasil e no mundo, investem em projetos relacionados a redes inteligentes de energia. Trazendo dessa forma, atualizações tecnologicas para as antigas redes de distribuição de energia, fazendo uso de sistemas eletrônicos para medição de energia, e de novas tecnologias de comunicação para o envio de infomações.

\subsection{Estimação de Estado}

$\mathrm{Na}$ formulação tradicional do processo de estimação de estado em sistemas elétricos de potência (SEP), as tensões complexas nodais são tomadas como as variáveis de estado do sistema, pois, através das mesmas é possível determinar o estado operativo corrente de 
um SEP (ABUR; EXPÓSITO, 2004). Tal formulação se baseia nas relações entre as medidas analógicas e as variáveis de estado expressas através de funções não lineares.

O problema de estimação de estado para um sistema com $m$ medidas e $n$ variáveis de estado é formulado usando o seguinte modelo de medição (PRIMADIANTO; LU, 2017):

$$
z=h(x)+e
$$

Onde " $z$ " é o vetor de medição $(m \times 1)$; " $x$ " é o vetor de variáveis de estado $(n \times 1)$; " $h(x)$ " é o $(m \times 1)$ conjunto de equações não lineares que relaciona as medições com as variáveis de estado; e "e" é o vetor de ruído de medição $(m \times 1)$ tipicamente assumido como variáveis aleatórias independentes normalmente distribuídas, com média zero e matriz de covariância conhecida. Tipicamente, o vetor de estado $x$ de um SEP é composto pela magnitude de tensão e ângulo de fase em todos nós da rede elétrica. O modelo de medição $h(x)$ é composto por medições de potência ativa e reativa (fluxo e injeções) e medidas de magnitude de tensão, e a relação com as variáveis de estado é obtida através de equações de fluxo de potência (PRIMADIANTO; LU, 2017).

Diversos métodos foram desenvolvidos para melhorar o processo de estimação de estado em SDs, desde o método clássico de Mínimos Quadrados Ponderados (MQP) até métodos específicos para SDs, como o estimador de estado Branch-Current (PRIMADIANTO; LU, 2017). Através da abordagem por MQP convencional, o objetivo é encontrar o vetor $n$ que minimiza o índice $J(x)$, definido da seguinte maneira:

$$
J(x)=[z-h(x)]^{T} R^{-1}[z-h(x)]
$$

Onde o vetor de estado $x$, é estimado formando recursivamente a matriz Jacobiana $H(x)=\partial h(x) / \partial x$, e resolvendo as equações normais:

$$
G(x) \cdot \Delta x=H^{T}(x) \cdot R^{-1} \cdot[z-h(x)],
$$

Com $G(x)=H^{T}(x) \cdot R^{-1} \cdot H(x)$, sendo a matriz de ganho do sistema.

O algoritmo acoplado de um EE MQP é formulado da seguinte maneira (SCHWEPPE; WILDES, 1970).

i) Fazer $v=0$ e escolher uma solução inicial $x^{v}=x^{0}$;

ii) Calcular $G(x)$ no ponto $x=x^{v}$;

iii) Obter a correção nas variáveis de estado: 


$$
\left\{\begin{array}{l}
\Delta x^{v}=\left[G\left(x^{v}\right)\right]^{-1} \cdot H^{T}\left(x^{v}\right) \cdot W^{-1} \cdot\left[z-h\left(x^{v}\right)\right] \\
x^{v+1}=x^{v}+\Delta x^{v}
\end{array}\right.
$$

iv) Testar a convergência: se $\left|\Delta x_{i}^{v}\right|_{\operatorname{Max}} \leq \varepsilon$, sendo $\varepsilon$ a tolerância pré-especificada, o processo convergiu e $\hat{x}=x^{k+1}$. Caso contrário, faça $v=v+1$ e volta ao passo (ii).

A seguir são apresentados alguns dos principais EEs desenvolvidos para monitoramento em tempo real de SDs. São apresentados também desenvolvimentos recentes no contexto de redes inteligentes e uso de novas tecnologias no apoio ao gerenciamento dos dados oriundos da rede de distribuição. Espera-se assim contextualizar o problema de estimação de estado em SDs assim como apresentar as diferentes estratégias adotadas para viabilizar a implementação de EEs nas novas redes de distribuição.

\subsection{Revisão Bibliográfica}

Como exposto anteriormente, o monitoramento em tempo real de SDs tem caraterísticas especificas necessitando de um tratamento apropriado para que se possa garantir a confiabilidade e a precisão das abordagens já consagradas em sistemas de transmissão. Nesta seção são apresentados alguns dos principais EEs desenvolvidos para monitoramento em tempo real de SDs, destacando as estratégias utilizadas para estimação de estado em SDs radiais.

Em (BARAN; KELLEY, 1995) é apresentado um estimador por MQP trifásico para SDs radiais, ou pouco malhados, que considera as correntes nos ramos como variáveis de estado, ao invés das tensões nodais. De acordo com os autores, dentre as vantagens desta abordagem, o processo de estimação pode ser desacoplado entre as fases e não apresenta problemas de condicionamento numérico (BARAN; MCDERMOTT, 2009). Este EE exige a conversão de medidas de potência ativa e reativa e das pseudo-medidas em medidas equivalentes de corrente na forma retangular. As medidas de amplitude de corrente são também decompostas em parte real e imaginária, a partir de uma estimativa do ângulo de fator de potência. Nesta versão inicial deste estimador não foram consideradas medidas de magnitude de tensão. Utiliza-se, ainda, uma regra para reduzir o tamanho do alimentador, para melhorar a eficiência computacional do algoritmo. Para isso, os ramais são reduzidos concentrando suas cargas no tronco do alimentador. Tal procedimento não é adequado quando se deseja estimar a carga de transformadores de distribuição, ou de consumidores da rede primária conectados nesses ramais. As tensões nodais são então atualizadas através de uma execução de varredura direta no alimentador a partir da tensão medida na subestação com as correntes estimadas. O critério de convergência é dado pela diferença da atualização 
do valor das correntes entre duas iterações sucessivas. Caso não haja convergência, as medidas de corrente equivalentes são novamente calculadas, com os novos valores de tensão nodais, e o processo é executado novamente. Em (LIN; TENG; CHEN, 2001) foram propostas melhorias na formulação deste EE para obter melhor performance numérica e computacional.

O monitoramento em tempo real de SDs com EEs utilizando Redes Neurais Artificiais (RNA) foi proposto em (BERNIERI et al., 1996). Nesta abordagem, a RNA é utilizada para estimar tanto as tensões nodais como as demandas de potência de transformadores de distribuição (injeções de potência ativa e reativa nas barras) a partir de um número pequeno de medidas em tempo real. Os autores apresentam resultados com precisão similar às metodologias tradicionais baseada no estimador por MQP, com erros na estimação relacionados principalmente com a incerteza das pseudo-medidas. Os autores também reconhecem o custo computacional oneroso do treinamento das redes neurais, mas afirmam que após o treinamento a rede neural apresenta desempenho computacional suficiente para aplicações on-line.

$\mathrm{Na}$ abordagem proposta por (BARAN, 2012), o método Branch-Current apresentado anteriormente em (BARAN; KELLEY, 1995), baseado no MQP, é utilizado para realizar a estimação de estado em tempo real em um SD de 34 barras. Além da utilização das recentes IMAs desenvolvidas para os novos SDs, o autor faz uso de dados históricos como pseudomedidas para ilustrar o efeito dos dados adicionais oriundos da IMA no processo de estimação de estado, considerando dois casos bases. No primeiro, a medição em tempo real é disponível apenas na SE e as cargas são representadas por pseudo-medidas com precisão de $30 \%$. Já no segundo caso existem medições em tempo real no alimentador bem como medições de carga através da IMA.

A pesquisa realizada por (RAMESH et al., 2012) propõe a alocação de MEls e um EE híbrido para alcançar uma operação confiável e o controle do sistema de gerenciamento de distribuição de energia. O algoritmo para posicionamento dos MEls é formulado usando Otimização de Enxame de Partículas (PSO - do inglês Particle Swarm Optimization) e o algoritmo para a estimativa de tensão nas barras é formulado usando metodologias de RNA. Os algoritmos formulados são verificados com sistemas testes do IEEE e do Conselho de Eletricidade de Tamil Nadu (TNEB - do inglês Tamil Nadu Electricity Board).

Em (HAUGHTON et al., 2013) é apresentado um algoritmo de estimação de estado trifásico linearizado para aplicação em SDs inteligentes. Casos trifásicos desequilibrados e equilibrados são apresentados na abordagem em que são incorporados, aos dados tradicionais, informações provenientes de medidores fasoriais sincronizados. Para isso é utilizado o conhecido MQP em um EE estático para sistemas lineares e não iterativos. Com a 
utilização do método e de medidas fasoriais sincronizadas para aumentar a precisão, são alcançadas melhorias nas estimativas de magnitude e ângulo das tensões, e da mesma forma também reduz o erro da magnitude de corrente calculada em aproximadamente $10 \%$.

O trabalho de (SHEN; LIANG, 2013) propõe um modelo de estimação de estado considerando gerações fotovoltaicas medidas e não monitoradas com base em algoritmos melhorados dos métodos de Branch-Current e Branch-Power. Para validação são utilizados exemplos numéricos na análise do impacto da localização e penetração da GD em uma rede de distribuição de 69 barras. Três abordagens são propostas para avaliar o impacto gerado, na primeira adicionam-se conjuntos de painéis fotovoltaicos com capacidade de $800 \mathrm{~kW}$ e com medição, para todos os nós, exceto o nó raiz (no da subestação). Na segunda é averiguado em qual nó da abordagem anterior exibe menor erro, e então é modificado o valor da potência injetada neste nó e analisada a relação entre o erro a e capacidade de penetração dada pela equação:

$$
k=\frac{P p v}{P l},
$$

Onde, $P p v$ é a saída de potência ativa dos painéis fotovoltaicos, $P l$ é a carga total do $\mathrm{SD}$, e $k$ o índice de penetração. Já na terceira abordagem é adicionada a potência gerada pelos painéis fotovoltaicos, não monitorada, de $120 \mathrm{~kW}$ somente na barra 50 . Os autores concluíram que a inserção de energia fotovoltaica na rede de distribuição, longe da subestação, tem pouco efeito sobre a estimativa de estado. Já os nós mais carregados têm forte capacidade de aceitação de painéis fotovoltaicos e influenciam mais na estimativa de estado do que os nós menos carregados.

Os autores de (CHEN et al., 2014) consideraram o uso de dados dos MEls para estimação de estado em SDs, coletados uma vez por dia. A eficácia dessa estratégia foi então comparada com uma segunda estratégia baseada na coleta de dados a cada 30 minutos. Primeiramente foi avaliada a adequação do uso dos dados para previsão de carga em transformadores e, em seguida, utiliza essa previsão como pseudo-medidas para o EE. As saídas do EE indicam o estado em tempo real de todo o sistema que pode ser usado para tomar decisões eficazes para controle e otimização do SD. Os resultados apresentados monstram que a aquisição de dados a cada 30 minutos melhoram significativamente a previsão de carga. No entanto, os resultados do EE mostram que nem a estratégia de coleta é suficiente para estimar o estado de um sistema com precisão, exigindo assim medições adicionais em tempo real. 
O trabalho de (YUEHAO et al., 2016) apresenta um método de estimação de estado para rede de distribuição com base nos dados oriundos dos sistemas de distribuição de energia elétrica. Os dados são tratados para complementar as medidas SCADA (do ingles Supervisory Control and Data Acquisition) com intuito de atingir a observabilidade ${ }^{2}$ do sistema e aumentar a precisão do processo de estimação de estado. Tal método utiliza dados de monitoramento de cargas existentes, como tensão, corrente, potência ativa e reativa dos transfomadores no lado da rede secundária, para adquirir informações de alimentadores especificados e informações de cada barra por meio do EE baseado em MQP. Os autores estabelecem um modelo de estimativa de MQP com restrição de igualdade, considerando a equação de injeção de corrente assimétrica, equação de medição virtual de ponto neutro, equação de amplitude de tensão de fase do nó e equação de restrição de igualdade de injeção zero do nó terra e no neutro, que baseia-se no modelo de fluxo de potência de distribuição.

A pesquisa realizada por (WAERESCH et al., 2017) propõe um conceito de EE para rede secundária baseado em dados oriundos de MEls instalados ao longo do SD. O algoritmo de um EE por MQP é utilizado, de modo que o SD não é propenso a problemas de convergência. As medidas processadas são magnitudes de tensão e corrente, bem como potências ativa e reativa. $O$ processo de detecção de erros grosseiros baseia-se na análise dos resíduos normalizados. Para garantir que as topologias da rede também sejam atualizadas corretamente em redes em malha, um novo algoritmo para detecção de falhas de topologia também é proposto no trabalho. Os resultados apresentados são obtidos a partir de simulações. Os resultados de testes em campo são promissores, apresentando precisões adequadas e probabilidades de detecção de dados ruins, especialmente para magnitude de tensão e de corrente.

Em (RADHOUSH; LIN, 2018) são empregados dois métodos disseminados de compressão de dados, a decomposição do valor singular e o algoritmo de análise de componentes principais. Estes métodos são utilizados para compactar os dados da rede de distribuição antes de enviá-los aos CODs, possibilitando que tais dados sejam descompactados nos CODs com a mínima perda possível. Dessa forma, estes dados serão utilizados no processo de estimação de estado para avaliação do desempenho da rede de distribuição considerando também a inserção de geração distribuída.

O trabalho de (ROSENBERG; BHATTACHARYA, 2018) apresenta um EE para SDs radiais baseado em um conjunto de filtros de Kalman, onde a estimativa no tempo ( $\mathrm{t}$ ) depende das estimativas (t-1). Esse modelo, ao contrário do MQP tradicional, não incorpora as

${ }^{2}$ A observabilidade consiste em verificar se é possível estimar todas as variáveis de estado do SEP através do conjunto de medidas disponíveis. 
equações do fluxo de potência para o estimador, tornando-se uma técnica versátil. Em vez disso, o EE depende de um solucionador de fluxo de potência externo. Dessa forma, os autores buscam superar os desafios relacionados à estimação de estado filtrada utilizando filtros de Kalman em cascata, para verificar se abordagem é vantajosa e traz benefícios ao processo de estimação de estado.

O estudo realizado em (SOUSA et al., 2018) expõe uma metodologia para estimação de estado em SDs baseada em um estimador sequencial MQP. Estimações sucessivas são realizadas substituindo as medições com menor precisão, em função da hierarquia dos erros dos respectivos equipamentos, por valores previamente estimados. Para validação é utilizado um modelo monofásico não linear para rede de distribuição e um sistema teste da literatura para avaliação de eficiência computacional de metodologias para o mesmo fim. As medidas classificadas como de baixa qualidade são aquelas que introduzem um erro maior que $15 \%$ nos valores de referência das medidas. Devido ao método MQP requerer baixo custo computacional, cerca de 0,15 s por iteração, permite que os requisitos de operação em quase tempo real sejam atingidos mesmo com a aplicação de um modelo sequencial iterativo. A Figura 2.4 exibe o fluxograma da metodologia proposta.

Figura 2.4:Metodologia de estimação de estado sequencial por WLS (do inglês - Weighted Least Squares) proposta em (SOUSA et al., 2018).

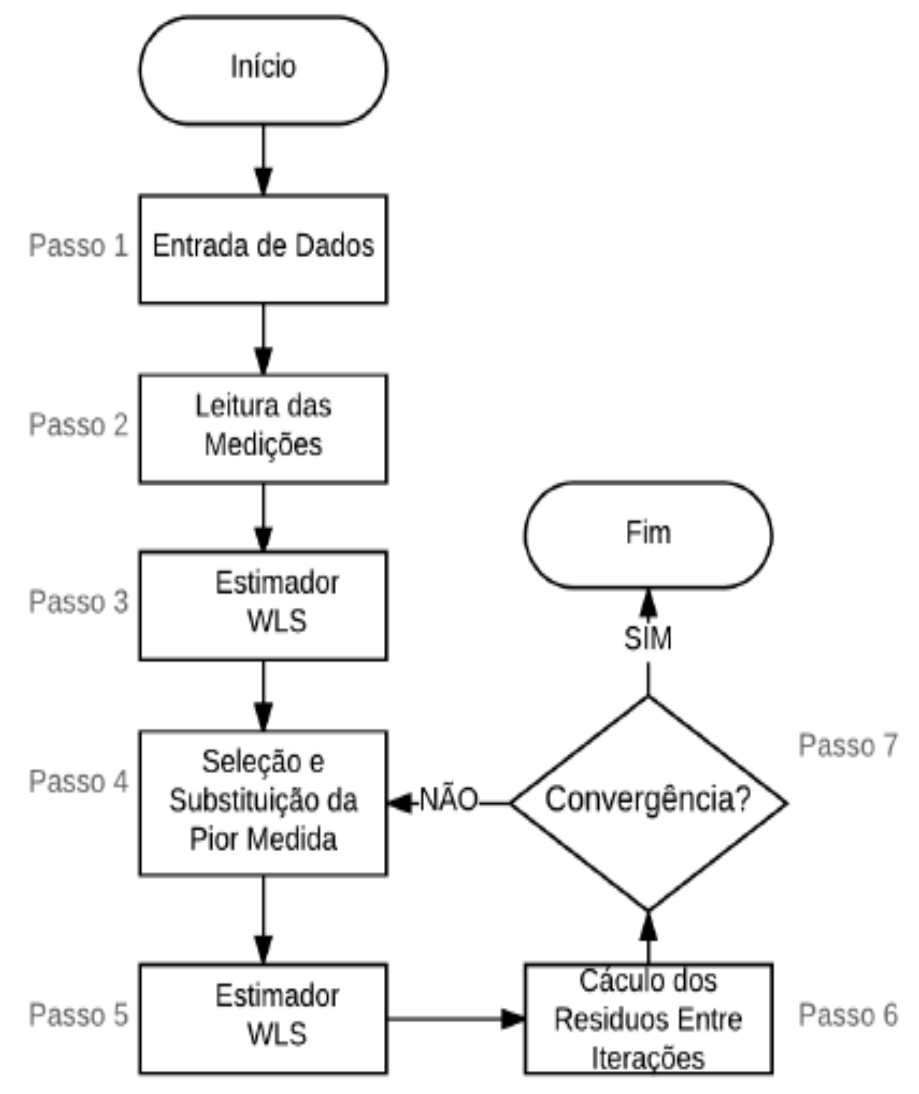

Fonte: Retirado de (SOUSA et al., 2018). 
O trabalho de (SILVA et al., 2018) concentra-se na análise do impacto das medições remotas na estimação de estado em SDs utilizando diferentes configurações e arranjos de MEls ao longo de uma rede de distribuição, utilizando um EE tradicional por MQP e um índice de aumento na precisão da estimativa, que avalia a qualidade da estimação. O software DIgSILENT PowerFactory, que tem suas aplicações voltadas para geração, transmissão, distribuição e sistemas que contenham GD, é empregado para avaliar o impacto das medidas remotas na estimação de estado. Os autores concluem que o arranjo e a quantidade de MEls instalados no SD analisado interferem na precisão do processo de estimação de estado. Isto, devido a altos desvios nas medições, distância dos centros de carga ou proximidades de grandes cargas com medidas com erros grosseiros, medidores mal alocados, baixo número de informações disponíveis na rede, erro de precisão dos próprios medidores, entre outros.

Devido aos estimadores tradicionais desenvolvidos para SDs possuírem limitações no tratamento redes com tamanhos elevados, e ao fato de cada parte do SD apresentar medidas com taxas de amostragem distintas, diversos pesquisadores propõem metodologias a fim de tratar tais déficits. Nesse contexto, destaca-se os estimadores descentralizados desenvolvidos para utilização em SDs de larga escala. Já para tratar medidas com taxas de amostragem diferentes, como medidas PMU (do inglês - Pashor Measurement Units), SCADA e, agora com o avanço das redes inteligentes de energia, oriundas dos MEls, são propostos alguns estimadores híbridos. A seguir serão apresentados alguns trabalhos que propõem o tratamento de medidas com taxas de amostragens distintas e também estimadores descentralizados.

Em (SANTOS; ORILLAZA, 2018) é proposto um EE hibrido também baseado em MQP que utiliza medidas provenientes dos sistema SCADA e medidas oriundas de micro PMUs. Um EE Simultâneo Híbrido é uma configuração capaz de processar tantos dados do sistema SCADA quanto das micro PMUs, processando ambas as medições e modificando internamente o estimador existente para utilizar medições de micro PMUs. Entretanto esse método não produz resultados satisfatórios na presença de erros grosseiros ${ }^{3}$, particularmente quando encontrados em medidas fasoriais. Simulações são realizadas em um sistema teste de 37 barras e os resultados mostram que a inclusão de dados fasoriais em $20 \%$ das barras da rede apresentam melhora na precisão e na variância da estimativa obtida, provando também ser um EE mais robusto quanto comparado ao EE MQP tradicional. Destaca-se, ainda, que nesse trabalho não foi considerado o fato de as medidas SCADA e de micro PMUs terem tempos de varredura distintos.

${ }^{3}$ Uma medida é portadora de erro grosseiro se desvia de seu valor verdadeiro de 3 vezes o valor de seu desvio padrão (ABUR; EXPÓSITO, 2004). 
Os autores de (GHOLAMI et al., 2018) estenderam o algoritmo do EE MQP baseado em tensão nodal tradicionalmente utilizado para a inclusão de medidas de PMUs para obter, assim como em (SANTOS; ORILLAZA, 2018), estimativas mais precisas nos SDs. Uma rede de distribuição do Reino Unido foi simulada no software OpenDSS e seus resultados do fluxo de potência alimentam o softaware MATLAB. Neste trabalho, a parte real e a imaginária das tensões nodais foram selecionadas como variáveis de estados, produzindo assim equações de medição linearizadas e isto pode ser traduzido para uma menor complexidade do processo de estimação em SDs quando utilizadas apenas medidas fasoriais sincronizadas. A metodologia proposta mostrou que as tensões nodais foram estimadas com precisão, além disso foi realizada uma comparação entre o método estendido e o método tradicionalmente utilizado em projetos de estimação de estado.

Em (FARAJOLLAHI; SHAHSAVARI; MOHSENIAN-RAD, 2018) é proposto um novo método de estimação de estado monitorando a configuração da rede, para se unir aos métodos já conhecidos de estimação em SDs, de modo que, faz uso das tensões nodais e de medidas fasoriais sincronizadas para atualizar os estados do sistema após a mudança de status de um elemento do sistema sem a necessidade de reexecutar o EE. As trocas na configuração do sistema podem ser detectadas pelos fasores de tensão e corrente fornecidos por micro PMUs conectadas aos SDs. A essência da proposta baseia-se na análise do circuito equivalente de um SD, fazendo uso de teoremas de compressão de circuitos. Os eventos do SD são definidos como qualquer alteração nos parâmetros do sistema que não interrompa o funcionamento normal do sistema, tal como uma mudança de carga um determinado local. Tais eventos são detectados pelo monitoramento de medições de tensão e corrente oriundas do micro PMUs. Os estudos de casos realizados no trabalho confirmam que o método proposto pode atualizar o status da rede com precisão no sistema utilizado. A eficácia do método é examinada também sobre as incertezas dos parâmetros do sistema e também para um intervalo razoável de erros na admitância de linhas e precisão da medição.

Em (UDUPA et al., 2016) é apresentado um modelo de estimativas de estado em sistemas de energia elétrica chamada técnica de divisão vertical de estimação de estado. Nesta técnica, as medições são agrupadas em torno dos nós e processadas independentemente, enquanto no método convencional toda rede de energia é processada de forma centralizada sendo essa a razão de o tempo computacional necessário para sua execução ser consideravelmente grande. Para abordar esta questão várias técnicas são desenvolvidas, fornecendo estimavas da variável de estado em um curto intervalo de tempo, com a utilização de técnicas de inteligência artificial, multi-área, estimativas de estado em dois níveis, etc. Os autores propõem a aplicação da técnica de divisão vertical em nível da área do nó. Um nó junto com seus nós conectados e a combinação de duas áreas de nó é chamado 
"Super Área de Nós". Aplicando essa metodologia, o número de processadores paralelos necessários pode ser reduzido drasticamente, mantendo o tempo computacional dentro do limite. Esse conceito é testado nos sistemas testes do IEEE de 13 e 30 barras. As conclusões apresentadas no texto trazem que o número de nós conectados não aumenta significativamente quando são agrupadas duas áreas de nós e o tempo de computação do EE não varia significativamente em comparação com a área do nó ou pela metodologia citada com múltiplos processadores. Deixando evidente que com o agrupamento dos nós da rede elétrica é possível reduzir pela metade o número de processadores necessários, tornando-se uma boa solução para sistemas com tamanho elevado, o que faz o processo de estimação de estado ser mais complexo.

Em (CHEN et al., 2018), um método para estimação de estado descentralizada é proposto para estimativa de consumo de carga em redes de distribuição com geração fotovoltaica. O objetivo é desenvolver um método para estimar com precisão o estado do SDs em tempo real com número limitado de sensores e de forma descentralizada. O primeiro passo é a divisão do SD em subáreas, de acordo com a localização das unidades geradoras e as informações mútuas entre os estados do sistema e as medições disponíveis. A proposta descentralizada depende apenas de informações locais e uma quantidade limitada de informações das áreas vizinhas. O conjunto mínimo de medidas a serem trocadas entre áreas vizinhas é selecionado utilizando os critérios de Redundância Mínima e Máxima Relevância propostos em (DING; PENG, 2005). Em cada área, uma RNA é usada para calcular a potência ativa e reativa absorvida pelas cargas nessa área. A abordagem proposta é testada em um alimentador de teste IEEE modificado de 34 nós. A eficácia do método é avaliada usando uma plataforma de simulação Harware in Loop.

O trabalho de (MUSCAS et al., 2017) propõe uma arquitetura multi-área, onde subáreas devem possivelmente ter um número semelhante de módulos, a fim de minimizar o tempo de execução geral para a estimação de estado em SD sem estar sujeito a nenhuma restrição particular na configuração do sistema de medição. Cada subárea deve possuir a quantidade de medidas necessárias para alcançar a observabilidade, mesmo considerando a possível presença de pseudo-medidas. Um nó sobreposto é assumido para ser compartilhado entre subáreas adjacentes; isso permite uma conversão fácil das quantidades elétricas trocadas entre subáreas quando eles se referem a diferentes referências de ângulo de fase, como geralmente acontece quando as medidas convencionais são consideradas Segundo os autores, os resultados dos testes mostram que tal abordagem pode ser rentável se aplicada a estimativa do perfil de tensão, independentemente da configurações de medição escolhida, embora seja particularmente útil também para estimativas que utilizam as medidas de 
corrente, isso quando o sistema de medição é projetado com medições compartilhadas nos módulos sobrepostos.

Em (CHEN et al., 2018), uma estimativa de estado descentralizada é proposta para estimar o consumo de carga em redes de distribuição com geração fotovoltaica. O objetivo é definir um método para estimar com precisão o status da distribuição redes em tempo real com número limitado de sensores de maneira totalmente descentralizada. Em primeiro lugar, a rede é dividida em subáreas, de acordo com a localização das unidades de geração e das medidas disponíveis. A proposta descentralizada de estimativa do estado depende apenas de informações locais e de uma quantidade limitada de informações de áreas vizinhas. $O$ conjunto mínimo das medidas a serem trocadas com medidores vizinhos são selecionados usando uma Critério de Relevância Máxima e Redundância Mínima. Em cada área, uma RNA é utilizada para calcular a potência ativo e reativa absorvida pelas as cargas nessa área. $\mathrm{A}$ abordagem proposta é testada com um alimentador de teste IEEE 34 barras modificado. Para avaliar a precisão e eficiência da abordagem proposta, os autores comparam os resultados obtidos a uma abordagem local centralizada. Em comparação com a estimativa de estado baseada em modelo clássico, a estimativa baseada em RNA requer menos medições em tempo real e enquanto a configuração do sistema permanecer a mesma, o custo computacional do EE é baixo. De modo que para estimar os estados de cada subárea, apenas medidas locais e troca limitada de informações de subáreas vizinhas são necessárias a comparação dos resultados da estimativa centralizada e descentralizado mostra que com o incremento das medidas, o desempenho do EE é significativamente melhorado sem um grande aumento dos requerimentos computacionais.

Um dos pontos principais para a implementação de estimadores de estado descentralizados, é a existência de uma infraestrutura de comunicação robusta, para a que a troca informações seja feita de forma segura e eficiente. Alguns aspectos técnicos sobre redes e tecnologias comunicação mais utilizadas para projetos dessa natureza, serão tratados no próximo capitulo.

No atual cenário em que se encontra os SDs, fazem-se necessárias melhorias no monitoramento em tempo real para que novas tecnologias que adentram o contexto de distribuição de energia possam ser incorporadas aos métodos de análise propostos paras os novos SDs. Esta linha de pesquisa encontra-se alinhada com o contexto de Smart Grids e com diversas aplicações para automatização dos SDs. Assim, o desenvolvimento de pesquisa e inovação a respeito de melhorias na estimação de estado em SD é algo de extrema importância para se obter melhores resultados na determinação da condição operacional e tomada de decisões em SDs. 


\subsection{Considerações Finais}

Os EEs direcionados para SDs têm como objetivo estimar, com certa precisão, o estado da rede de distribuição a partir de um número reduzido de medidas disponíveis em tempo real. Conforme relatado neste capítulo, de uma forma geral os trabalhos desenvolvidos no contexto de monitoramento em tempo real de SDs, em especial os mais recentes, preocupam-se com o tratamento de dados provenientes de unidades de medição fasorial, utilização de pseudo-medidas, instalação de MEls nas redes secundárias, entre outras abordagens conexas às novas redes inteligentes de energia.

Face ao exposto, verifica-se que a proposta desta dissertação de mestrado é atual e pode contribuir de forma significativa com o estado da arte da área em pauta. 



\section{Capítulo 3 - Redes e Protocolos de Comunicação}

\subsection{Introdução}

Este capítulo tem como objetivo apresentar as tecnologias de comunicação mais usadas para monitoramento em tempo real de SDs, assim como os protocolos de comunicação que se fazem necessários quando estas tecnologias são empregadas. Com isto revela-se a importância deste tema no âmbito de redes inteligentes de energia e da necessidade de metodologias apropriadas para tratamento de dados oriundos dos SDs.

\subsection{Tecnologias de Comunicação por Rádio Frequência}

As aplicações que utilizam o método de comunicação por Rádio Frequência (RF) operam em frequências entre $3 \mathrm{KHz}$ e $3 \mathrm{GHz}$. Cada aplicação terá restrições diferentes em termos de topologia, largura de banda, latência, custo, privacidade de dados e confidencialidade. É por isso que várias tecnologias e protocolos já foram propostos para atender a requisitos de comunicação para as atuais e futuras aplicações. ZigBee, 6LoWPAN, Bluetooth, RF-Mesh, RFID, Longe Range (LoRa) Wireless HART são apenas algumas das soluções atualmente implementadas (MALANDRA, 2017).

O tamanho da rede de cobertura pode ser classificado em três áreas: Wide Area Network (WAN), Neighborhood Area Network (NAN) e Home Area Network (HAN) ou Building Area Network (BAN). HAN ou BAN tem um pequeno alcance para a cobertura da rede, enquanto as outras redes oferecem um alcance maior para seus usuários. A Tabela 3.1 mostra o alcance, os requerimentos de taxa de dados e as tecnologias potenciais dos diferentes tipos de rede (KHEAKSONG; LEE, 2014).

Tabela 3.1- Requisitos de comunicação de diferentes tipos de redes

\begin{tabular}{|c|c|c|c|}
\hline $\begin{array}{c}\text { Tipos } \\
\text { de } \\
\text { Redes }\end{array}$ & Alcance & Requerimentos de Taxa de Dados & $\begin{array}{c}\text { Tecnologias } \\
\text { Potenciais }\end{array}$ \\
\hline $\begin{array}{c}\text { HAN or } \\
\text { BAN }\end{array}$ & $\begin{array}{c}10 \mathrm{~m}- \\
100 \mathrm{~m}\end{array}$ & $\begin{array}{c}\text { Aplicação utilizando dispositivo } \\
\text { de baixa taxa de dados }{ }^{4} \text { para } \\
\text { comunicação }\end{array}$ & $\begin{array}{c}\text { ZigBee, Wi-Fi, Ethernet, } \\
\text { PLC }\end{array}$ \\
\hline
\end{tabular}

4 Taxas de dados menores que $250 \mathrm{kbit} / \mathrm{s}$. 


\begin{tabular}{|c|c|c|c|}
\hline $\begin{array}{c}\text { Tipos } \\
\text { de } \\
\text { Redes }\end{array}$ & Alcance & Requerimentos de Taxa de Dados & $\begin{array}{c}\text { Tecnologias } \\
\text { Potenciais }\end{array}$ \\
\hline NAN & $\begin{array}{c}100 \mathrm{~m}- \\
10 \mathrm{~km}\end{array}$ & $\begin{array}{c}\text { Dependente da densidade dos } \\
\text { nós da rede de comunicação }\end{array}$ & $\begin{array}{c}\text { ZigBee,Wi-Fi, } \\
\text { PLC,Tecnologia Celular }\end{array}$ \\
\hline WAN & $>10 \mathrm{~km}$ & $\begin{array}{c}\text { Roteador ou dispositivo de } \\
\text { chaveamento de alta velocidade de } \\
\text { tráfego de dados (100 Mbps a Gbps) }\end{array}$ & $\begin{array}{c}\text { Links de Fibra Optica, } \\
\text { 3G/LTE, Ethernet, } \\
\text { WiMAX. }\end{array}$ \\
\hline
\end{tabular}

A seguir são apresentadas algumas das principais redes que utilizam o método de comunicação por RF desenvolvidos para aplicações de loT e Smart Cities e amplamente utilizadas em projetos de monitoramentos de ativos.

\subsubsection{Long Range}

Aplicações em projetos com comunicação Máquina a Máquina (do inglês - Machine to Machine - M2M) e loT tornaram-se o principal alvo da implantação do LoRa devido à sua especificação de longo alcance e baixa potência para comunicação entre dispositivos eletrônicos. Além disso, o algoritmo de taxa de dados adaptativo de A tecnologia LoRa ajuda a maximizar a vida útil da bateria do nó e a capacidade de rede de transmitir dados (ZOURMAND, 2019).

O LoRa é um sistema de comunicação LPWAN (do inglês - Low Power Wide Area Network) que têm capacidades de transmissão de longa distância, e recebe apoio de empresas como a IBM, Semtech e Actility, que são membros da Aliança LoRa, para o desenvolvimento da rede de comunicação. O objetivo de desenvolvimento do LoRa é criar uma rede de baixa potência para transmissão de dados oriundos de dispositivos finais que transmitiram determinada quantidade pacotes de dados em determinado tempo. A rede LoRa especificamente desenvolvido pela Semtech, é projetada para trabalhar em faixas de frequência de 433, 868 e $915 \mathrm{MHz}$ (dependendo da localidade) e com taxa de transmissão entre 0,25kbps-50kbps (ERIDANI et al., 2020).

A rede de comunicação típica baseada em LoRa, conforme definido no padrão LoRaWAN pela Aliança LoRa, é baseado em uma topologia em estrela em que gateways retransmitem as mensagens entre dispositivos finais e a rede principal (AMADOU; FOUBERT; MITTON, 2019)

No geral, o LoRa é tratado com um benefício para o sistema de loT, fazendo-se necessário para comunicações que necessitam ser realizadas a longas distâncias e que 
quando comparado com protocolos de curto alcance como Wi-Fi e Bluetooth mostra-se bastante vantajoso, embora haja algumas desvantagens no velocidade de transmissão e limitação do tamanho do payload (ZOURMAND, 2019).

\subsubsection{Sigfox}

O SigFox é uma rede que opera de forma proprietária. Nesta situação, o usuário paga um pequeno soma de dinheiro que permite o acesso à rede e dependendo do número de pacotes a serem enviados, as taxas referentes ao pacotes contratados, podem sofrer acréscimos (LAVRIC; PETRARIU; POPA, 2019).

A rede SigFox propõe uma nova estratégia quando se trata de lidar com o conceito de loT, tornando-se um modelo de negócio que tem características de um operador de rede. As aplicações que utilizam esta tecnologia são as que necessitam uma pequena transferência de dados, fazendo uso de uma rede de Banda Ultra Estreita ( do inglês - Ultra Narrow Band - UNB) (LAVRIC; PETRARIU; POPA, 2019).

Assim como outras tecnologias LPWAN, o Sigfox utiliza bandas não licenciadas e realiza um uso eficientemente da largura de banda com um baixo nível de ruído, baixo consumo de energia, e um design de antena de baixo custo utilizando modulação BPSK em UNB (100 Hz) sub-GHz. Os dispositivos finais são conectados em estações rádio base enviando os dados oriundos da medição de processos físicos, monitoramento de ativos, e diversas outras aplicações a serem processados (OSMAN; ABBAS, 2018).

A Tabela 3.2 ilustra os principais dados utilizados pela tecnologia Sigfox.

Tabela 3.2: Dados utlizados pela rede Sigfox (OSMAN; ABBAS, 2018).

\begin{tabular}{|c|c|}
\hline $\begin{array}{c}\text { Número de mensagens ao logo do } \\
\text { uplink }\end{array}$ & 140 mensagens \\
\hline Máximo payload para cada uplink & 12 bytes \\
\hline $\begin{array}{c}\text { Máximo payload para cada } \\
\text { downlink }\end{array}$ & 8 bytes \\
\hline Taxa de transferência & 100 bps \\
\hline
\end{tabular}

\subsubsection{Zigbee}

O ZigBee é uma tecnologia sem fio desenvolvida pela aliança ZigBee para permitir comunicações M2M de baixo custo, de baixa potência e com pequena taxa de dados visando aplicações loT. Para desenvolvimentos utilizando Zigbee espera-se que os dispositivos sem fio transmitam em uma faixa de 10 a 75 metros, dependendo do ambiente em que estão 
inseridos e da potência dos módulos utilizados. O ZigBee opera nas bandas de frequências Industrial Scientific and Medical (ISM) não licenciadas, como $2.4 \mathrm{GHz}, 915 \mathrm{MHz}$ e $868 \mathrm{MHz}$ (ALI et al., 2019)

ZigBee é uma comunicação de alto nível que utiliza rádios pequenos, de baixa potência e de baixo custo. É baseado no protocolo IEEE 802.15.4 que descreve apenas as camadas física e MAC. O Zigbee utiliza taxa de transmissão de dados por volta de $250 \mathrm{Kbps}$ e operam basicamente em três bandas de frequências: $868 \mathrm{MHz}$ na Europa, $915 \mathrm{MHz}$ na América e 2,4 GHz em todo o mundo (ELARABI, 2020).

A tecnologia ZigBee permite o desenvolvimento de diferentes topologias de rede, sendo elas: estrela, malha, pares e grupo de árvores. Existem três tipos de nós que são utilizados para o design de topologias, são eles (OSORIO et al., 2019) :

- Coordenador ZigBee: Responsável pela gestão da rede, assim como o endereçamento e o envio de mensagens e definir um identificador de rede. $O$ nó deve estar sempre conectado à rede e só é permitido e existência de um em toda a rede.

- Roteador ZigBee: É o nó que determina as interfaces entre os módulos e o nó coordenador. Dessa forma, permite expansão da rede em termos de escopo e cobertura.

- ZigBee End Device: São nós que permitem realizar a comunicação com o nó coordenador diretamente ou através de um nó roteador.

\subsection{Tecnologias de Comunicação Celular}

A indústria de comunicação sem fio tem sido uma das que mais cresceu nos últimos anos, com diversar aplicações, como serviços de comunicação pessoal, comunicações celulares, comunicações por satélite, radiodifusão, TV de alta definição (HDTV), redes sem fio, Bluetooth entre outras tecnologias de comunicação.

O Global System for Mobile (GSM), sistema utilizado para comunicações móveis, é uma segunda geração do sistema celular, sendo o primeiro a especificar arquiteturas de modulação digital e requisitos de rede (GU; PENG; OVERVIEW, 2010).

A tecnologia General Packet Radio Service (GPRS) é um serviço de dados móveis que, da mesma forma que o GSM, é utilizado para troca de dados em aplicações móveis. As principais características de um sistema GPRS são: operação com baixa latência, reconhecimento de log in rápido, transmissões de alta velocidade, comutações livres, etc. Do mesmo modo, possui vários modelos de interfaces, uma delas sendo a interface aérea do GSM, interfaces de protocolos de comunicação com cinco camadas, buttom up para camadas 
físicas, camada MAC entre outras e taxa de transmissão pode variar de 56 até 114 Kbps (LIU et al., 2011).

Duas das principais tecnologias celulares, recentemente desenvolvidas para aplicações móveis e que necessitam de alta taxa de transferência de dados são apresentadas a seguir.

\subsubsection{Long Term Evolution}

Long Term Evolution (LTE) é uma arquitetura de comunicação móvel que foi previamente projetada para a comunicação de dispositivos sem fio e para operar nas bandas licenciadas. Possui alta proficiência espectral, excelentes taxas de dados, baixa latência na troca de mensagens e flexibilidade de utilização da faixa de frequência. É um padrão que foi projetado pela 3rd Generation Partnership Project (3Gpp). A camada física de um sistema LTE possui recursos de downlink e uplink e requer altas taxas de transmissão de pico. $O$ método de acesso que o LTE usa é baseado em Orthogonal Frequency Division Multiple Access (OFDMA) com uma mistura de maior modulação de largura de banda (MEKONNEN et al., 2018).

Devido à sua ampla cobertura, suporte as aplicações e a garantia de Qualidade de Serviço (do inglês - Quality of Services - QOS), redes LTE são consideradas uma escolha adequada para aplicações que de M2M que utilizam comunicação sem fio. As redes LTE são as redes celulares mais adequadas que podem ser utilizadas para aplicações wireless devido à sua escalabilidade, longevidade, baixa latência e eficiência espectral (ALTHUMALI, 2018).

O sistema LTE é baseado em multicarrier modulações - FDMA single carrier para uplink e OFDMA para downlink - que proporcionam robustez, flexibilidade e adaptável gerenciamento de recursos de rádio. Por essa razão, é mais adequado para suportar altas taxas de dados do que single carrier convencionais soluções ou soluções CDMA. Além disso, o múltiplo o gerenciamento de acesso, é mais eficiente do que o CSMA/CA do IEEE 802.11a e $b$, e permite facilmente diferenciar a qualidade do serviço do rádio em vários terminais envolvidos na troca de dados (SACCHI, 2019).

O LTE é atualmente o padrão dominante em comunicações terrestres, sendo utilizados em diversas aplicações onde se faz necessária a comunicação com o mundo externo, como em veículos não tripulados, projetos aeroespaciais, sistemas voltados para a agricultura inteligente entre outros diversos modos de utilização da tecnologia LTE. O sistema é comumente chamado de $4 \mathrm{G}$ pela indústria.

O Futuro 5G considerará o LTE como linha de base (pelo menos para o que diz respeito ao design de forma de onda (SACCHI, 2019). 


\subsubsection{Narrow Band loT}

O consórcio internacional 3GPP desenvolveu, em 2016, um novo padrão de comunicação chamado Narrow Band loT (Nb-loT) que opera em uma frequência canal de largura de $200 \mathrm{kHz}$. O NB-loT é uma comunicação wireless da família LPWAN desenvolvida também para aplicações M2M, que são tecnologias que permitem que sensores e outros dispositivos eletrônicos se comuniquem entre si (ALEXEY S. PETRENKO, SERGEI A. PETRENKO, KRYSTINA A. MAKOVEICHUK, 2018).

A NB-loT, em comparação com outras tecnologias LPWANs, oferecem recursos necessários a comunicação de sistemas eletrônicos a baixo custo que permite a troca de dados em locais de difícil acesso e com condições desafiados para outras redes de comunicação como locais subterrâneos ou porões. Utiliza mecanismos aprimorados de economia de energia para melhorar a vida útil da bateria e para suportar pequena transferência de dados. Para facilitar a utilização das redes NB-loT, os procedimentos de rede foram projetados para simplificar a complexidade de acesso (POPLI; JHA; JAIN, 2020).

A arquitetura NB-IoT utiliza 6 protocolos de camada diferentes, onde são oferecidos vários controles de acesso e recursos relacionados ao sistema, o que melhora a segurança, como na utilização da camada de protocolo de convergência de dados de pacotes (do inglês - Packet Data Convergence Protocol - PDCP) e da Camada de Acesso ao Meio (do inglês Media Access Protocol - MAC). Já a camada de controle do link de rádio (do inglês - Radio Link Contoler - RLC) é responsável pela mobilidade e também fornece segurança, que está condizente com as redes LTE (NAIR; ABU-MAHFOUZ; LEFOPHANE, 2019).

\subsection{Comunicação pela rede elétrica}

A rede de BT é uma nova candidata ao mercado de comunicações fornecendo acesso a transmissão de dados com alta velocidade, concretizando o conceito de banda larga com a tecnologia de Power Line Communication (PLC), tornando possível construir internamente uma rede de comunicação ou para acessar a Internet utilizando o cabeamento já existente da rede elétrica. No entanto, ao contrário da outras comunicações a partir de fios como o par trançado, ou cabos coaxiais, o poder de alcance da estrutura de cabo foi otimizada principalmente para 50 ou $60 \mathrm{~Hz}$, pois não foi projetado para transmissão de dados e sim para transmissão de energia elétrica (MINGYUE, 2006).

PLC, também conhecido como Power Line Carrier, é uma tecnologia que utiliza o sistema elétrico como rede de comunicação. O PLC permite que os consumidores usem seu sistema de fiação para conectar eletrodomésticos a outros pela rede interna ou utilizando a 
internet. Existem também aplicações que enviam dados através da rede de corrente alternada (ELAKSHUMI; PONRAJ, 2017).

Nos últimos anos, os estudos sobre comunicação em sistemas de eneriga tem sido intensificados. Além do PLC, outras tecnologias de alta velocidade de transmissão, modulação e demodulação de dados, tecnologias de acoplamento e protocolos de rede, vem sendo estudas e implementadas em sistemas reais. Do mesmo modo, algumas pesquisas são desenvolvidas na área das teorias básicas da comunicação por linha de energia, como tecnologias incluindo multi canais, modelos de propagação, teste e análise do canal e ruídos característicos (MINGYUE, 2006).

\subsection{Protocolos de Rede e de Comunicação Para Aplicações de Internet das Coisas}

Os dias atuais vem se tornando a era dos objetos conectados. A loT está ganhando muita importância em quase todos os campos, como negócios, indústria, eletrônicos de consumo, automotivo e muito mais. Todos os objetos no mundo de hoje estão bem conectados uns aos outros de uma forma ou de outra. Nós podemos controlar as luzes e equipamentos em nossas casas sentados em nosso escritório. Nas indústrias e outras atividades do campo equipamentos podem ser controlados de um lugar remoto, como as lampadas de iluminação publica (DEVALAL; KARTHIKEYAN, 2018).

Atualmente tem sido desenvolvido diversos protocolos para a utilização em aplicações que envolvam os temas de IoT e Smart Grids. Cada um deles dentro de suas peculiaridades, visam atender vertentes relacionadas à redução do consumo de energia, velocidade de troca de dados, capacidade de processamento, dentre outros parâmetros.

Esta seção tem como objetivo apresentar alguns dos protocolos de redes e de comunicação mais utilizados no meio industrial, no que diz respeito à projetos, pesquisas e aplicações que necessitam de redes de comunicação sem fio para transmissão de dados.

\subsubsection{LoRaWAN}

Long Range (LoRaWAN) é uma nova conecção wireless da família loT que recentemente evoluiu e está ganhando popularidade em sistemas embarcados alimentados por bateria de baixa potência. Dessa forma, opera transferindo pequenas quantidades de dados em intervalos curtos e a longo alcance (DEVALAL; KARTHIKEYAN, 2018).

Existem muitas opções de tecnologia de comunicação para implementação dos MEls, como GSM / GPRS, PLC, Wi-Fi, Bluetooth, ZigBee, malha de rádio e LoRaWAN. A tecnologia de acesso GSM / GPRS é usada para medidores trifásicos, porque eles serão usados para 
transferir muitos dados como perfil de carga, faturamento final, possiveis violações e eventos que ocorram nos medidores. LoRaWAN é a melhor escolha para ser implementada em Smart Grids, por ter alcance a longa distância, baixa potência, ser open source e custo menor do que GSM / GPRS. A faixa de frequência alocada para utilização da comunicação pelo LoRaWAN varia de 902 a $928 \mathrm{MHz}$ (WIBISONO et al., 2017).

A Figura 3.1 apresenta um comparativo entre algumas das diversas tecnologias presentes no mercado.

Figura 3.1: Taxa de dados vs alcance da tecnologia.

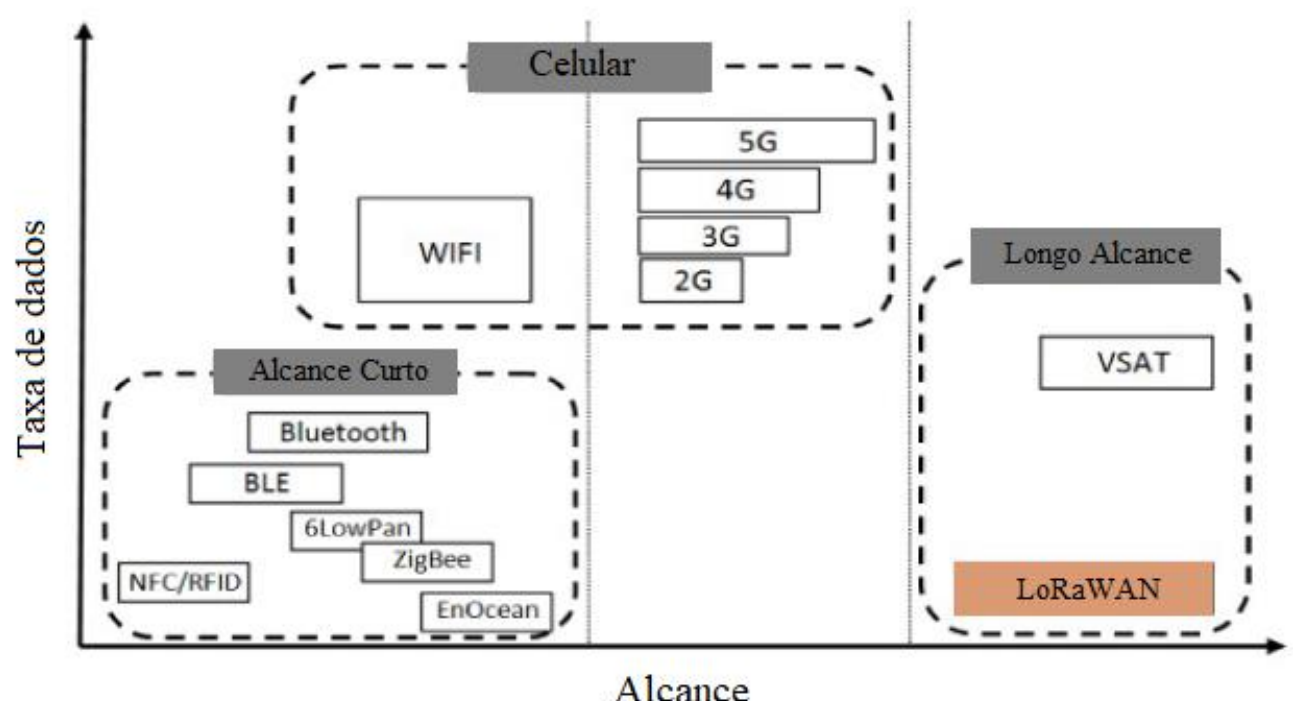

Fonte: Adaptado de (MEKKI et al., 2018).

\subsubsection{SigFox}

A rede e tecnologia Sigfox é voltada para o baixo custo de máquina em áreas de aplicação onde ampla cobertura é necessária. O Sigfox usa um UNB (Ultra-Narrow Band) baseada em tecnologia de rádio para conectar dispositivos a sua rede. O uso da UNB é fundamental para fornecer uma alta capacidade escalável e enorme economia de energia. A rede opera no mercado mundial de bandas de frequência livres de licença e coexiste nestas frequências com outras tecnologias de rádio, mas sem qualquer risco de colisões ou problemas de capacidade utilizando a faixa de $915 \mathrm{MHz}$ na América do Norte e $868 \mathrm{MHz}$ na Europa. A sigfox criou um sistema de comunicação UNB loT projetado para suporte a implantações de loT com distâncias a cerca de $20 \mathrm{~km}$ entre um dispositivo escravo e a central de processamento (CHUNG; AHN; HUH, 2018).

Os dispositivos escravos se conectam às centrais de processamento usando modulação Binary Phase Shift keying (BPSK) em uma UNB de $100 \mathrm{~Hz}$ a uma taxa de dados máxima de 100 bps. O Sigfox utiliza eficientemente a banda de frequência e tem níveis de 
ruído muito baixos, levando a um consumo de energia muito pequeno, alta sensibilidade do receptor e design de antena de baixo custo (MEKKI et al., 2018).

\subsubsection{Message Queuing Telemetry Transport (MQTT)}

A chegada do loT permitiu que a maioria dos dispositivos eletrônicos colete, processe e monitore os dados de "tudo no mundo" em tempo real. Para compartilhar esses dados via internet, o protocolo MQTT é o mais popular dos protocolos. É por causa disso é um protocolo leve e de fácil implementação. O MQTT adequa-se ao sistema que precisa compartilhar muitos dados em tempo real. Existem dois elementos da mensagem enviada via Protocolo MQTT, eles incluem tópico e mensagem. Os dados são enviados de um editor para os assinantes que se inscreverem no tópico que é publicado pelo editor (TANTITHARANUKUL et al., 2017).

O controlador central que distribuiu a mensagem é chamado broker MQTT. O broker MQTT encaminha, filtra e prioriza a publicação de solicitações dos editores para os inscritos. Para se comunicar via protocolo MQTT, o editor (ou gerador de dados, por exemplo, sensor ou sistema incorporado) deve definir os dois elementos supracitados (mensagem e tópico) para o broker MQTT. O conteudo da mensagem são os dados da string que o editor deseja compartilhar com os assinantes por meio do broker MQTT. Enquanto isso, o tópico é uma string usada pelo broker para filtrar e decidir quais assinantes devem receber quais mensagens (TANTITHARANUKUL et al., 2017).

\subsubsection{Rest HTTP}

Devido aos grandes volumes de dados que serão gerados e trafegados com os novos dispositivos eletrônicos que utilizam o conceito de loT, é necessário construir sistemas de comunicação e arquiteturas que suportem diversas comunicações em diferentes ambientes de rede. Um dos protocolos de comunicação mais populares em sistemas de computação é o REST HTTP (do inglês - Representational State Transfer - REST e Hypertext Transfer Protocol - HTTP). Com sua popularidade entre os projetos de desenvolvedores de software devido a seu bom desempenho computacional, testado em sistemas tradicionais de computação em nuvem (PHUNG; DIZDAREVIC; JUKAN, 2020)

O REST HTTP segue-se o modelo de interação cliente-servidor, o que implica que cada pedido é independente. REST usa diferente verbos GET, POST, PUT, etc. para abordar recursos e as representações podem ser transmitidas em diferentes formatos como HTML, XML ou JSON. O protocolo HTTP, seguindo a arquitetura definida pelo REST, é amplamente usado como um protocolo de comunicação para serviços web e também para a criação de APIs REST para distribuições do sistema (IGLESIAS-URKIA et al., 2018). 
A facilidade de uso e compatibilidade com os sistemas já existentes fizeram sua adoção como uma comunicação protocolo mais rápido do que com qualquer outro protocolo, mesmo com as limitações conhecidas que este protocolo tem em alguns cenários. Implementações do REST HTTP, em aplicações que utiliza sensores wireless, com condições de redes instáveis são muito desafiadoras, devido a necessidade de enviar solicitações de comunicação durante o processo de conexão, e utilizando redes instáveis o número de retransmissão aumenta consideravelmente (PHUNG et al., 2019) (PHUNG; DIZDAREVIC; JUKAN, 2020).

\subsubsection{LowPAN}

Como um protocolo de baixa potência, o IEEE 802.15.4 atraiu a atenção da academia e da indústria no campo das redes de sensores sem fio. O IPv6 over Low-Power Wireless Personal Area Networks (6LoWPAN) é proposto pelo grupo IETF 6LoWPAN e realiza a transmissão de pacotes IPv6 em redes de sensores sem fio baseados no protrocolo IEEE 802.15.4. Existem muitas pesquisas atuais que são focadas no design do gateway 6LoWPAN, a fim de realizar a interconexão entre as redes 6LoWPAN e Internet e, eventualmente, melhorar o conceito atrelado ao IoT (HONGGANG; CHEN, 2018).

O 6LoWPAN através da introdução de camada de adaptação entre a camada de rede e a camada de enlace de dados fornece um protocolo de rede de confiança para aplicações em larga escala de IoT. Usualmente há muitos dispositivos que utilizam o 6LoWPAN que têm uma capacidade limitada de armazenamento de tabelas de roteamento e endereço para armazenar. Portanto, foi criado um mecanismo hierárquico conhecido como HiLow, baseado no endereço curto atribuído dinamicamente em 6LoWPAN que não necessita de tabela de roteamento e realiza a descoberta de nós vizinhos de forma simples, o que aumenta as vantagens da utilização do protocolo em projetos com um número elevado de elementos escravos (XUE; ZHIXIN, 2015).

\subsection{Faixas de Frequência e Possibilidade de Interferência}

Dentro do espectro de frequência dispónivel para os serviços de comunicação no Brasil, existem diferentes faixas de frequência, em que algumas delas são regulamentadas pelo governo (3G, 4G e NB-loT) e algumas não são (LoraWAN, Wifi, etc). Isso faz com que as frequências regulamentadas possuam uma baixa possibilidade de intereferencia, com tanto que tenham autorização do governo para operar atraves de cessão de direitos (do mesmo modo em que operam as redes de televisão) (AGÊNCIA NACIONAL DE TELECOMUNICAÇÕES, 2018). Nesse modelo de operação, geralmente uma empresa de telecomunicações ganha a cessão e realizam o serviço de transmissão de dados. Com todo esse tramite, o custo operacional do sistema aumenta, porém mantém uma maior 
confiabilidade para a operação do sistema. Já as redes que não precisam de autorização do governo para operar (faixas de frequencia livres como $2.4 \mathrm{GHz}$ do Wifi ou $900 \mathrm{MHz}$ do LoraWAN) apresentam um custo de operação menor, pois não precisa pagar para uma empresa de telecomunicaçãoes pela utilização, contudo pode haver interferencia de outras antenas (é o caso do Wifi residencial em um apartamento), diminuindo a confiabilidade de operação.

\subsection{Considerações Finais}

Neste capítulo foi apresentada uma sucinta revisão bibliográfica destacando pesquisas recentes a respeito das redes e protocolos de comunicação mais utilizados no que se refere a projetos com aplicações de loT. Da mesma forma, algumas dessas redes e protocolos também têm grande empregabilidade nas aplicações de redes inteligentes de energia, sejam elas realizadas pelas próprias concessionárias de energia ou empresas qualificadas no ramo das telecomunicações. 



\section{Capítulo 4 - Plataforma Embarcada Para Monitoramento Descentralizado de Redes Inteligentes de Energia}

\subsection{Introdução}

Inicialmente este capítulo propõe arquiteturas descentralizadas para alocação de módulos eletrônicos de processamento para monitoramento de SDs, cada um deles contando com um estimador de estado (embarcado) por mínimos quadrados ponderados.

Em seguida, apresenta, de forma detalhada, um estudo comparando as arquiteturas descentralizas propostas com a estrutura centralizada usualmente utilizada para monitoramento de SDs. Essa comparação será realizada em termos de quantidade de dados transitando pela rede de comunicação e requisitos computacionais para execução do monitoramento em tempo real de SDs desde a rede secundária, passando pela primária até as subestações.

Posteriormente, propõe o desenvolvimento e implantação de um estimador de estado por mínimos quadrados ponderados em um módulo eletrônico (embarcado), a partir da utilização de placas de desenvolvimento eletrônicos dotadas de processadores de alta performance, com sistema operacional Linux para possibilitar análises matriciais referentes ao processo de estimação de estado.

O capítulo termina apresentando a metodologia de desenvolvimento e implantação, em bancada, de uma IMA para validação da arquitetura descentralizada proposta neste projeto que obteve os melhores resultados nos estudos comparativos realizados.

\subsection{Arquiteturas Descentralizadas para Alocação de Módulos Eletrônicos para Monitoramento de SDs}

Conforme apresentado no capítulo 2, no contexto da estimação do estado em SD, três aspectos devem ser levados em conta para projetos de IMAs: volume de dados, requisitos de comunicação e capacidades de processamento. Estes três aspectos podem impor sérias limitações às IMAs e para implementação automática de funções para as redes inteligentes. Para lidar com estes três aspectos, este trabalho propõe arquiteturas descentralizadas para monitoramento em tempo real de SDs. De forma mais específica, para realização de estimação de estado. O cerne dessas arquiteturas é a proposição de um módulo eletrônico 
(plataforma) no qual é implementado (embarcado) um EE por mínimos quadrados ponderados.

A Figura 4.1 ilustra o módulo eletrônico que está sendo proposto, destacando a troca de dados dó módulo, com os demais equipamentos presentes na rede de energia elétrica, para realização de estimação de estado.

Figura 4.1: Parâmetros de entrada e saída do estimador embarcado.

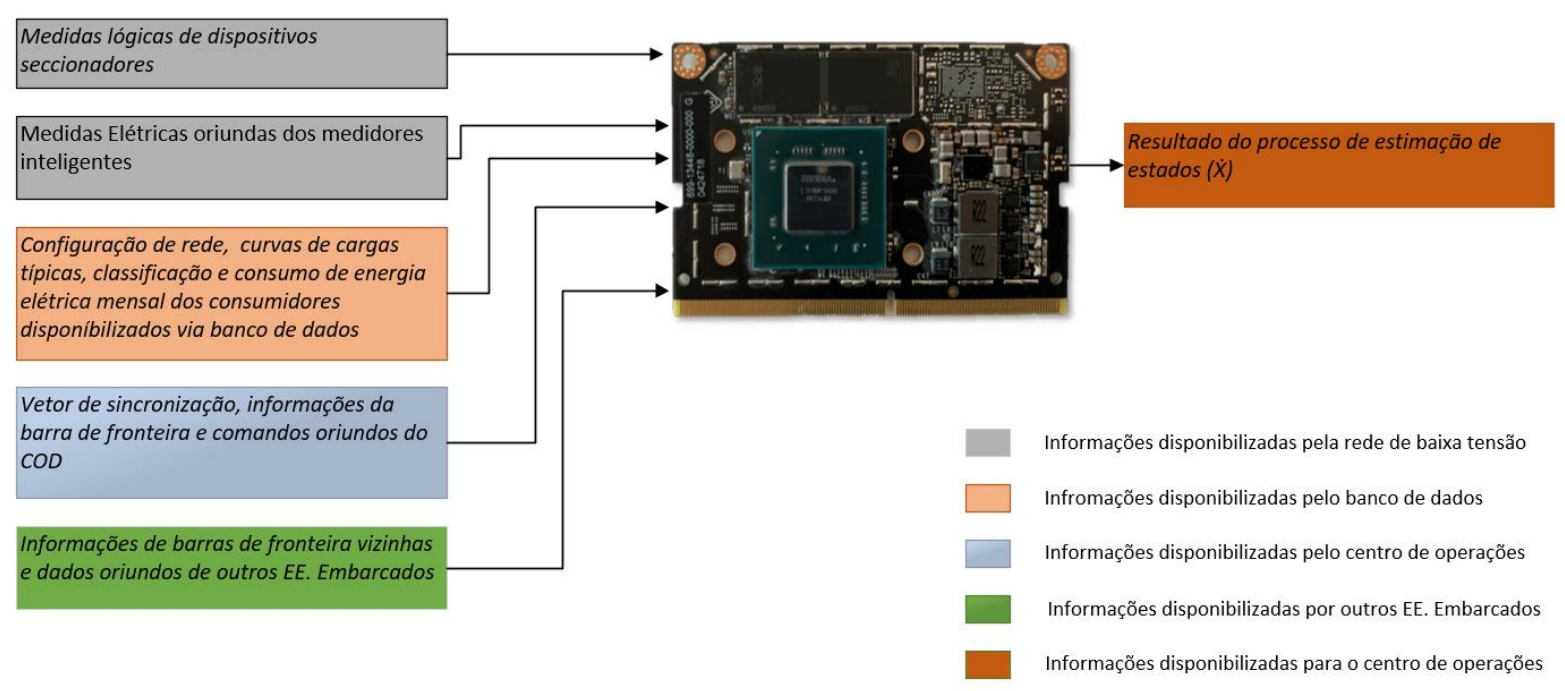

Fonte: Elaborada pelo autor.

A partir da distribuição do módulo eletrônico proposto (que passaremos a chamar simplesmente de Estimador de Estado Embarcado (EEE), ao longo de um SD, cinco arquiteturas descentralizadas são propostas:

$\left.1^{\circ}\right)$ Contendo EEEs instalados no secundário de todos os transformadores de distribuição de um SD. Nessa configuração os EEEs realizarão o processo de estimação de estado para rede de BT. Ou seja, cada EEE fica responsável pelo processamento das informações dos MEIs instalados nas UCs alimentadas por um determinado transformador de distribuição. Após a execução desses processos de estimação de estado, cada EEE envia, para o COD, as estimativas de demanda (estimativas de injeção liquida de potência ativa e reativa) de cada transformador. A partir dessas estimativas executa-se, no COD, um estimador de estado para todos os alimentadores (rede de MT) e subestações do SD em análise. Essa arquitetura é ilustrada na Figura 4.2. Observe que as estruturas de medição e comunicação necessárias para implantação dessa arquitetura são dotadas de um MEI para cada UC e módulos de comunicação wireless, instalado em cada transformador de distribuição, que será responsável pelo processamento de dados de todas as UCs 
Plataforma Embarcada Para Monitoramento Descentralizado de Redes Inteligentes de Energia

conectadas e alimentadas por aquele transformador e o envio dos dados processados para o COD.

Figura 4.2: llustração da implementação da primeira arquitetura proposta.
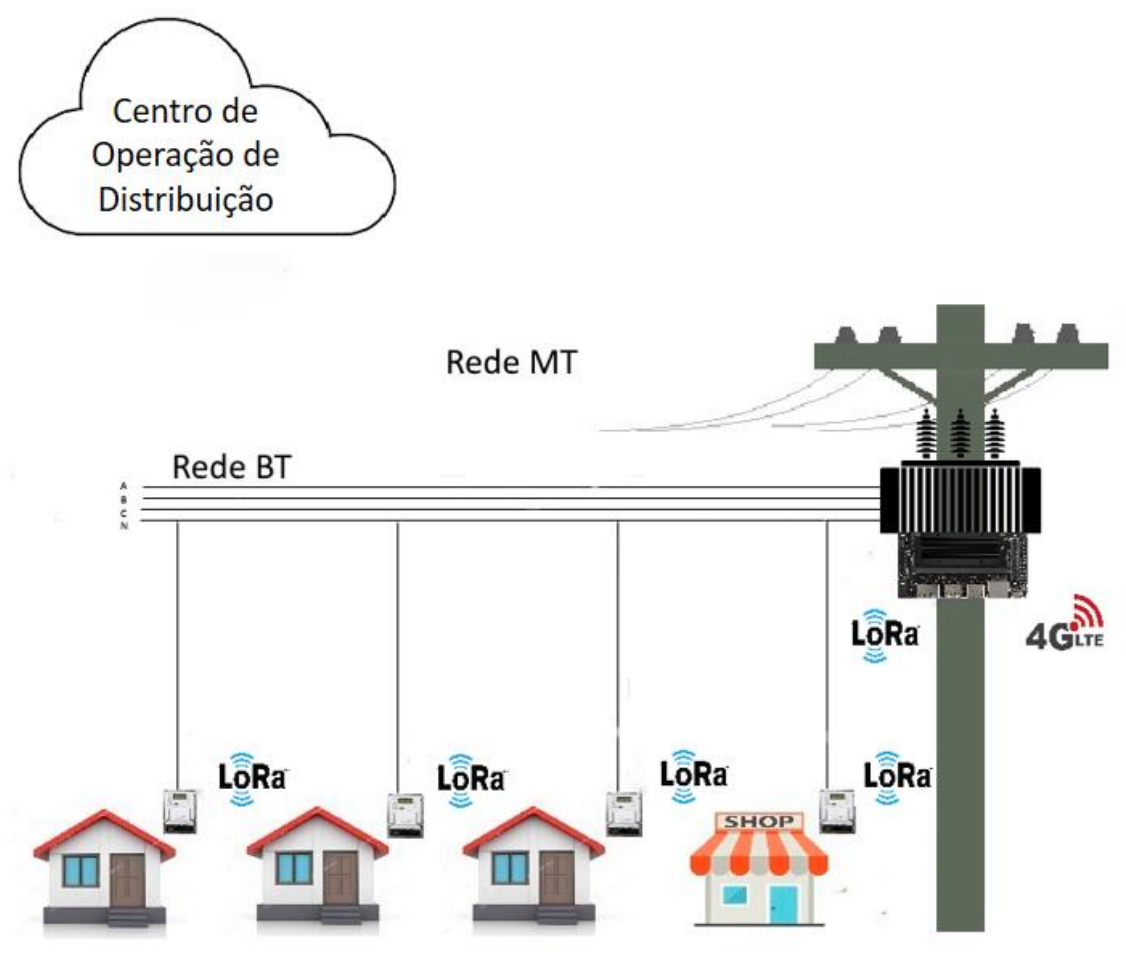

Fonte: Elaborada pelo autor.

$\left.2^{\circ}\right)$ Contendo EEEs necessários para cobrir toda a rede de distribuição em análise, considerando que o alcance de cada EEE seja de $500 \mathrm{~m}$. Nessa configuração cada EEE ficará responsável pelo processamento de informações de todos os medidores (seja medidores SCADA na rede MT ou MEls na rede de BT) dentro de um raio de $500 \mathrm{~m}$ e do envio, para o COD, das estimativas obtidas para essa porção da rede. A partir dessas estimativas executa-se, no COD, um estimador de estado para todos os alimentadores e subestações do SD em análise (rede de MT);

$3^{\circ}$ ) Contendo EEEs necessários para cobrir toda a rede de distribuição em análise, considerando que o alcance de cada EEE seja de $750 \mathrm{~m}$. Arquitetura similar à segunda, porém cada EEE ficará responsável pelo processamento de informações de todos os medidores (seja medidores SCADA na rede MT ou MEIs na rede de BT) dentro de um raio de 750 m e do envio, para o COD, das estimativas obtidas para essa porção da rede;

$\left.4^{\circ}\right)$ Contendo EEEs necessários para cobrir toda a rede de distribuição em análise, considerando que o alcance de cada EEE seja de $1.000 \mathrm{~m}$. Estrutura similar à terceira arquitetura, porém cada EEE terá uma área de cobertura com raio de 1.000 m; 
5º) Contendo EEEs instalados na saída de cada alimentador. Nessa configuração cada EEE ficará responsável pelo processamento de informações de todos os medidores (seja medidores SCADA na rede MT ou MEls na rede de BT) de cada alimentador do SD em análise e de envio, para o COD, das estimativas obtidas para cada alimentador. A partir dessas estimativas executa-se, no COD, um estimador de estado para todo o SD.

\subsection{Comparando as Arquiteturas Descentralizas Propostas Com Uma Centralizada em Um SD Real}

\subsubsection{Rede de Distribuição da Cidade de Londrina-PR}

Um estudo de caso foi adotado neste trabalho usando um SD real de larga escala da COPEL, localizada no Estado do Paraná, ilustrada na Figura 4.3. Este SD atualmente não está equipado com uma AMI e é usado apenas para fornecer um cenário de SD brasileiro. É o SD da cidade de Londrina-PR, com tensão de 13,8 kV, 36.851 barras, 3.289 chaves normalmente fechadas, 391 chaves normalmente abertas, 7 subestações, 73 alimentadores e mais de 274.000 clientes conectados em 7.755 transformadores de distribuição (AUGUSTO et al., 2018).

O SD da COPEL foi utilizado neste estudo em função de o autor ter acesso às informações desse sistema tem razão de ter participado, como pesquisador bolsista, do desenvolvimento de um P\&D com essa empresa (Projeto P\&D ANEEL 2866-0504/2018 intitulado "Plataforma Integrada de Autorrecuperação Considerando Geração Distribuída, Estimação de Demanda e Mudanças Topológicas Visando Redes Inteligentes”).

Figura 4.3: Sistema de distribuição em larga escala da cidade de Londrina-PR .

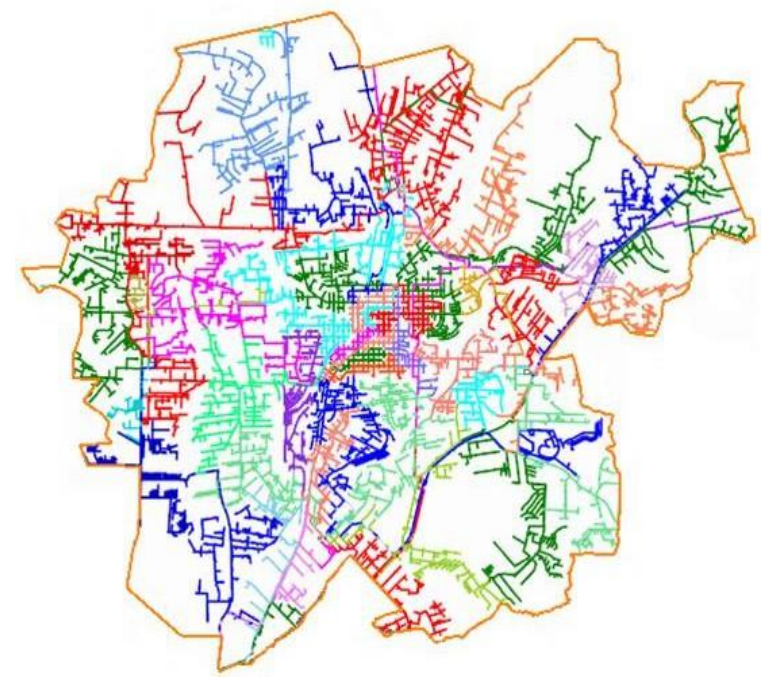

Fonte: Retirado de (AUGUSTO et al., 2018). 
Plataforma Embarcada Para Monitoramento Descentralizado de Redes Inteligentes de Energia 53

Os dados elétricos necessários para execução do estudo foram disponibilizados por engenheiros da COPEL (número de alimentadores, de transformadores por alimentador, de UCs por transformador, etc.). A área total da cidade de Londrina/PR utilizada neste estudo de caso é $1.651 \mathrm{~km}^{2}$. O número de EEEs para cada arquitetura descentralizada proposta, conforme descritas na seção anterior, é apresentado na Tabela 4.1, bem como o número médio de UCs para cada EEE.

Tabela 4.1- Quantidade de EEEs e média de UCs por EEE de cada uma das Arquiteturas Descentralizadas Propostas - Com base no SD Real da COPEL.

\begin{tabular}{|c|c|c|}
\hline Alcance do estimador embarcado & Número de EEEs & Média de UCs por EEE \\
\hline 1 por transformador & 7755 & 35 \\
\hline $500 \mathrm{~m}$ & 2013 & 130 \\
\hline $750 \mathrm{~m}$ & 935 & 293 \\
\hline $1000 \mathrm{~m}$ & 526 & 522 \\
\hline 1 por alimentador & 73 & 3759 \\
\hline
\end{tabular}

Como referência para os dados enviados e recebidos por MEls, foram adotados valores disponíveis na literatura. A quantidade de dados enviados e recebidos pelos medidores são apresentados em (LUAN; SHARP, 2013) e utilizados para realizar a extrapolação do tráfego de informações exigido pela IMA neste estudo de caso. Conforme proposto por (LUAN; SHARP, 2013), os MEls enviam pacotes da ordem de 3.185 bytes convencionais por dia, enquanto a quantidade de informação recebida soma 272 bytes no mesmo período de tempo.

\subsubsection{Requerimentos Computacionais do EEE Proposto}

O tempo de processamento computacional exigido por um EE por MQP para estimação de estado em SEP está diretamente relacionado à abordagem utilizada para solução das equações normais, descritas pela Equação (2.3). Ou seja, está diretamente associado ao método utilizado para fatoração triangular da matriz Ganho (definida no capítulo 2), processo que se realiza iterativamente para solução do sistema de equações não lineares representado pela equação (2.4). Desta forma, a eficiência computacional de um EE por MQP pode ser avaliada em função da complexidade da técnica utilizada para realização daquela fatoração. Tomando como base a fatoração LU clássica, o número de operações de ponto flutuante $T(n)$ de tal técnica é dado por (4.1) (GENE H. GOLUB, 1996) e está relacionado à dimensão da matriz que será fatorada, neste caso a matriz ganho com dimensão $n x n$ (sendo no número de variáveis de estado a serem estimadas). 


$$
T(n)=\frac{2}{3} n^{3}+2 n^{2}
$$

Isso é usado para avaliar a carga computacional e os requisitos de processamento para executar o processo de estimação de estado através do método dos MQP, dividindo o número de operações pela capacidade de processamento do hardware em floating-point operations per second (FLOPS).

O primeiro aspecto avaliado foi o requisito computacional de processamento para executar a estimação de estado. A Tabela 4.2 resume a análise baseada no custo computacional avaliado para o EEE nas cinco arquiteturas descentralizadas propostas, e na arquitetura centralizada usualmente utilizada nos SDs, contendo apenas um EE no COD processando a estimação para todo o sistema em análise. O número de variáveis de estado no problema de estimação de estado (magnitude e ângulo de fase de tensão em todos os nós da rede) foi calculado considerando um número de nós como três vezes o número de UCs para cada transformador de distribuição. O tempo computacional da estimação de estado foi calculado considerando um número típico de cinco iterações e o desempenho computacional de uma RaspBerry PI 3 (que será considerada para implantação de EEE), através de uma operação single-threads (0,4 GFLOPS) e operação multi-threads (1,6 GFLOPS). Destaca-se que na realidade o tempo de execução deve ser maior por causa dos overheads não contabilizados como o sistema operacional, sistemas de comunicação, armazenamento de dados, leitura de I/Os entre outros.

Tabela 4.2: Custo e tempo computacional para executar a estimação de estados para as arquiteturas definidas.

\begin{tabular}{|c|c|c|c|c|}
\hline \multicolumn{5}{|c|}{ Desempenho Computacional Estimado Necessário } \\
\hline $\begin{array}{c}\text { Alcance dos } \\
\text { estimadores } \\
\text { de estados }\end{array}$ & $\begin{array}{c}\text { Número das } \\
\text { variáveis de } \\
\text { estado }(\boldsymbol{n}) \text { por } \\
\text { EEE }\end{array}$ & $\begin{array}{c}\text { Número de } \\
\text { operações com } \\
\text { ponto flutuante por } \\
\text { iteração }\end{array}$ & $\begin{array}{c}\text { Tempo de } \\
\text { processamento } \\
\text { teórico (s) - Single } \\
\text { Thread }\end{array}$ & $\begin{array}{c}\text { Tempo de } \\
\text { processamento } \\
\text { teórico (s) - Multi } \\
\text { Thread (4 cores) }\end{array}$ \\
\hline $\begin{array}{c}1 \text { por } \\
\text { transformador }\end{array}$ & 210 & $6.263 \mathrm{E}+06$ & $7.829 \mathrm{E}-02$ & $1.044 \mathrm{E}-02$ \\
\hline $500 \mathrm{~m}$ & 780 & $3.176 \mathrm{E}+08$ & $3.970 \mathrm{E}+00$ & $5.294 \mathrm{E}-01$ \\
\hline $750 \mathrm{~m}$ & 1.758 & $3.629 \mathrm{E}+09$ & $4.536 \mathrm{E}+01$ & $6.048 \mathrm{E}+00$ \\
\hline $1,000 \mathrm{~m}$ & 3.132 & $2.050 \mathrm{E}+10$ & $2.563 \mathrm{E}+02$ & $3.417 \mathrm{E}+01$ \\
\hline 1 por & 22.524 & $7.651 \mathrm{E}+12$ & $9.563 \mathrm{E}+04$ & $1.275 \mathrm{E}+04$ \\
\hline 1 por SD & $1.644,074$ & $2.963 \mathrm{E}+18$ & $3.703 \mathrm{E}+10$ & $4.938 \mathrm{E}+09$ \\
\hline
\end{tabular}

À medida que à porção da rede, para realização da estimação de estado cresce, também cresce a quantidade de variáveis de estado e os requisitos computacionais necessários. É importante notar que nas últimas abordagens, que representam arquiteturas mais centralizadas ( 1 estimador por alimentador ou 1 por SD) e a abordagem integrada de 1 
$\mathrm{km}$, apresentam tempo de processamento computacional indesejado para requisitos de monitoramento em tempo real (mais de minutos). Esta é uma vantagem importante das arquiteturas mais descentralizadas, como, em especial, da primeira proposta neste trabalho. Vale ressaltar que este tempo de processamento pode ser ainda reduzido através da escolha de melhores algoritmos para resolver as equações normais, como solucionadores esparsos ou implementações paralelas para explorar arquiteturas multi-threads mais rápidas, como unidades de processamento gráfico. Destaca-se, ainda, que quanto mais descentralizada a arquitetura de monitoramento, maior é a quantidade de processos passíveis de paralelização.

\subsubsection{Avaliação dos Requisitos de Volume de Dados}

A partir da quantização dos dados dos MEls é possível ter uma noção de volume de dados e requisitos de comunicação para realizar o monitoramento em tempo real de um SD no contexto de redes inteligentes. Utilizando o número total de UCs e a quantidade de dados enviados e recebidos por cada $\mathrm{MEI}$, o volume de dados para a arquitetura centralizada foi calculado. Lembrando que essa arquitetura considera que toda a cidade de Londrina está conectada à IMA, e todos os MEIs enviam informações diretamente para o COD. Para esse cenário seria necessário encaminhar, mensalmente, um montante de aproximadamente 28 Gbytes. Pelo período de uma semana esse montante seria de aproximadamente 6,5 Gbytes. A quantidade de dados recebidos e processados diariamente, pelo COD, seria de aproximadamente 0,93 Gbytes.

A quantização dos dados foi realizada considerando a comunicação dos pacotes de dados dos MEls uma vez ao dia. Porém existem abordagens que utilizam outras taxas de transmissão para os dados dos MEls, mais próximas da taxa de amostragem do MEI, uma vez a cada 15 minutos. Como resultado, o aumento no número de informações trafegando na rede pode aumentar dezenas de vezes, o que causa problemas não apenas para o processamento e armazenamento dos dados, mas também para a transmissão de tais informações devido a taxa de transferência e a largura de banda necessária para a aplicação, conforme mostrado na Tabela 4.2. O volume de dados mais alto pode indicar um custo operacional adicional para as concessionárias se elas não utilizarem redes dedicadas, como redes RF e PLC, e optarem por usar redes de banda larga.

\subsubsection{Redução do Volume de Dados Utilizando o Estimado de Estado Embarcado}

Ao processar dados em uma arquitetura descentralizada, ao menos para realizar aplicações de redes inteligentes em tempo real, o EEE proposto visa reduzir a quantidade de dados a serem transmitidos. O conceito do EEE foi avaliado de acordo com as diferentes 
arquiteturas de implantação. A Tabela 4.3 apresenta a quantização dos dados de acordo com a arquiteturas descentralizadas propostas.

Tabela 4.3: Quantização de dados processados por cada estimador embarcado nas arquiteturas descentralizadas propostas.

\begin{tabular}{|c|c|c|c|}
\hline \multicolumn{4}{|c|}{ Quantidade de dados em kbytes por arquitetura descentralizada } \\
\hline Alcance do estimador de estado & Mensal (kb) & Semanal (kb) & Diário (kb) \\
\hline 1 por transformador & $3.584,1$ & 836,3 & 119,4 \\
\hline $500 \mathrm{~m}$ & $13.215,8$ & $3.083,6$ & 440,5 \\
\hline $750 \mathrm{~m}$ & $29.735,6$ & $6.938,3$ & 991,2 \\
\hline $1000 \mathrm{~m}$ & $52.863,2$ & $12.334,7$ & $1.762,1$ \\
\hline 1 por alimentador & $380.757,4$ & $88.843,4$ & $12.691,9$ \\
\hline
\end{tabular}

Portanto, fica clara a redução significativa de processamento, memória e largura de banda necessária para a operação em tempo real de SDs devido ao uso de sistemas embarcados distribuídos na rede de BT. A Figura 4.4 mostra a quantidade de dados do cenário em que cada transformador de distribuição possui seu próprio EEE, responsável pelo gerenciamento de todas as UCs conectadas à sua rede secundária. Os montantes foram calculados para os 7.755 transformadores de distribuição do SD e representam o tráfego diário em Kbytes para cada transformador.

Figura 4.4: Quantidade de dados processados pelo EEE em cada transformador de distribuição no período de um dia.

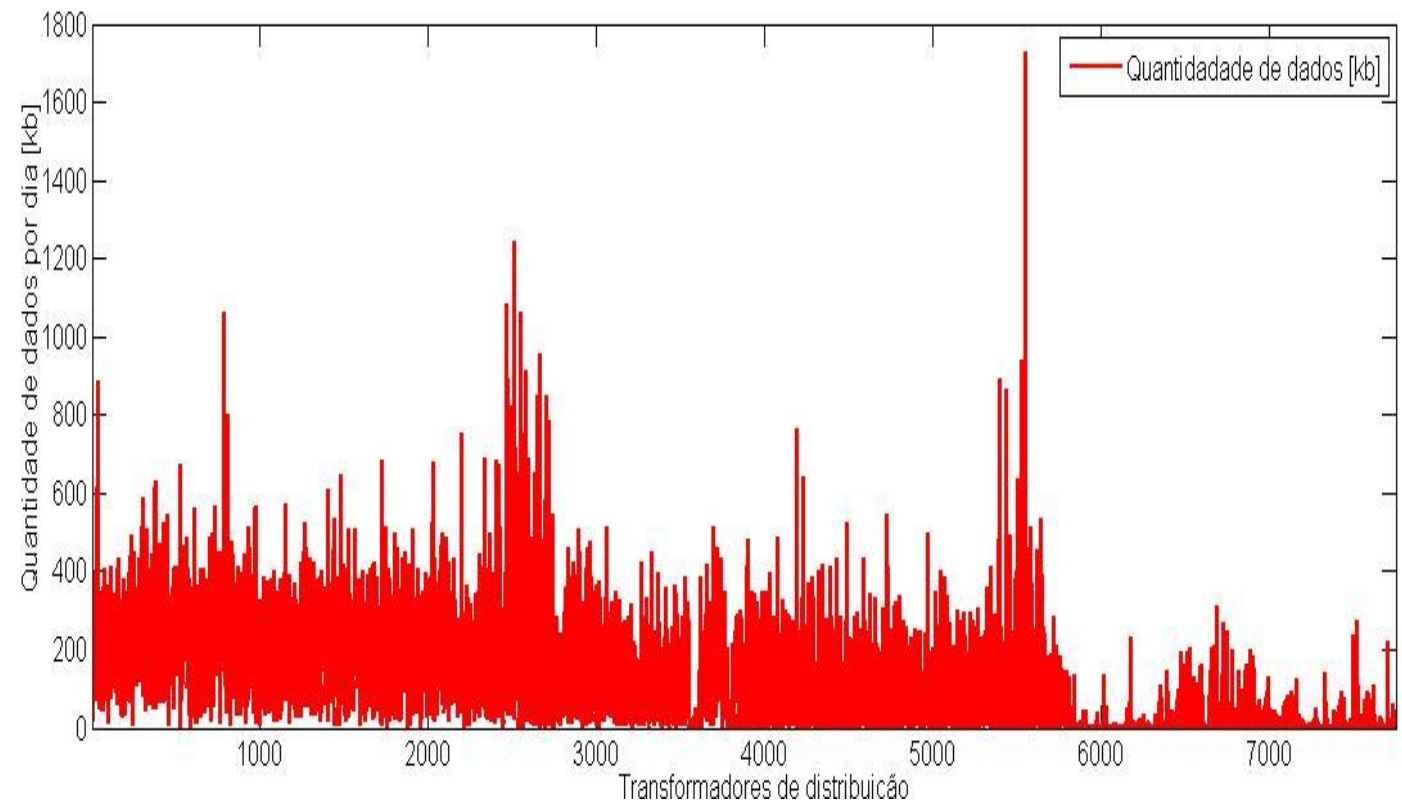

Fonte: Elaborada pelo autor. 
Plataforma Embarcada Para Monitoramento Descentralizado de Redes Inteligentes de Energia 57

Como pode ser visto, não apenas o número médio de volume de dados deve ser considerado ao definir os requisitos de comunicação para a AMI, mas também as individualidades das redes que estão sendo monitoradas. Além de poder apresentar as vantagens e benefícios do EEE proposto, a implementação de sistemas descentralizados também permite diferentes aplicações de redes inteligentes para redes de distribuição de BT, tais como localização de faltas, gerenciamento de recursos de energia distribuída, operação ótima de sistemas de armazenamento, etc.

\subsection{Metodologia de Implementação da Plataforma Embarcada}

Tendo em vista que a primeira arquitetura descentralizada proposta foi a que se mostrou mais eficiente nas análises realizadas, ela foi a escolhida para implantação em bancada. Para isso foi desenvolvido e implantado, em bancada, uma IMA, em que fosse possível emular o comportamento de uma rede real de distribuição de energia elétrica, com MEls acoplados aos seus consumidores finais.

Descreve-se, a seguir, todo o processo de desenvolvimento dessa IMA e do EEE proposto.

\subsubsection{Rede Teste Utilizada}

Para a execução dos testes para validação da plataforma embarcada para monitoramento descentralizado de SDs foi utilizado o sistema real de distribuição de energia apresentado em (ROLIM; TRINDADE, 2019), onde a MT opera em $13.8 \mathrm{kV}$ e a BT em $220 \mathrm{~V}$, com extensão total do sistema de MT de $4.71 \mathrm{~km}$. O sistema completo modelado em (ROLIM; TRINDADE, 2019) conta com 536 barras de média e 1659 consumidores em BT. Afim de demostrar a proposta dessa dissertação de mestrado, foi utilizada uma fração desse sistema que conta com 114 barras de MT e 5 transformadores de distribuição, sendo cada um deles conectados com suas respectivas UCs, representando assim as redes de BT presentes no sistema, totalizando 208 barras. A Figura 4.5 apresenta o esquema das conexões da fração da rede utilizada para a realização dos testes. 
Figura 4.5: Rede teste utilizada para implementação.

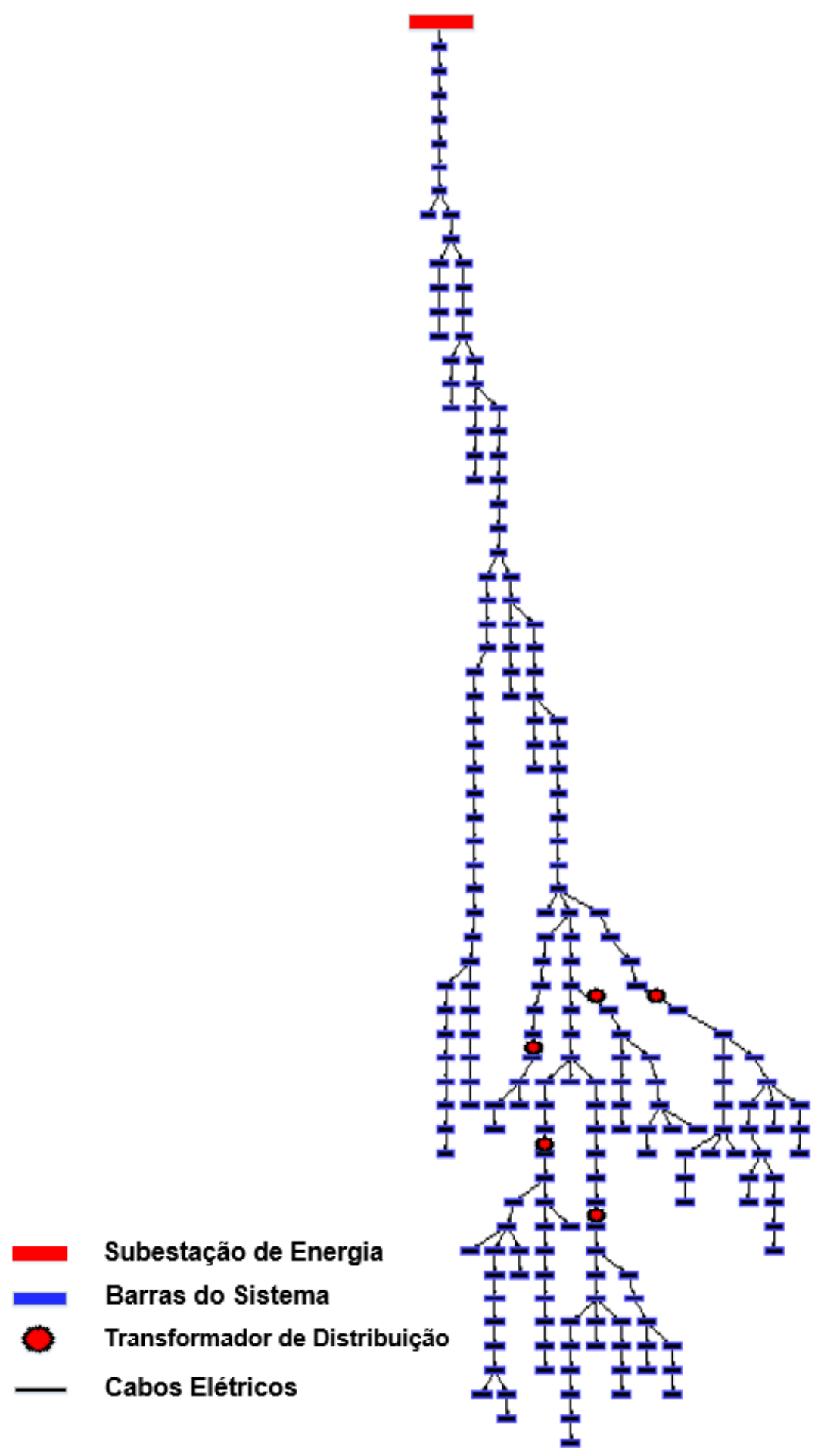

Fonte: Elaborada pelo autor.

A Tabela 4.4 traz a quantidade de UCs conectadas a cada transformador presente no SD utilizado como sistema teste. 
Tabela 4.4: Quantidade de UCs por transformador.

\begin{tabular}{|c|c|}
\hline \multicolumn{2}{|c|}{ Quantidade de UCs por transformador de distribuição } \\
\hline Identificação do Transformador & Quantidade de UCs \\
\hline 2960 & 5 \\
\hline 1370 & 27 \\
\hline 1371 & 13 \\
\hline 1372 & 25 \\
\hline 1373 & 24 \\
\hline
\end{tabular}

Os transformadores de distribuição 2960, 1370, 1371, 1372 e 1373 fazem a conexão da rede de BT com a rede de MT. Tais transformadores estão conectados respectivamente às barras $94,114,97,103$ e 110 da rede primária do SD teste.

\subsubsection{Requerimentos de Hardwares}

Para emular uma IMA em laboratório submetemos a proposta do EEE para o Programa de Parcerias em loT da empresa Qualcomm Wireless Tecnhology \& Innovation em 2018, onde foram selecionados projetos brasileiros para receber kits de desenvolvimento com tecnologias de comunicação embarcada. O Módulo TELIT ME910C1-WW recebido para prototipagem do projeto suporta as redes de comunicação GPRS, EDGE, CAT M1 e CAT NB-loT, e possui os seguintes periféricos (TELIT COMMUNICATIONS, 2017):

- Conector para SIM Card;

- Dois conectores de antenas e circuito de RF, com conectores SMA para as antenas GPS e de sinal celular;

- Conector mini-USB, que permite conexão com a porta USB do modem;

- Alguns jumpers que aceleram o desenvolvimento e permite reconfiguração rápida da placa;

- Level translators de 1,8 V do modem para 2,8 V expostos na interface inferior da placa;

- 2 conectores $100 \mathrm{mil} / 2.54 \mathrm{~mm}$ na parte inferior, que permitem acesso a todas as funções do modem;

Tal módulo é responsável por executar a conexão e envio de dados, após o processamento do EEE, para um servidor utilizando redes de comunicação 3G e 4G LTE.

A plataforma embarcada de desenvolvimento escolhida para emulação dos dados gerados por um MEI foi a Raspberry PI 3, por sua alta capacidade de processamento capaz 
de executar programas com ótima eficiência computacional em pequenos períodos de tempo, além de seu baixo custo de aquisição.

A Raspberry PI 3 é uma placa eletrônica embarcada com um processador Broadcom BCM2837 64 bits ARMv8 Cortex-A53 Quad-Core com clock de $1.2 \mathrm{GHz}$ que possibilita alta performance em cálculos computacionais e baixo consumo de energia, representa uma ótima solução para aplicações que necessitam de resoluções de cálculos numéricos (LECCESE et al., 2016).

A placa Raspberry PI 3 conta ainda com diversos periféricos que podem ser utilizados na aplicação, como o adaptador Wifi 802.11n integrado, bluetooth 4.1 Bluetooth Low Energy (BLE) integrado, conector de vídeo HDMI, 4 portas USB 2.0, conector Ethernet, interface para câmera, interface para display, slot para cartão microSD e conector de áudio e vídeo (PI, 2016).

O modulo Ra-01 foi utilizado para o envio de dados provenientes da emulação de um MEI utilizando a rede comunicação LoRa, apresentada no capitulo 3. O modulo conta com o chip SX1278 amplamente empregado em projetos que fazem uso de comunicação LoRa e possui comunicação serial SPI (Al-THINKER, 2017).

Para a recepção e conversão dos dados oriundos do modulo Ra-01 foi utilizado a ESP32 LoRa, fazendo uso do chip SX127X, com sensibilidade de recepção de -139 dbm. Alcance máximo do LoRa (utilizando a antena do módulo) é de $3 \mathrm{~km}$ em áreas abertas e não muito populosas. Com a utilização ESP32 LoRa é possível operar nas frequências de 868915, $923 \mathrm{MHz}$, quando empregado o chip SX1276, e de 433 a $510 \mathrm{MHz}$ para o chip SX1278. O Range de temperatura para operação é de $-40^{\circ} \mathrm{C}$ até $80^{\circ} \mathrm{C}$ (AUTOMATION, 2020)

Para a execução do processo matricial de estimação de estado, foi utilizada a placa Jetson Nano, recentemente lançada pela NVIDIA para execução de projetos voltados para Inteligência Artificial e Aprendizado de Máquina (do inglês - Machine Learning). A Jetson Nano apresenta uma performance computacional apontada pela NVIDIA de 472 GFLOPS. Ela possui um processador quad-core ARM A57 de $1,43 \mathrm{GHz}$ e uma Unidade de Processamento Gráfico (do inglês - Grafic Processing Unit - GPU) de 128 cores NVIDIA Maxwell. Vem também com 4 GB de memória RAM LPDDR4 e opera a baixo consumo, para aplicações que utilizam a GPU (NVIDIA CORPORATION, 2020).

Abordando o conceito de System on a Chip (SoC) a Unidade Central de Processamento ( do inglês - Central Processing Unit - CPU) da Jetson Nano apresenta as seguintes características técnicas, descritas na Figura 4.6 (NVIDIA EMBEDDED, 2020). 
Figura 4.6: Especificações Técnicas Jetson Nano.

\begin{tabular}{|c|c|}
\hline GPU & Arquitetura NVIDIA Maxwell" com 128 NVIDIA CUDA" cores \\
\hline CPU & Processador Quad-core ARM" Cortex"-A57 MPCore \\
\hline Memória & 4 GB 64-bit LPDDR 4 \\
\hline Armazenamento & $16 \mathrm{~GB}$ eMMC 5.1 Flash \\
\hline Video Encode & 4K 10 30 (H.264/H.265) \\
\hline Video Decode & $4 \mathrm{~K} 1060$ (H.264/H.265) \\
\hline Câmera & 12 lanes [ $3 \times 4$ or $4 \times 2$ ] MIPI CSI-2 DPHY 1.1 [ $18 \mathrm{Gbps}$ ] \\
\hline Conectividade & Gigabit Ethernet \\
\hline Visor & HDMI 2.0 ou DP1.2 | eDP 1.4 | 2 DSI simultâneos [1 x2] \\
\hline UPHY & $1 \times 1 / 2 / 4 \mathrm{PCIE}, 1 \times$ USB $3.0,3 \times$ USB 2.0 \\
\hline $1 / 0$ & $1 \times \mathrm{SDIO} / 2 \times \mathrm{SPI} / 4 \times 12 \mathrm{C} / 2 \times 12 \mathrm{~S} / \mathrm{GPIOS}$-> IC, IS \\
\hline Dimensões & $69.6 \mathrm{~mm} \times 45 \mathrm{~mm}$ \\
\hline Mecânico & Conector de ponta com 260 pinos \\
\hline
\end{tabular}

Fonte: Retirado de (NVIDIA EMBEDDED, 2020).

A placa base de desenvolvimento conta ainda com os seguintes periféricos (NVIDIA CORPORATION, 2020) :

- Conector de 260 pinos SO-DIMM para placa CPU Jetson Nano;

- Saída de video - HDMI 2.0 e eDP 1.4;

- $\quad$ Conectividade - Gigabit Ethernet mais o conector PoE de 4 pinos;

- USB - 4 portas USB 3.0, 1 portas USB 2.0;

- Câmera I/F - 1x MIPI CSI-2 DPHY compatível com o módulo de câmera Leopard Imaging LI-IMX219-MIPI-FF-NANO;

- Socket M.2 Key E (PCle x1, USB 2.0, UART, I2S e I2C) para cartões de rede sem fio;

- 40 pinos de GPIOs, I2C, I2S, SPI, UART;

- 8 Pinos com resets e liga-desliga;

- Misc - LED que indica que está alimentada, Header para ventoinha de 4 pinos;

- Power Supply - 5V/4A ou 5V/2A por micro USB;

- Suporte opcional a Power over Ethernet.

\subsubsection{Requerimentos de Softwares}

Em função dos hardwares escolhidos para a utilização no projeto, alguns softwares se tornaram essenciais para a implementação, entre eles, o já disseminado na área de 
prototipagem eletrônica, o ambiente de programação da plataforma Arduino utilizado para acesso e configuração do ESP32 LoRa.

Com relação à configuração de acesso ao módulo TELIT ME910C1-WW, é disponibilizado o software de interface TELIT AT Controller onde a comunicação é feita através de comandos AT, sendo possível a conexão física ser realizada de duas maneiras, através da porta USB ou pela conexão dos pinos RX TX em 1,8 V.

Para a implementação do algoritmo de emulação das medidas provenientes dos MEls na RB, foi empregado o Rasphian, um ambiente de desenvolvimento planejado para aplicações de Linux Embarcado, e a linguagem de programação escolhida foi o Python. A mesma foi utilizada para gerenciamento do módulo RA-01 e o envio das medidas emuladas.

A imagem em Linux desenvolvida pela NVIDIA para a Jetson Nano, empregada juntamente com a IDE Visual Studio, permitiu implementação do processo de Estimação de Estado e o controle do Módulo Telit para o envio do resultado do processamento dos dados para o servidor da Plataforma Things Board.

A plataforma Things Board é uma plataforma amplamente utilizada por empresas e usuários no gerenciamento de projetos que envolvem conceitos de internet das coisas, apresentando recursos que permitem desde o processamento de configuração de alarmes até visualização dos dados em dashboards totalmente customizáveis. A plataforma vem sendo utilizada em projetos de smart metering, smart energy, Internet das Coisas e de indústria 4.0 (THINGSBOARD INC., 2020)

O Python é uma linguagem que vem ganhando destaque entre os programadores, além de apresentar bastante relevância no meio acadêmico por ser uma linguagem de alto nível interpretada, imperativa e orientada objetos. Umas das principais características é a facilidade de leitura do código e o tamanho reduzido. No quesito linhas de código, em relação a outras linguagens de programação, assim como outras vantagens como ser multiplataforma, possuí bibliotecas abertas e sintaxe intuitiva (BELOTSKY; MAJOR, ). A Figura 4.7 apresenta o esquemático do protótipo de desenvolvimento proposto. 
Figura 4.7: Esquemático de desenvolvimento.
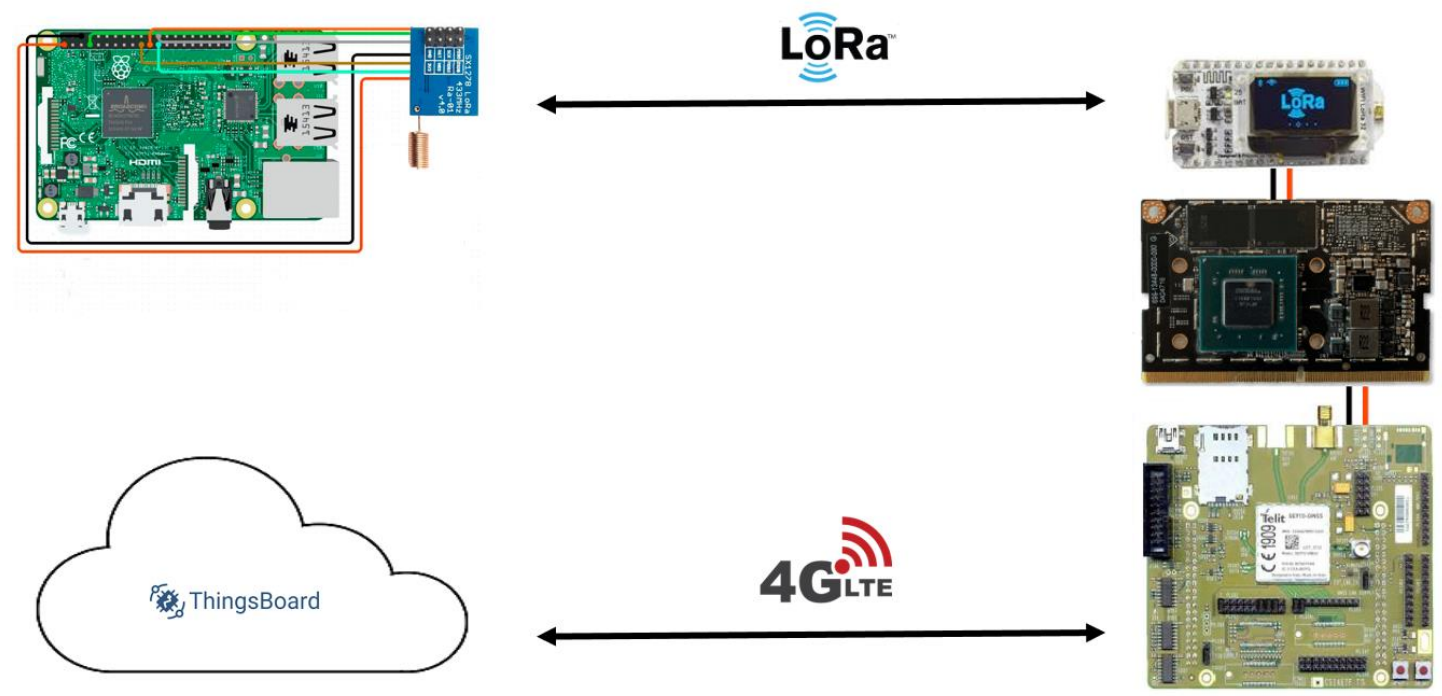

Fonte: Elaborada pelo autor.

\subsection{Considerações Finais}

Com uma abordagem de monitoramento centralizado, onde todas as informações precisam ser enviadas e processadas pelos CODs, a potência de processamento e a largura de banda da rede de comunicação precisam ser muito altas para manter um desempenho confiável de aplicações em tempo real. Uma redução considerável é observada para todas as arquiteturas descentralizadas propostas com base no EEE proposto do ponto de vista de quantidade de dados a serem transmitidos e processados para executar a estimação de estado. Assim, além de permitir a redução do tráfego de informações, a utilização do EEE proposto, de forma descentralizada, também permite uma redução nos custos operacionais relacionados aos serviços de comunicação exigidos pelas redes de energia elétrica monitoradas por MEls.

No próximo capítulo são apresentados resultados das simulações realizadas para validação da arquitetura descentralizada proposta e implementada em bancada. 



\section{Capítulo 5 - Testes e Análises dos Resultados}

\subsection{Introdução}

Neste capítulo serão apresentados os resultados das simulações realizadas para validação da arquitetura descentralizada proposta e implementada em bancada, conforme apresentada no Capítulo 4. Vale ressaltar que a implantação foi realizada utilizando módulos industriais e redes de comunicação empregadas em aplicações reais de projetos de smart grids. Para validação foi utilizado um SD real para validação do EEE proposto.

\subsection{Detalhamento da Implementação da Plataforma Embarcada}

Para realizar a emulação do comportamento de um MEI, foi utilizado uma RaspBerry PI em conjunto com um módulo LoRa Ra-01 fazendo o envio dos dados referentes às medições de energia nas UCs a cada $0,5 \mathrm{~s}$. O código para o gerenciamento das modulo LoRa Ra-01, as configurações da placa embarcada e o envio das medidas para o gateway de processamento foram realizados utilizando a linguagem Python. A Figura 5.1 apresenta a conexão entre a Raspberry PI e o módulo LoRa.

Figura 5.1: Conexão entre a Raspberry PI e o módulo LoRa Ra-01.

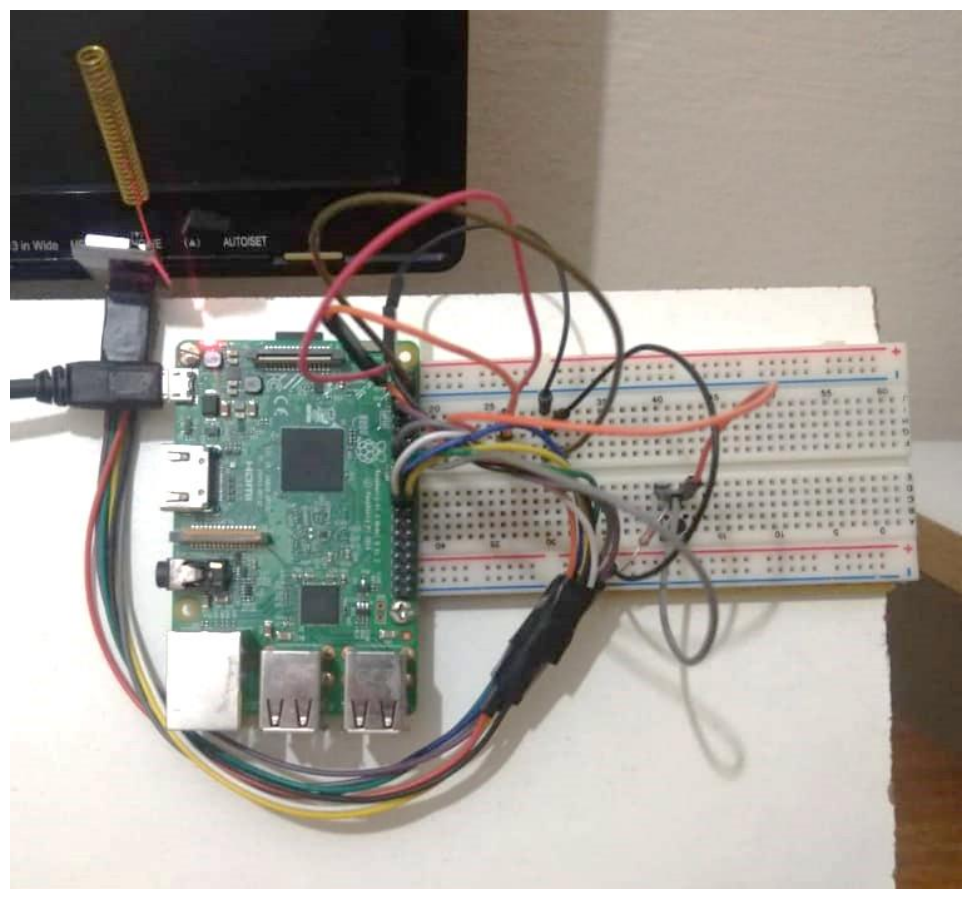

Fonte: Elaborada pelo autor.

Para o desenvolvimento do gateway de processamento, foram empregados os módulos ESP32 LoRa e 4G LTE, e como central de processamento a placa NVIDIA Jetson 
Nano. O módulo ESP32 LoRa foi utilizado como receptor dos dados enviados pelo Ra-01 e após recebidos, os dados são pré processados e convertidos para serem enviados ao processador central via interface UART. Uma vez que os dados, oriundos da emulação dos MEI, estão disponíveis no processador Jetson, estes constituem parte dos parâmetros de entrada juntamente com a matriz de conexão das barras da rede e os parâmetros da linha, para o EEE programado na linguagem Python. Dessa forma executa-se o processo de estimação de estado para a rede secundária que se está gerenciando no momento.

Com o resultado do processo de estimação de estado, inicia-se a conexão com o módulo 4G LTE da empresa TELIT. O módulo é acessado via comunicação serial UART, onde são enviados comandos AT por esse canal de comunicação, que estabelece o registro do módulo da rede celular da operadora e permite requisição de um endereço IP para acesso à rede de internet. Ao final de toda a configuração inicial é possível realizar uma request HTTP e abertura de sockets de comunicação diretamente para o servidor escolhido e assim encaminhar os dados referentes ao resultado do EEE que podem ser acessados pelos CODs das concessionárias, sendo de alta importância para o conhecimento do estado operativo corrente da rede elétrica. A Figura 5.2 monstra a configuração física das conexões realizadas entre as placas utilizadas no gateway de processamento.

Figura 5.2: Conexão física do gateway de processamento.

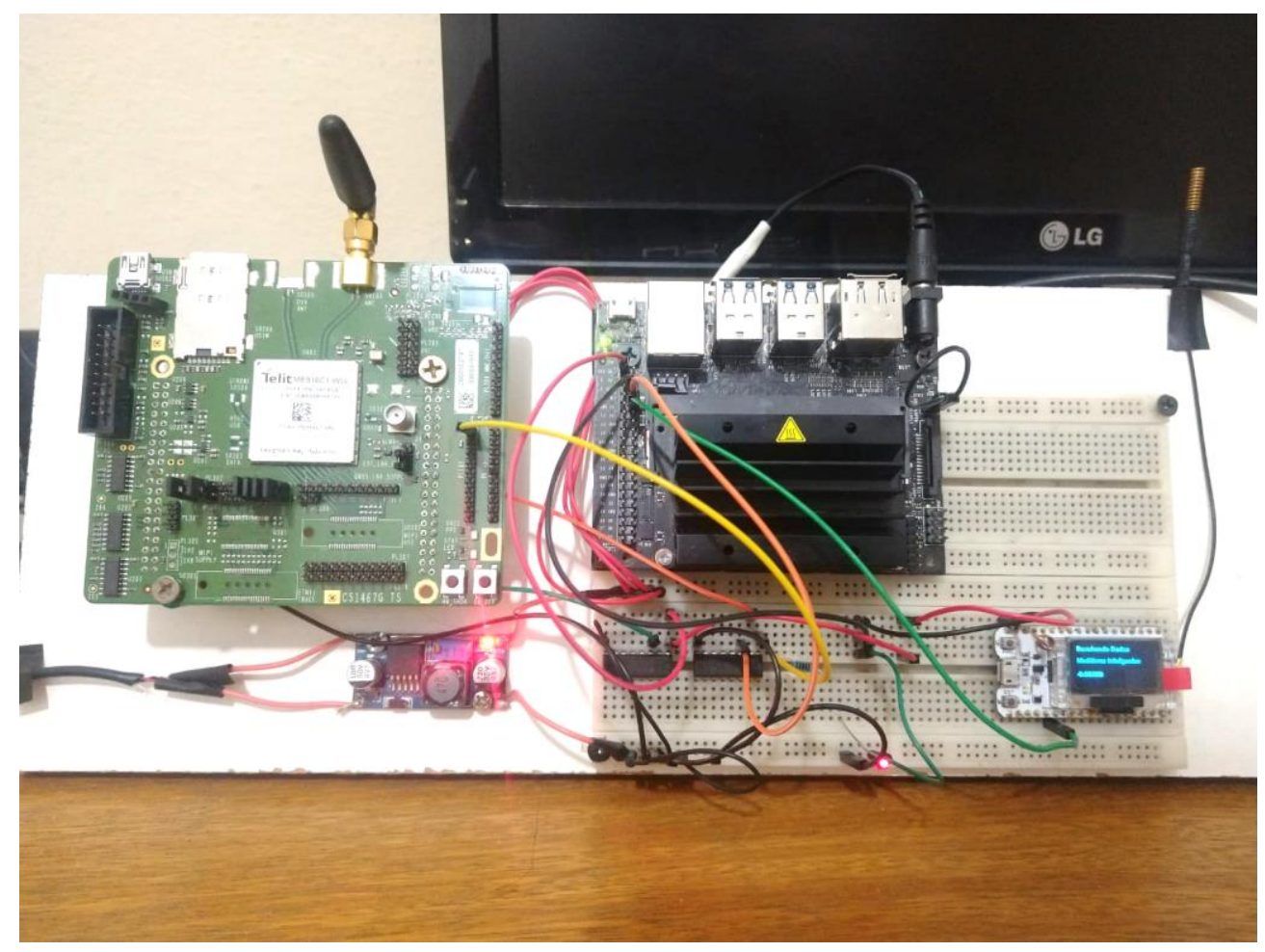

Fonte: Elaborada pelo autor.

A plataforma para projetos de internet das coisas Things Board foi utilizada para receber os dados do resultado do processo de estimação de estado realizado na Jetson Nano. 
Os dados são enviados em formato JSON e armazenado no servidor para serem exibidos no dashboard desenvolvido. O servidor Things board foi desenvolvido em parceria com o Laboratório de Eletrônica da Faculdade de Ciências da Univsersidad de Salamanca, na cidade de Salamanca na Espanha, devido ao autor ter realizado um período de mobilidade internacional na instituição.

As informações sobre o estado de operação do SD em análise são apresentadas em um dashboard desenvolvido na plataforma Things Board para visualização e monitoramento da rede secundária analisada. A Figura 5.3 monstra o dashboard desenvolvido apresentando dados de uma das redes de BT presentes no SD utilizado.

Figura 5.3: Dashboard desenvolvido na plataforma Things Board.

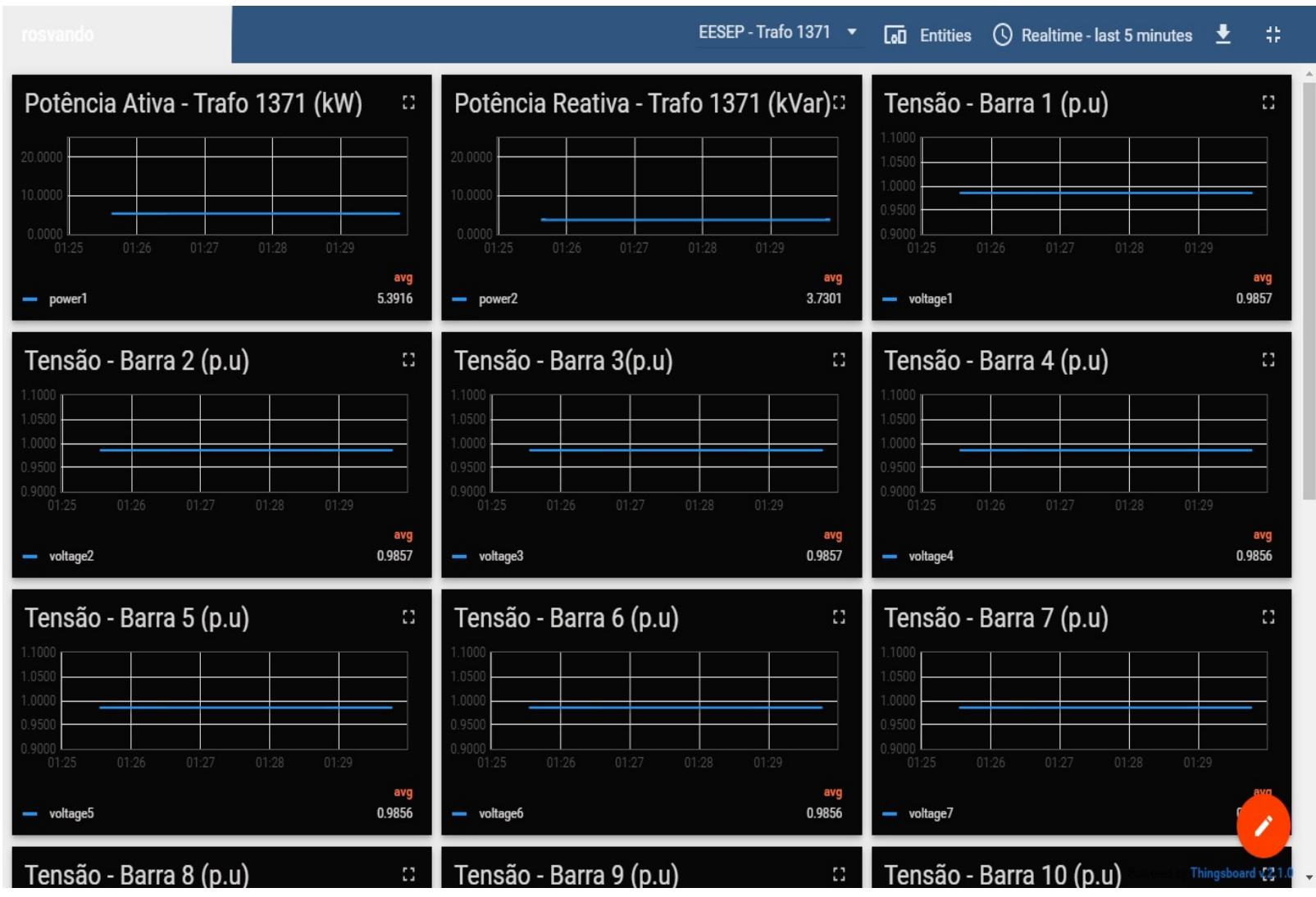

Fonte: Elaborada pelo autor.

A Figura 5.4 apresenta a plataforma completa, conectada e em funcionamento. 
Figura 5.4: Plataforma completa em funcionamento.

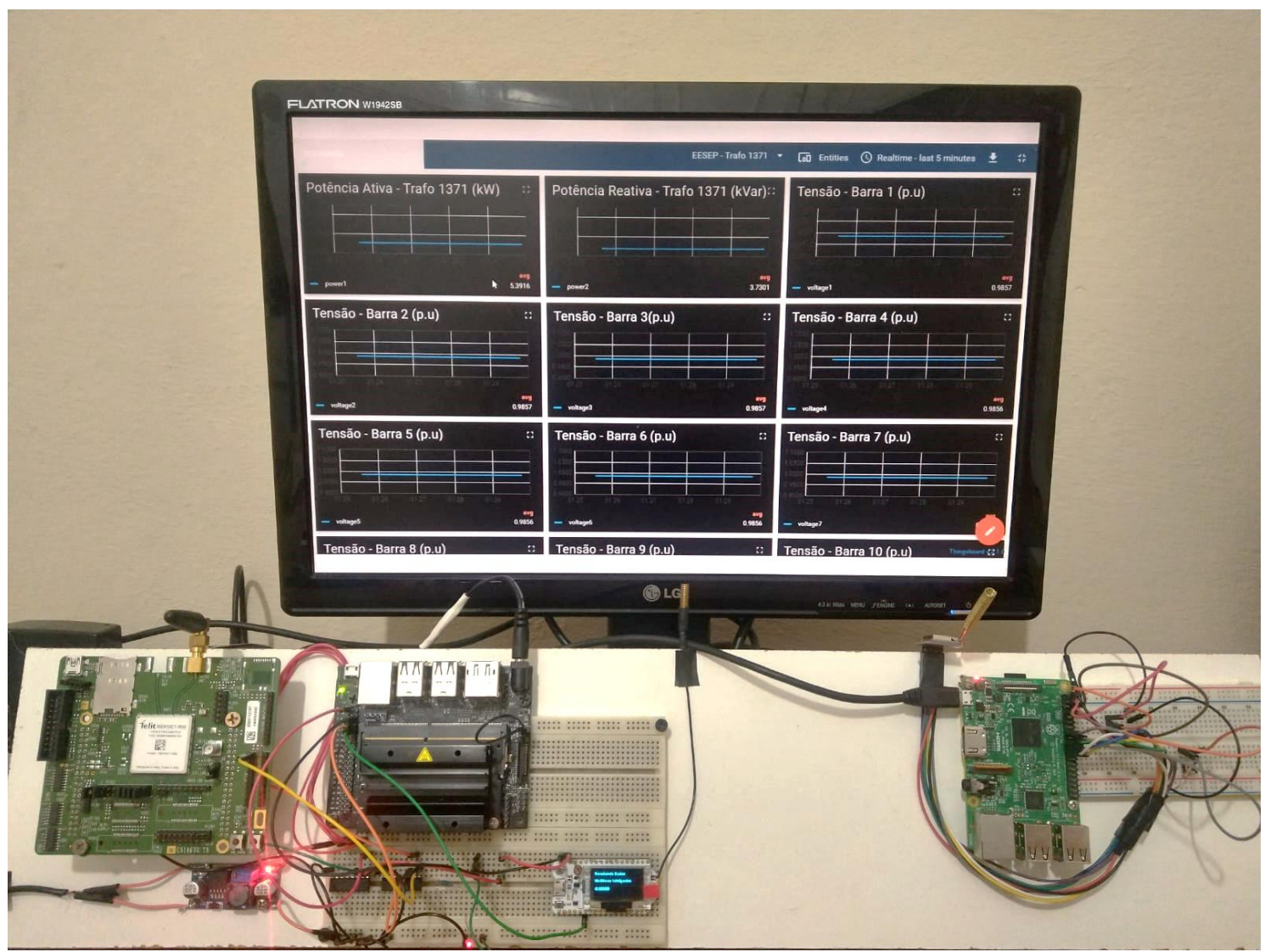

Fonte: Elaborada pelo autor.

As informações provenientes dos EEEs são customizáveis, atendendo às requisições dos operadores quanto a quais parâmetros adquirir. Podendo, assim, enviar informações somente da barra onde o EEE foi instalado, na hipótese de instalação de um estimador por transformador de distribuição, como também informações especificas de uma UC.

De uma maneira geral, saindo um pouco do escopo deste trabalho, essas informações podem ser: o estado dos dispositivos seccionadores telecomandados que estejam presentes em uma micro rede, avisos sobre faltas e desconexões locais, informações sobre a utilização de geração distribuída, armazenamento de energia em banco de baterias e conexão de veículos elétricos à rede de distribuição de energia. Todas essas tecnologias possuem alta penetração no mercado de energia elétrica.

A Figura 5.5 apresenta a estrutura de funcionamento da rede de comunicação proposta neste trabalho. 
Figura 5.5: Estrutura de funcionamento da rede de comunicação.

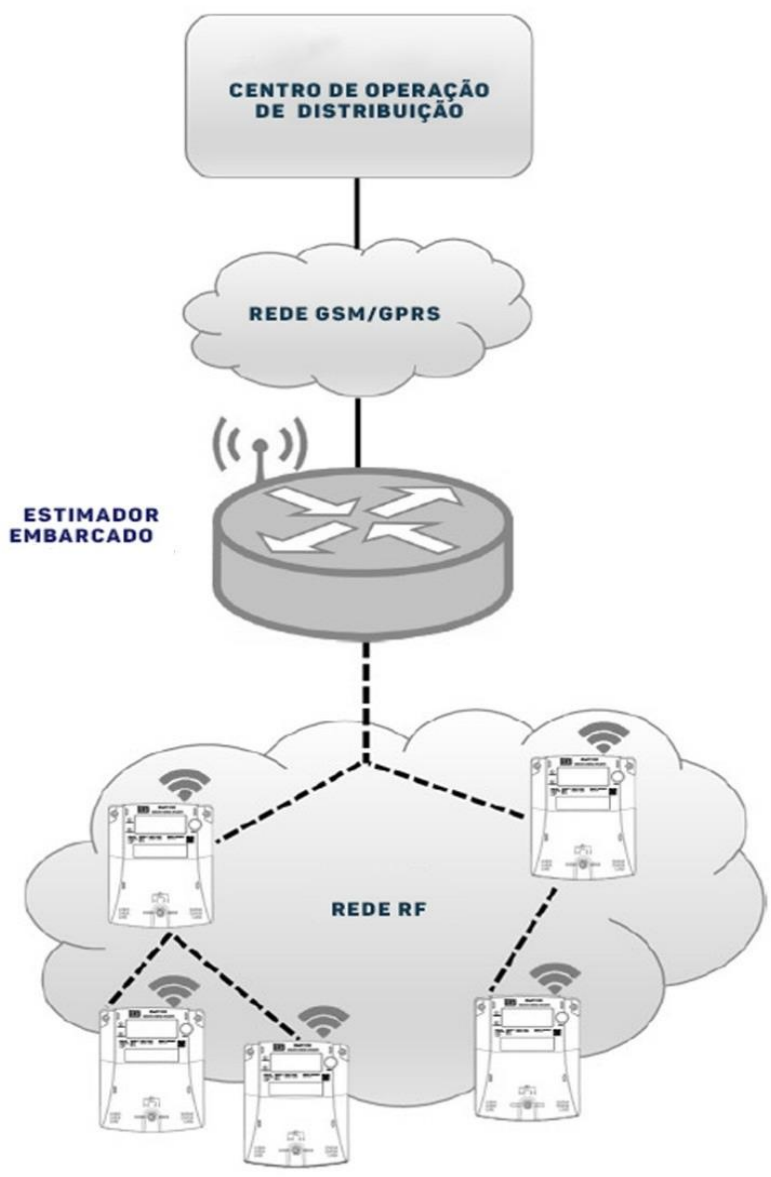

Fonte: Elaborada pelo autor.

Conforme mencionado no Capítulo 4, em função de a arquitetura descentralizada proposta possuindo um EEE por transformador de distribuição ter se mostrado a mais eficiente nas análises realizadas naquele capítulo, foi ela a escolhida para ser implantada e testada em bancada. A Figura 5.6 ilustra essa arquitetura. Para essa arquitetura o gateway de processamento fica responsável por gerenciar todas as UCs conectadas a cada transformador, realizando a aquisição dos dados oriundos dos medidores eletrônicos e a execução do processo de estimação de estado para correspondente rede secundária. Logo após a execução da estimação de estado, o resultado é enviado para um servidor web, de forma a ser visualizado e utilizado para o gerenciamento da rede distribuição. 
Figura 5.6: Implementação da arquitetura proposta.

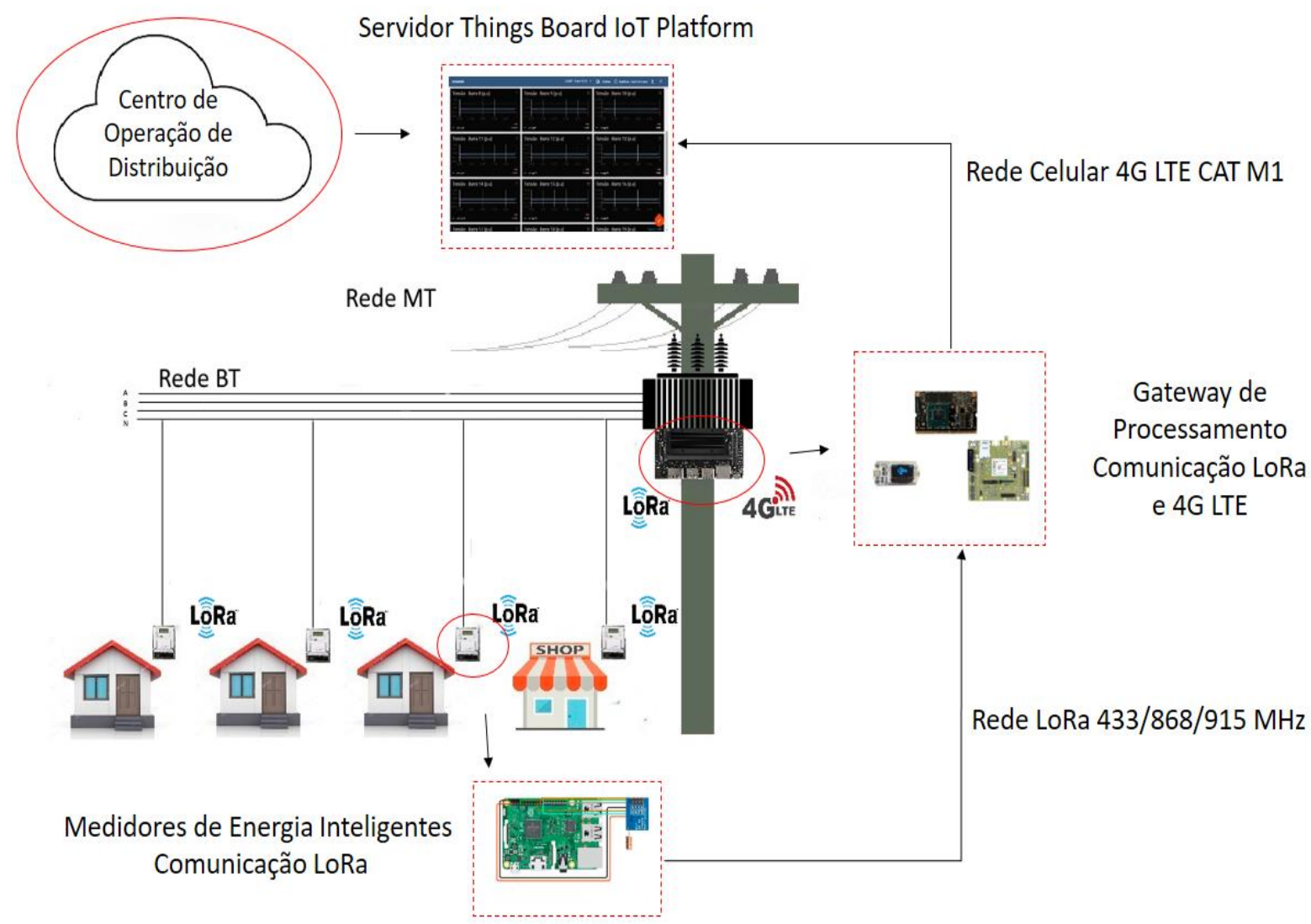

Fonte: Elaborada pelo autor.

O SD utilizado como sistema teste possui 5 transformadores de distribuição e suas respectivas UCs como descrito na Tabela 4.4. Sendo assim, cada EEE será responsável por gerir as informações das UCs. A Figura 5.7 apresenta as conexões das UCs conectadas a saída de baixa tensão do transformador 1370 . 
Figura 5.7 Rede de baixa tensão do transformador 1370.

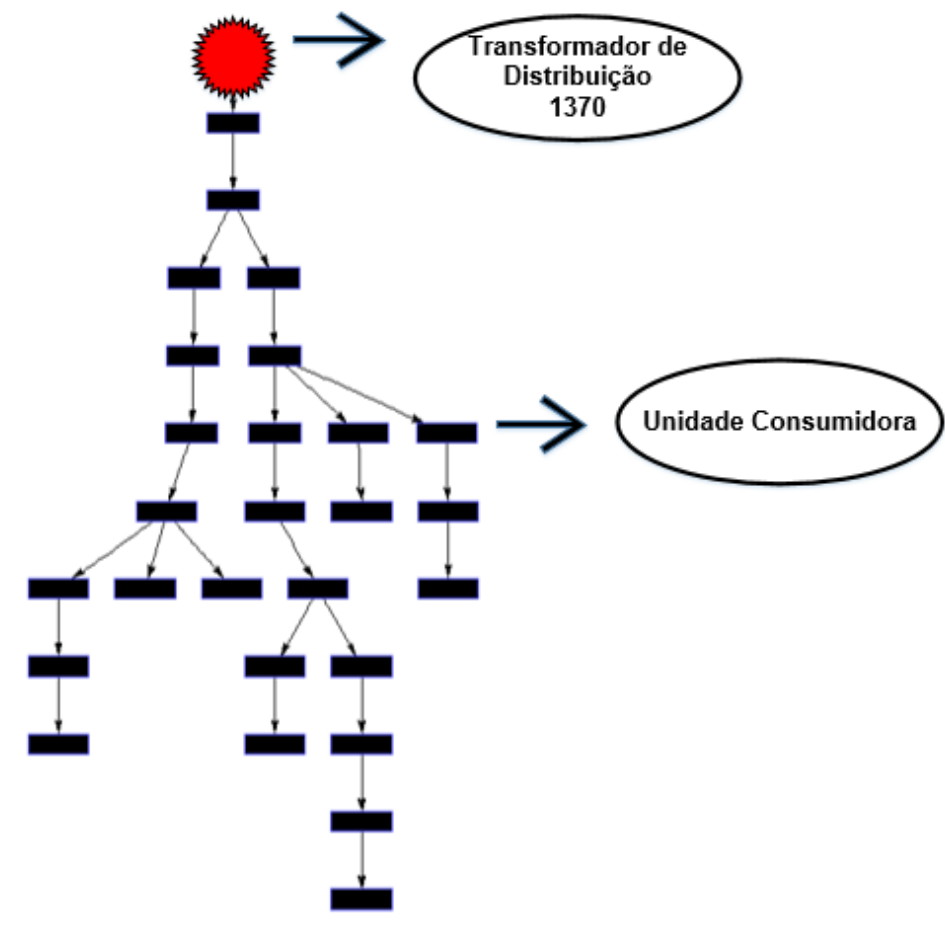

Fonte: Elaborada pelo autor.

A metodologia de análise da implementação de uma plataforma embarcada para monitoramento descentralizado de SDs baseia-se no tratamento de dados oriundos dos medidores inteligentes instalados nas UCs e que fazem uso das atuais redes de comunicação desenvolvidas para projetos de Internet das Coisas e Smart Grids. Com a utilização desses dados e novas tecnologias relacionadas à computação e a eletrônica permite-se realizar o processamento de informações de forma descentralizada e mais próxima as UCs.

A partir da arquitetura decentralizada implantada em bancada realizar-se-á uma comparação, das estimativas obtidas por essa arquitetura, com as resultantes do processo de monitoramento centralizado usualmente empregado atualmente nos SDs. Ou seja, com as estimativas obtidas por um estimador de estado por mínimos quadrados ponderados considerando ao mesmo tempo as redes de MT e BT.

Face ao exposto, para a abordagem centralizada o EE será executado para o sistema completo, ou seja, considerando a rede primária e secundária juntas, totalizando 208 barras.

O SD teste utilizado possui 5 transformadores e consequentemente 5 redes de BT conectadas ao secundário de cada transformador. Na arquitetura descentralizada proposta os EEE realizam a estimação de estado para cada uma das 5 redes de BT, fazendo uso da plataforma embarcada desenvolvida. Em seguida enviam, para o servidor (que seria o COD), o resultado dos processos de estimação, geralmente tensões complexas nodais, e a Potência 
Ativa $(Q)$ e Reativa $(Q)$ de cada transformador da rede primária. Dessa forma, busca-se demonstrar a viabilidade de execução de EEE de forma decentralizada e o gerenciamento das redes de BT sendo realizado por placas instaladas nos SD. Com os dados de P e $Q$ de cada transformador será possível executar o EE para rede primária, sem ter a necessidade de enviar todos os dados diretamente para o COD e permitindo o gerenciamento do SD completo.

\subsection{Sistemática de Avaliação do EEE}

O primeiro passo para validação do EEE proposto foi a emulação de valores de referência para as medidas e variáveis de estado. Para isso foi executado um fluxo de potência para rede teste completa (rede primária e secundária), totalizado 208 barras, para obter os valores de tensão complexa e injeção de $P$ e $Q$ em todas as barras dos sistemas e valores de fluxo de potência ativa e reativa em todos os ramos da rede. A partir desses valores foram obtidos os valores de referência para o vetor de medidas $\left(\underline{Z}^{\text {ef }}\right)$ e de variáveis de estado da rede $\left(\underline{x^{\text {ref }}}\right)$.

Para emular medidas obtida e tempo real $(Z)$, é necessário inserir ruído no vetor $\underline{Z}^{\text {ref }}$. O ruído é obtido através da amostragem aleatória em uma quantidade total de simulações de Monte Carlo (foi utilizado uma amostra de 100). As amostras de ruído são geradas individualmente, para cada medida, a partir de um gerador de números aleatórios e do desvio padrão da respectiva medida, conforme as equações (5.1) e (5.2) (SINGH; PAL; VINTER, 2009)(CASTILLO et al., 2011)(FERNANDES; ALMEIDA, 2018).

$$
\begin{gathered}
z_{i}=z_{i}^{r e f}+u_{i} \cdot \sigma_{i} \\
\sigma_{i}=\frac{\left|z_{i}^{r e f}\right| \cdot p r_{i}}{3}
\end{gathered}
$$

Onde, $z_{i}$ é o valor da medida $i$ com a inserção de ruído que será utilizado como dado de entrada para os estudos (isto é, como valores medidos para execução do EE), $z_{i}^{\text {ref é o }}$ respectivo valor da grandeza elétrica obtida no caso de referência, $p_{r i}$ é a respectiva precisão do medidor em percentual obtido de sua classe de precisão dos dados de placa, e $u_{i}$ é uma variável aleatória com distribuição normal padronizada, de média zero e desvio unitário, ou seja, $u_{i} \sim \mathrm{N}(0,1)$, cujo valor é obtido através de um gerador de números aleatórios. A metodologia utilizada neste trabalho se baseia na inserção de ruído com distribuição Gaussiana conforme as hipóteses assumidas no modelo de medição clássico do problema de estimação de estado. Os valores de $p_{r i}$ utilizados para a inserção de ruídos, em função dos tipos de medidas, são apresentados na Tabela 5.1 . 
Tabela 5.1: Valores utilizados para a inserção de ruídos.

\begin{tabular}{|c|c|}
\hline \multicolumn{2}{|c|}{ Valores de precisão dos medidores } \\
\hline Tipo de Medida & Valor \\
\hline Medidor Inteligente & 0,05 \\
\hline Medidor SCADA & 0,02 \\
\hline Medidas Virtuais & 0,01 \\
\hline
\end{tabular}

Após a obtenção do vetor de medidas $\underline{Z}$, o próximo passo consiste em executar o EE MQP para a rede completa, e o resultado do processo é armazenado. Os resultados dessa etapa são apresentados no Apêndice A.

Para a validação da proposta inicia-se a execução dos EEEs descentralizados para cada rede de distribuição de baixa tensão presente no sistema, totalizando 5 . Dessa forma, faz-se uso da plataforma embarcada desenvolvida para emulação de uma cidade inteligente. Considera-se que estejam disponíveis medidores inteligentes, nos consumidores finais, com infraestrutura de comunicação disponibilizando as medidas para os EEEs alocados nos respectivos transformadores de distribuição, responsáveis pela conexão dos consumidores finais com a rede primária de distribuição de energia. Para cada uma das 5 redes de baixa tensão foram enviadas as medidas referentes a cada consumidor até o EEE que executará o processo de estimação para a respectiva rede, obtendo o $\underline{\hat{x}}$ e os valores de $\mathrm{P}$ e $\mathrm{Q}$ para a barra da rede primária representando o correspondente transformador de distribuição. Os resultados dessa etapa para a rede de distribuição de baixa tensão do transformador 1370 estão apresentados no Apêndice B.

Após a execução dos EEEs, o resultado do processo, $\underline{\hat{x}}$ e os valores de $\mathrm{P}$ e $\mathrm{Q}$, são enviados para o servidor web da Plataforma Things Board e apresentados no dashboard emulando o funcionamento de um COD. O processo é executado para todas as redes de baixa presentes no sistema e os resultados enviados para o servidor web onde é possível realizar o monitoramento dos dados recebidos e a visualização gráfica. As figuras Figura 5.8, Figura 5.9, Figura 5.10 e Figura 5.11 apresentam o dashboard com os resultados do processo estimação de estado da rede BT do transformador 1370 em cada instante de tempo. 
Figura 5.8: Dashboard da rede do trafo 1370 parte 1.

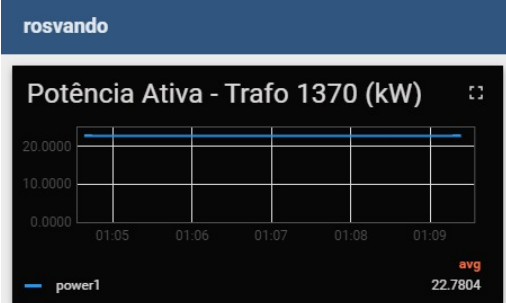

EESEP - Trafo 1370

[010 Entities (1) Realtime- last 5 minutes

t
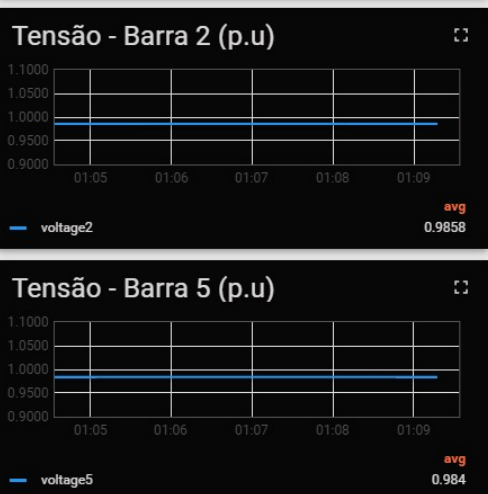

Tensão - Barra 8 (p.u)
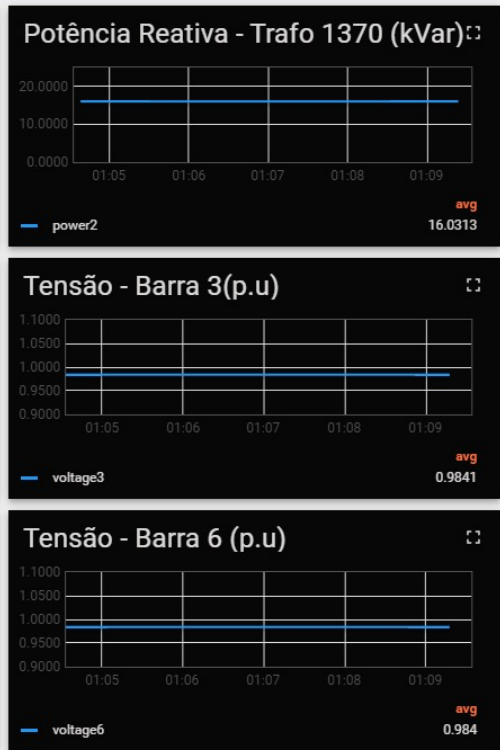

Tensão - Barra 9 (p.u)
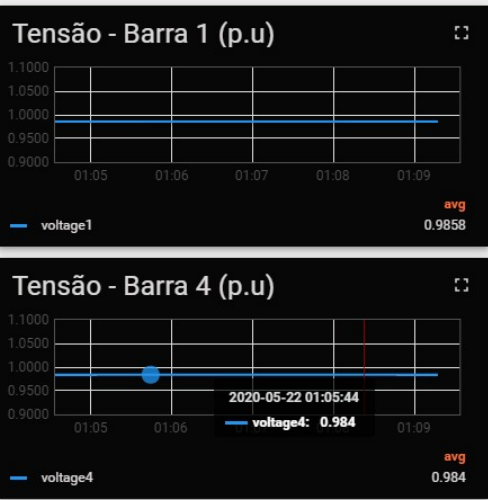

Tensão - Barra 7 (p.u)

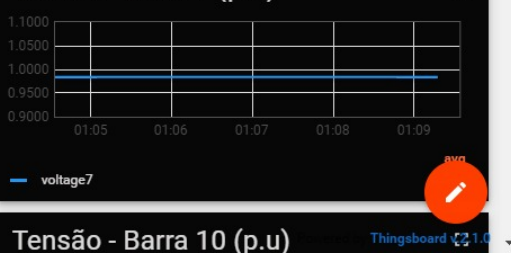

Fonte: Elaborada pelo autor.

Figura 5.9: Dashboard da rede do trafo 1370 parte 2.

rosvando
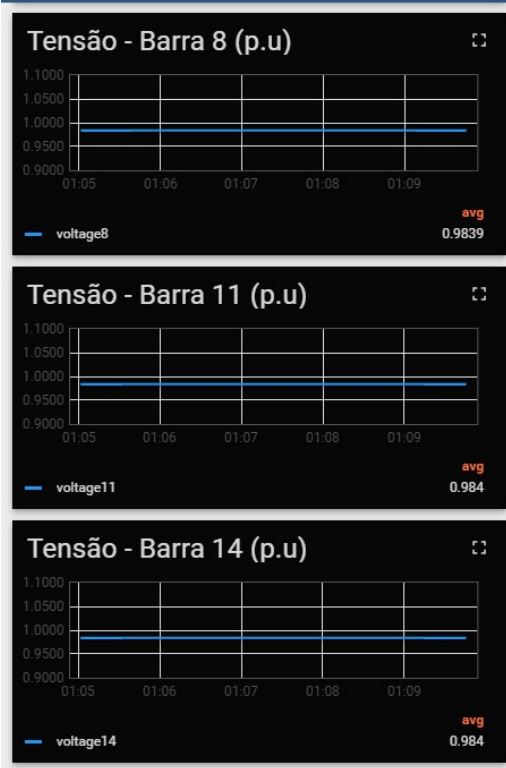

Tensão - Barra 17 (p.u
EESEP - Trafo 1370 - Loㅁ Entities (1) Realtime - last 5 minutes
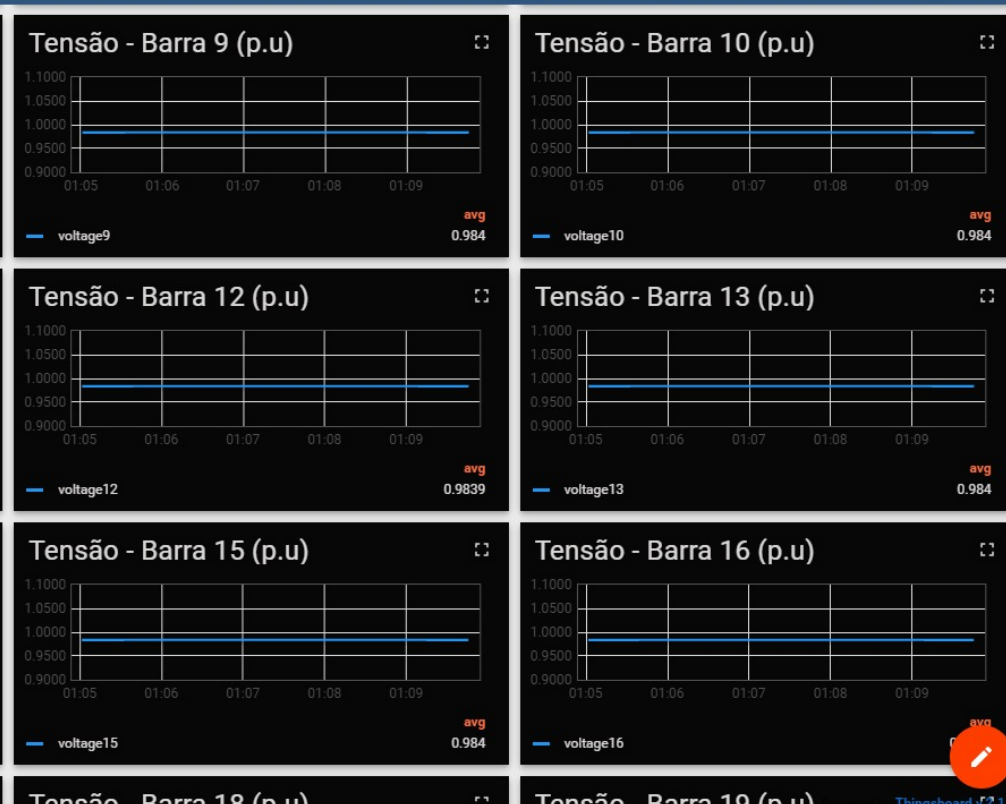

Tensão - Barra 18 (p.u)

Fonte: Elaborada pelo autor.
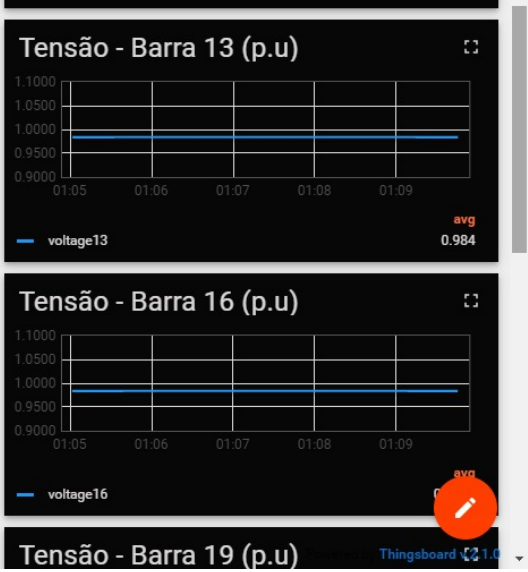
Figura 5.10: Dashboard da rede do trafo 1370 parte 3.

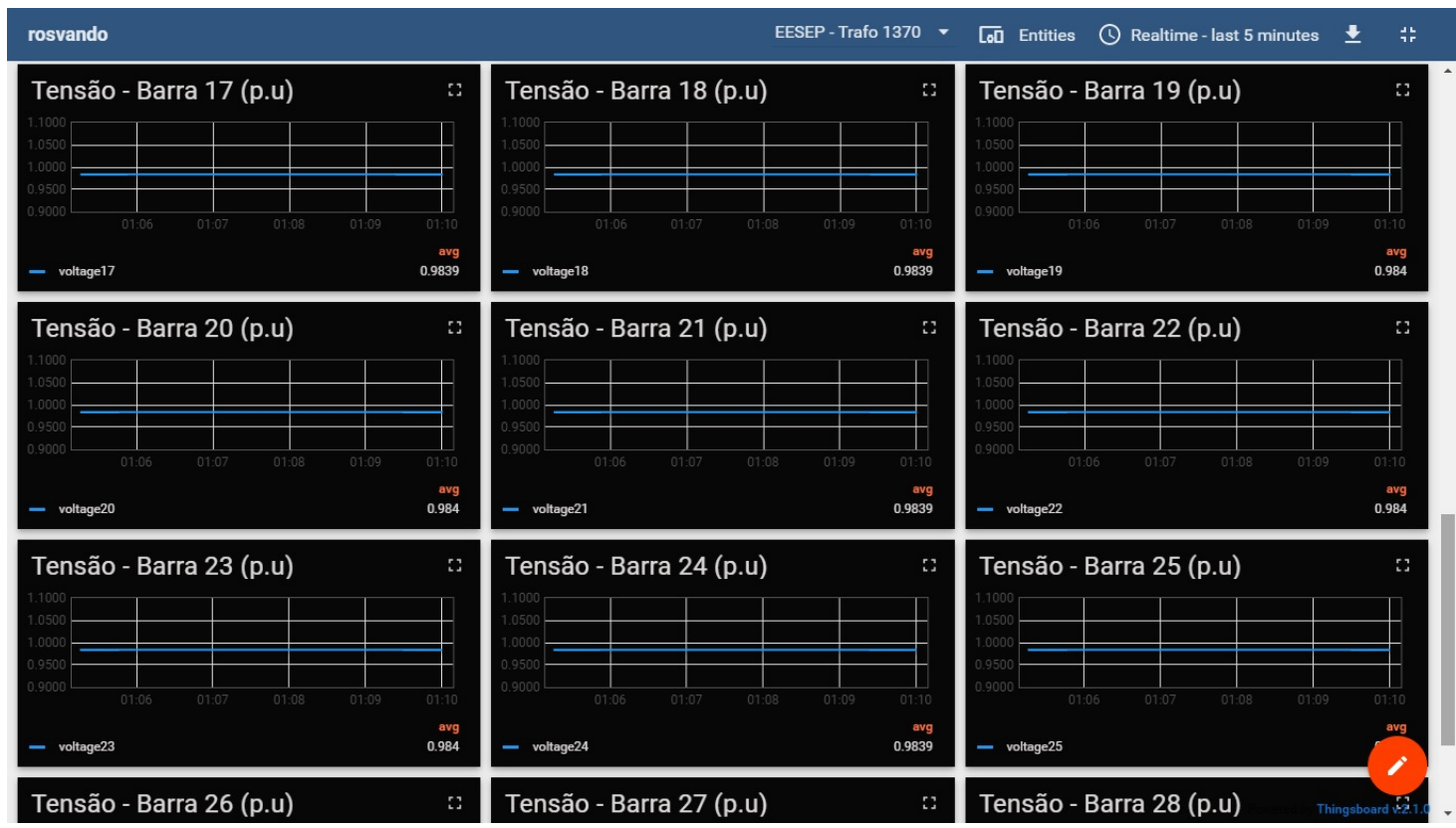

Fonte: Elaborada pelo autor.

Figura 5.11:Dashboard da rede do trafo 1370 parte 4.

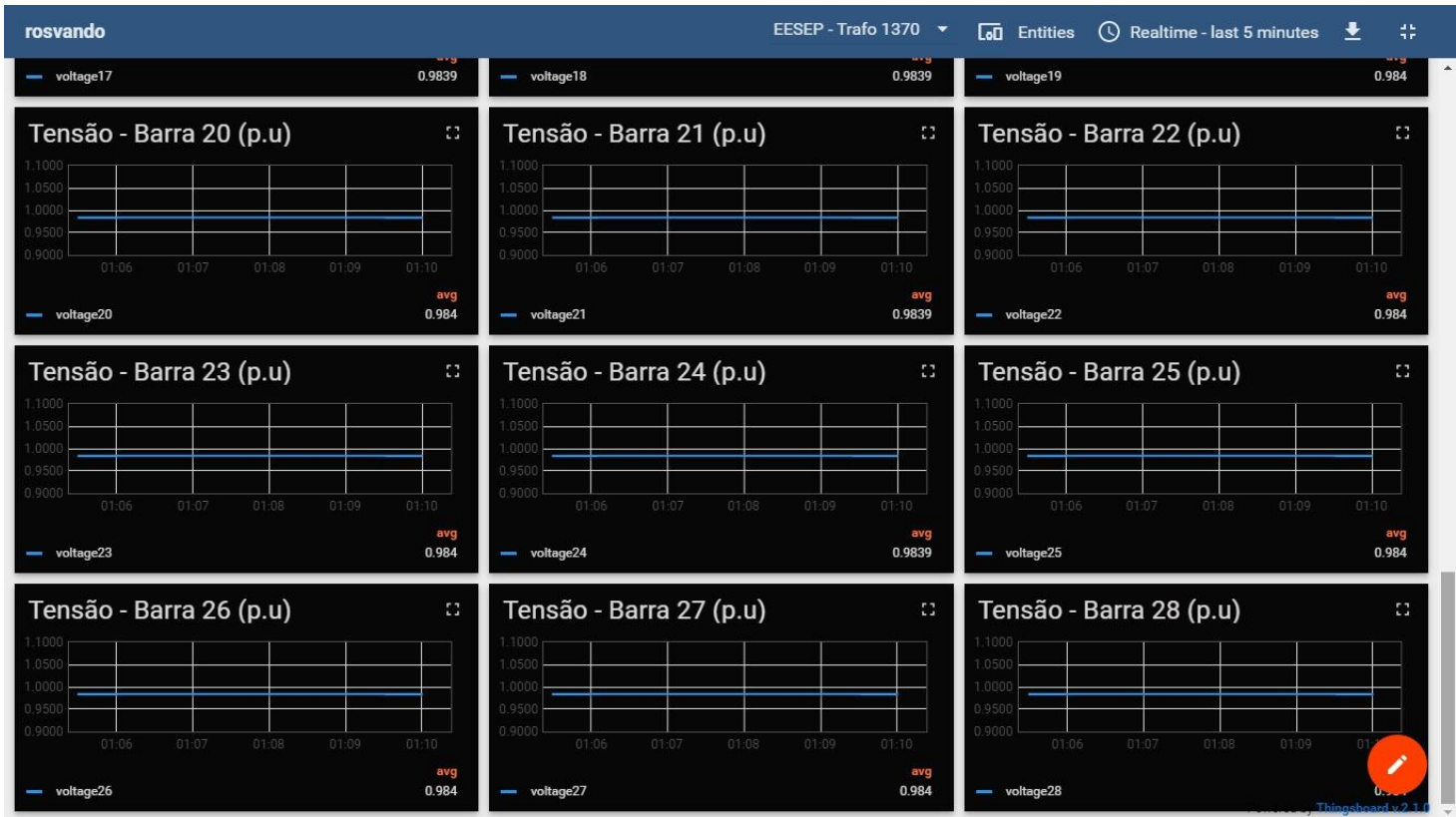

Fonte: Elaborada pelo autor.

Com os valores de $\mathrm{P}$ e $\mathrm{Q}$ recebidos dos EEEs executa-se um EE para a rede primária afim de que se possa comprovar a possibilidade de execução do processo de estimação de estado de forma descentralizada e sem prejuízo para a qualidade e confiabilidade do processo. O resultado do EE para a rede primária está disponibilizado no Apêndice C. 
Afim de demonstrar a confiabilidade da proposta deste trabalho foram geradas 30 amostras de medidas para obter o Erro Médio Relativo $\left(E M R_{30}\right)$ e o Desvio Padrão $\left(\sigma_{E M R}\right)$ do processo de estimação de estado como dado nas equações 5.3 e 5.4 .

$$
\begin{gathered}
E M R_{30}=\frac{1}{n_{p}} \sum_{K=1}^{n_{p}}\left|\frac{\hat{E}_{k}-E_{k}^{r e f}}{P_{k}^{r e f}}\right| * 100 \\
\sigma_{E M R}=\sqrt{\frac{1}{\left(n_{p}\right)} \sum_{K=1}^{n_{p}}\left(\left|\frac{\hat{E}_{k}-E_{k}^{r e f}}{E_{k}^{r e f}}\right| * 100-E M R_{P}\right)^{2}}
\end{gathered}
$$

Onde, $K$ denota o número de barras, $\hat{E}_{k}$ o resultado do processo estimação de uma das 30 amostras e $E_{k}^{r e f}$ é o resultado do processo de estimação utilizado como referência e armazenado anteriormente.

A Tabela 5.2 apresenta o comparativo entre o resultado do EE executado de forma centralizada e para o EE utilizando dados de $P$ e $Q$ dos transformadores presentes no SD enviados pela plataforma embarcada.

Tabela 5.2: Comparativo entre os resultados dos EE executados para a rede completa e para rede primária.

\begin{tabular}{|c|c|c|c|}
\hline \multicolumn{4}{|c|}{ Resultado do processo de estimação de estado para a rede completa } \\
\hline $\begin{array}{c}\text { EMR rede } \\
\text { Completa }\end{array}$ & $\begin{array}{c}\text { Desvio Padrão rede } \\
\text { completa }\end{array}$ & $\begin{array}{c}\text { EMR rede } \\
\text { primária }\end{array}$ & $\begin{array}{c}\text { Desvio Padrão rede } \\
\text { primária }\end{array}$ \\
\hline 0,0255 & 0,0072939 & 0,0297 & 0,008119 \\
\hline
\end{tabular}

O tempo de execução médio, para as 30 execuções do algoritmo de estimação de estado utilizando como CPU a NVIDIA Jetson Nano, foi armazenado para cada rede de BT presente no sistema teste e é apresentado na Tabela 5.3. Destaca-se que na forma descentralizada é possível realizar o processamento dos EEEs instalados nos transformadores de forma paralela, ou seja, no mesmo período de tempo. Da mesma forma, apresenta o tempo de execução do algoritmo também para abordagem centralizada, onde todas as barras do sistema são processadas em uma única máquina e para a proposta em que somente a rede primária é executada no COD fazendo uso dos dados de $P$ e $Q$ de cada transformador do SD. Para a arquitetura centralizada foi utilizado um computador com as seguintes especificações técnicas: processador Intel Core i3 $180 \mathrm{GHz}$ e memória RAM de 4GB. 
Tabela 5.3: Tempo de execução do EE para as redes definidas.

\begin{tabular}{|c|c|}
\hline \multicolumn{2}{|c|}{ Tempo de execução do processo de estimação de estado } \\
\hline REDE ELÉTRICA UTILIZADA & TEMPO MÉDIO (S) \\
\hline Completa ( Barras de MT e BT) & 46.4579 \\
\hline Primária ( Somente as barras de MT) & 35.7633 \\
\hline Barras de BT conectadas ao Trafo 2960 & 0.3380 \\
\hline Barras de BT conectadas ao Trafo 1370 & 1.409 \\
\hline Barras de BT conectadas ao Trafo 1371 & 0.7472 \\
\hline Barras de BT conectadas ao Trafo 1372 & 1.3451 \\
\hline Barras de BT conectadas ao Trafo 1373 & 1.1043 \\
\hline
\end{tabular}

\subsection{Considerações Finais}

O presente capítulo apresentou os testes realizados para validação do plataforma embarcada proposta com base no sistema teste criado a partir do apresentado em (ROLIM; TRINDADE, 2019). A plataforma embarcada proposta se baseia em: informações disponibilizadas pelos MEI instalados nas UCs, enviando dados para um módulo eletrônico instalado nos transformadores de distribuição para a execução do processo de estimação de estado; o algoritmo do EE embarcado desenvolvido em linguagem Python; e nas redes de comunicação desenvolvidas para aplicações de smart grids e loT.

Considerando a instalação de medidores inteligentes nas UCs, a plataforma embarcada proposta e implantada em laboratório permite o processamento dos dados de forma descentralizada, utilizando módulos eletrônicos dotados de tecnologias de comunicação de baixo consumo, que seriam instalados nos transformadores de distribuição. Além disto, processando as medidas de P e Q oriundas de cada UCs no modulo embarcado, permite que não seja necessário o envio de todas informações ao servidor web.

Os resultados apresentados utilizando o SD teste mostram o bom desempenho da plataforma embarcada, avaliando a viabilidade de implementação de sistemas embarcados em cada transformador de distribuição, permitindo que o processo de estimação de estado seja realizado fazendo o uso de uma arquitetura de processamento de dados descentralizada. 



\section{Capítulo 6 - Conclusões e Perspectivas Futuras}

\subsection{Considerações Finais}

Dados os crescentes desafios tecnológicos exigidos pelas redes inteligentes de energia, é necessário melhorar a forma como as concessionárias gerenciam as informações das redes elétricas. Tais desafios têm contribuído para aumentar a complexidade da operação dos SDs, com a inserção de novas arquiteturas de redes elétricas que podem operar autonomamente, novas fontes de energia renováveis, armazenamento de energia em baterias e o aumento da utilização de veículos eletrizem trazem novos paradigmas para a operação dos SDs.

Com atualização tecnológica dos campos da eletrônica e computação, cada vez mais é possível realizar o monitoramento em tempo real de dispositivos conectados à rede de energia. Dessa forma, os módulos, redes e protocolos criados para atender demandas oriundas dessas novas tecnologias, podem ser empregadas em projetos que visam a automatização das novas redes de energia elétrica. Dentre os desenvolvimentos realizados recentemente, destacam-se as novas redes de comunicação desenvolvidas para o ecossistema de loT, que permitem a conexão de vários dispositivos, com longo alcance e baixo consumo de energia e o aumento da capacidade de processamento para módulos eletrônicos embarcado, permitindo a realização de atividades antes cofiadas a supercomputadores.

Este trabalho propôs arquiteturas descentralizadas baseadas na inserção de módulos eletrônicos de processamento, para realizar monitoramento em tempo real de SDs, cada uma delas contando com um EEE por mínimos quadrados ponderados. O EEE proposto visa a utilização de hardwares e tecnologias atuais, que trazem inúmeras vantagens se comparadas com dispositivos desenvolvidos num passado recente.

A partir das arquiteturas descentralizada propostas foi realizada a comparação com uma estratégia centralizada para monitoramento de SDs. Abordagem essa, usualmente utilizada para monitoramento de SDs, onde todas as informações precisam ser enviadas e processadas pelo COD. Os resultados apontam que dessa maneira o poder de processamento e a largura de banda da rede de comunicação precisam ser muito altos para manter o bom desempenho e confiabilidade de um sistema de monitoramento em tempo real. Uma redução considerável é observada para todas as arquiteturas de implantação EEE do ponto de vista da quantidade de dados a serem transmitidos e processados para realizar a 
estimativa de estado. Assim, além de permitir a redução do tráfego de informações, a utilização do EEE proposto de forma descentralizada também permite uma redução nos custos operacionais relacionados aos serviços de comunicação exigidos pelas redes de energia elétrica monitoradas por MEls.

Em seguida, apresentou, de forma detalhada o desenvolvimento e implantação, em bancada, de uma IMA, fazendo uso de módulos de comunicação que permitem o desenvolvimento de redes wireless para o envio e recebimento de mensagens em tempo real, utilizando conceitos de Internet das Coisas e Edge Computing. Essa infraestrutura, utilizando módulos industriais e redes de comunicação empregadas em aplicações reais de projetos de smart grids, foi utilizada para validação de uma das arquiteturas descentralizadas proposta, a que propõe a instalação de módulos eletrônicos em cada transformador de distribuição de energia. A utilização da infraestrutura buscou possibilitar a simulação de uma rede inteligente de energia, no que se refere ao tráfego de informações existente entre os MEls e os CODs e para isso foi empregado um sistema real brasileiro de distribuição de energia para avaliação da plataforma embarcada proposta.

Considerando a instalação de MEls nas UCs, a plataforma embarcada proposta e implantada em bancada, permite o processamento dos dados de forma descentralizada, utilizando placas eletrônicas a módulos de comunicação com tecnologias desenvolvidas para serem de baixo consumo. Os módulos eletrônicos instalados nos transformadores de distribuição são responsáveis pela aquisição de dados e execução do processo de estimação de estado para todas a UCs que pertencem a rede de BT do transformador. Além disto, processando as medidas de $\mathrm{P}$ e $\mathrm{Q}$ oriundas de cada UCs no modulo embarcado e 0 recebimento do resultado do $E E$, permite que não seja necessário o envio de todas informações ao servidor web para estimar estado operativo corrente de todo o SD.

Os resultados obtidos, alguns dos quais apresentados neste documento, mostram o bom desempenho da plataforma embarcada, avaliando a viabilidade de implementação de sistemas embarcados em cada transformador de distribuição e a redução do tráfego de dados na rede de comunicação, quando não se faz necessário o envio de dados diretamente ao COD. Permitindo dessa forma, que o processo de estimação de estado seja realizado fazendo o uso de uma arquitetura de processamento de dados descentralizada. 


\subsection{Perspectivas Futuras}

Como apresentado ao longo do texto, as novas redes de energia trazem desafios interessantes em diversas áreas relacionadas às Smart Grids. Entre os requisitos necessários para a impletação dessas redes, estão as redes de telecomunicações desenvolvidas para apliações que necessitam de baixo consumo e alta troca de dados, os MEls, e os processos realizados para a operação de uma rede.

Entretanto, a aplicação de novas tecnologias traz a tona inumeros desafios inerentes a aplicação destas em SDs, abrindo os horizontes de pesquisa para beneficios oriundos das atualizações tecnologicas. A integração tecnologica, seja no campo das telecomunicações ou da computação, podem trazer beneficios para a área de tarifação, para o monitoramento em tempo real dos SDs, permitindo um rastreamento sobre as perdas técnicas e não técnicas, podendo ajudar a melhorar os indicadores de qualidade de energia das concessionárias.

Dessa forma, com as informações das redes secundarias sendo disponibilizadas em tempo real, a inserção cada vez mais massiva de geração distribuida, seja na forma solar ou eolica e a utilização de veiculos elétricos, faz com que haja uma mudança de paradigmas no setor elétrico. O que permite que processos já consolidados em SEP possam ser revistos e atualizados, como o desevolvimento de novas tecnicas de estimação de estado , considerando o atual cenário de desenvolvimento das tecnologias de comunicação e processamento de dados.

Sendo assim, trabalhos futuros compreendem a avaliação da robustez numérica necessária para o processo de estimação de estado como fator limitante de cobertura pelo EEE. A utilização de uma tecnoloia de comunicação inserida no mercado de eneria recentemente, nos deixa margem para a relização de um estudo detalhado da capacidade de comunicação, frente ao probelmas enfrentados em campo, nos quesitos de que a tecnologia utlizada nos testes se possa atender o maior numero de UCs com os recursos alocados sem que se deixe de cumprir os parametros técnicos e de segurança para uma rede inteligente de energia opere em perfeitas condições, podendo também, serem avaliadas as diretrizes econômicas para implementação de um projeto, instalação e operação de uma Smart Grid junto as concessionárias. Além disso, existe a possibilidade de implementação de uma versão piloto desta proposta e futuras aplicações em redes BT reais aproveitando a criação de IMA pelas concessecionárias podendo avaliar o desenpenho em projetos reais.

Dentro do contexto da inserção de MEls no SD, o desenvolvimento de um EEE trifásico a quatro fios para redes de BT se faz interessante considerando a presença de consumidores monitorados e não monitorados através de medidores inteligentes. Trazendo também 
questionamentos relacionados a quais tecnologias utilizar, sejam elas voltadas para comunicação ou para o processamento de dados.

Finalmente, a validação do EEE trifásico embarcado pode ser desenvolvida a partir de simulações computacionais e implementações em laboratórios de pesquisa. Para isso, além da utilização de sistemas testes disponíveis na literatura, poderão ser utilizados e ainda sistemas elétricos reais, dotados de MEls, pertencentes as concessionárias de energia.

\subsection{Publicações}

Destacam-se, a seguir as publicações realizadas ao longo do desenvolvimento deste trabalho que concedeu a elaboração e publicação de um artigo diretamente relacionado com o tema desta dissertação, um relacionado a capacidade de acomodação de redes de distribuição e de outros 2 artigos (coautoria).

1.Título: An Embedded State Estimator for Reducing Data Volume and Processing in Smart Grids Monitoring

Autores: Rosvando M. Gonzaga Junior, Julio A. D. Massignan, Carlos D. Maciel, João Bosco A. London Junior, Rodrigo M. A. de Almeida e Marcos H. M. Camillo.

Congresso: IEEE 2018 Workshop on Communication Networks and Power Systems (WCNPS)

2. Título: Analysis of the Hosting Capacity of Real Distribuition Feeder With Wind Generation

Autores: Rosvando M. Gonzaga Junior, Julio A. D. Massignan, João Bosco A. London Junior

Congresso: IEEE ISGT 2010 Innovative Smart Grid Technologies Latin America

3.Título: Estudo de Máxima Penetração de Painéis Fotovoltaicos em um Alimentador Primário de Distribuição de Energia Elétrica

Autores: Kaê Augusto, Julio A. D. Massignan, Rosvando M. Gonzaga Junior e João Bosco A. London Junior.

Congresso: XXII Congresso Brasileiro de Automática

4. Título: Estimador de Demanda Trifásico em Tempo Real com Tratamento para Transformadores Conectados em $\Delta-Y_{N}$.

Autores: Luana L. Avelino, Julio A. D. Massignan, Rosvando M. Gonzaga Junior, João Bosco A. London Junior, José Paulo R. Fernandes.

Congresso: XII Congresso Brasileiro de Automática 


\section{Referências Bibliográficas ${ }^{5}$}

ABUR, A.; EXPÓSITO, A. G. Power System State Estimation: Theory and Implementation. Nova York: CRC Press, 2004.

AGÊNCIA NACIONAL DE TELECOMUNICAÇÕES, A. Plano de Atribuição, Distribuição e Destinação de Radiofrequências. Disponível em: <http://www.anatel.gov.br/setorregulado/atribuicao-destinacao-e-distribuicao-de-faixas>.

Al-THINKER. Datasheet Ra-01 LoRa ModuleAI-Thinker, , 2017. .

ALEXEY S. PETRENKO, SERGEI A. PETRENKO, KRYSTINA A. MAKOVEICHUK, P. V. C. The IloT / loT Device Control Model Based on. p. 2018-2021, 2018.

ALI, A. I. et al. ZigBee and LoRa based Wireless Sensors for Smart Environment and IoT Applications. p. 19-23, 2019.

ALTHUMALI, H. A Survey of Random Access Control Techniques for Machine-toMachine Communications in LTE / LTE-A Networks. IEEE Access, v. 6, p. 74961-74983, 2018.

AMADOU, I.; FOUBERT, B.; MITTON, N. LoRa in a haystack: a study of the L O R A signal behavior. p. 0-3, 2019.

AUGUSTO, J. et al. In-Field Validation of a Real-Time Monitoring Tool for Distribution Feeders. v. 33, n. 4, p. 1798-1808, 2018.

AUTOMATION, H. WiFi LoRa 32. Disponível em: <https://heltec.org/project/wifi-lora32/>. Acesso em: 15 jul. 2020.

BARAN, M. Branch Current Based State Estimation for Distribution System Monitoring. 2012 IEEE Power and Energy Society General Meeting, p. 1-4, 2012.

BARAN, M. E.; KELLEY, a. W. A branch-current-based state estimation method for distribution systems. IEEE Transactions on Power Systems, v. 10, n. 1, p. 483-491, 1995.

BARAN, M.; MCDERMOTT, T. E. Distribution system state estimation using AMI data. 2009 IEEE/PES Power Systems Conference and Exposition, v. 15236, p. 1-3, 2009.

BELOTSKY, G.; MAJOR, T. Python Success Stories. Disponível em: <https://www.python.org/about/success/>. Acesso em: 23 abr. 2018.

BERNIERI, A. et al. Neural networks and pseudo-measurements for real-time monitoring of distribution systems. IEEE Transactions on Instrumentation and Measurement, v. 45, n. 2, p. 645-650, 1996.

CAMPOS, F. et al. ADMS4LV - advanced distribution management system for active management of LV grids. CIRED - Open Access Proceedings Journal, v. 2017, n. 1, p. 920923, 2017. Disponível em: <http://digital-library.theiet.org/content/journals/10.1049/oapcired.2017.0663>.

CASTILLO, M. R. M. et al. Offline Detection, Identification, and Correction of Branch Parameter Errors Based on Several Measurement Snapshots. v. 26, n. 2, p. 870-877, 2011.

CHEN, Q. et al. Reconsidering the Smart Metering Data Collection Frequency for Distribution State Estimation. 2014 IEEE International Conference on Smart Grid Communications, n. Lv, p. 517-522, 2014.

CHEN, Y. et al. Decentralized State Estimation for Distribution Systems using Artificial Neural Network. 2018 IEEE International Instrumentation and Measurement Technology

${ }^{5}$ De acordo com a Associação Brasileira de Normas Técnicas. NBR 6023 
Conference (I2MTC), p. 1-6, 2018.

CHUNG, Y.; AHN, J. Y.; HUH, J. Du. Experiments of A LPWAN Tracking ( TR ) Platform Based on Sigfox Test Network. 2018 International Conference on Information and Communication Technology Convergence (ICTC), p. 1373-1376, 2018.

CPFL ENERGIA. Apresentação Institucional CPFL Energia. Disponível em: $<$ https://cpfl.riweb.com.br/ShowApresentacao.aspx?IdApresentacao=x5pEK30eMwGeTg7Qf ApO8g==>. Acesso em: 13 ago. 2020.

CRUZ, E. Smart Grid Light. Disponível em: <http://redesinteligentesbrasil.org.br/smart-grid-light.html>. Acesso em: 12 ago. 2020.

DELLA GIUSTINA, D. et al. Electrical distribution system state estimation: measurement issues and challenges. IEEE Instrumentation \& Measurement Magazine, v. 17, n. 6, p. 36-42, dez. 2014.

DEVALAL, S.; KARTHIKEYAN, A. LoRa technology-an overview. 2018 Second International Conference on Electronics, Communication and Aerospace Technology (ICECA), n. Iceca, p. 284-290, 2018.

DING, C.; PENG, H. Minimum Redundancy Feature Selection From Microarray Gene Expression Data. Journal of Bioinformatics and Computational Biology, v. 03, n. 02, p. 185-205, 2005.2 Disponível em: <http://www.worldscientific.com/doi/abs/10.1142/S0219720005001004>.

ELAKSHUMI, S.; PONRAJ, A. A Server Based Load Analysis Of Smart. 2017 International Conference on Nextgen Electronic Technologies: Silicon to Software (ICNETS2), p. 141-144, 2017.

ELARABI, T. Design and Simulation of State-of-Art ZigBee Transmitter for loT Wireless Devices. p. 297-300, 2020.

ENERGIA, C. Energia Inteligente. Disponível em: $<$ https://www.cpfl.com.br/atendimento-a-consumidores/energiainteligente/paginas/default.aspx>.

ERIDANI, D. et al. Monitoring System in Lora Network Architecture using Smart Gateway in Simple LoRa Protocol. p. 200-204, 2020.

FARAJOLLAHI, M.; SHAHSAVARI, A.; MOHSENIAN-RAD, H. Tracking State Estimation in Distribution Networks Using Distribution-level Synchrophasor Data. 2018 IEEE Power \& Energy Society General Meeting (PESGM), p. 1-5, 2018.

FERNANDES, T. R.; ALMEIDA, M. C. De. Specifying angular reference for three-phase distribution system state estimators. p. 1655-1663, 2018. 1996. .

GENE H. GOLUB, C. F. V. L. Matrix Computations-Golub G.H-Van Loan C.pdf,

GHOLAMI, M. et al. Linear Voltage Based State Estimator for Active Distribution System Including Phasor Measurement Unit ( PMU ). 2018 Electrical Power Distribution Conference (EPDC), p. 1-6, 2018.

GÓMEZ-EXPOSITO, A. et al. A taxonomy of multi-area state estimation methods. Electric Power Systems Research, v. 81, p. 1060-1069, 2011.

GU, G.; PENG, G.; OVERVIEW, A. A. The Survey of GSM Wireless Communication System. 2010 International Conference on Computer and Information Application, p. 121-124, 2010.

HAUGHTON, D. A. et al. Smart Distribution Systems. IEEE Transactions on Power Systems, v. 28, n. 2, p. 1187-1195, 2013.

HONGGANG, Z.; CHEN, S. Design and Implementation of Lightweight 6LoWPAN Gateway Based on Contiki. 2018 IEEE International Conference on Signal Processing, 
Communications and Computing (ICSPCC), p. 1-5, 2018.

IGLESIAS-URKIA, M. et al. Validation of a CoAP to IEC 61850 Mapping and Benchmarking vs HTTP-REST and WS-SOAP. p. 1015-1022, 2018.

JOOS, G. et al. The Need for Standardization: The Benefits to the Core Functions of the Microgrid Control System. IEEE Power and Energy Magazine, v. 15, n. 4, p. 32-40, 2017.

KAGAN, N.; OLIVEIRA, C. C. B. de; ROBBA, E. J. Introdução aos sistemas de distribuição de energia elétrica. São Paulo: Edgard Blucher, 2005.

KERSTING, W. H. Distribution System Modeling and Anlysis. Second ed. [s.I: s.n.]

KHEAKSONG, A.; LEE, W. Packet Transfer of DLMS / COSEM Standards for Smart Grid. The 20th Asia-Pacific Conference on Communication (APCC2014), p. 391-396, 2014.

LAVRIC, A.; PETRARIU, A. I.; POPA, V. SigFox Communication Protocol: The New Era of IoT? p. 28-31, 2019.

LECCESE, F. et al. A New Power Quality Instrument Based on Raspberry-Pi. Electronics, v. 5, n. 4, p. 64, 2016. Disponível em: <http://www.mdpi.com/2079-9292/5/4/64>.

LEFEBVRE, S.; PREVOST, J.; LENOIR, L. Distribution state estimation: A necessary requirement for the smart grid. IEEE Power and Energy Society General Meeting, v. 2014Octob, n. October, 2014.

LIN, W. M.; TENG, J. H.; CHEN, S. J. A highly efficient algorithm in treating current measurements for the branch-current-based distribution state estimation. IEEE Transactions on Power Delivery, v. 16, n. 3, p. 433-439, 2001.

LIU, W. et al. Research and Development of Communication Between PC and Mobile Base on Embedded System and GPRS. 2011 2nd International Conference on Artificial Intelligence, Management Science and Electronic Commerce (AIMSEC), p. 4180-4183, 2011. 2013.

LUAN, W.; SHARP, D. Data Traffic Analysis of Utility Smart Metering Network. p. 1-4,

M.V., L. K.; H.A., M. P.; ANANTHAPADMANABHA, T. A Literature Review on Distribution System State Estimation. Procedia Technology, v. 21, p. 423-429, 2015.

MALANDRA, F. Performance Analysis of Large Scale RF-Mesh Networks for Smart Cities and loT. n. October, p. 13-18, 2017.

MANTOVANI, J. R. S.; CASARI, F.; ROMERO, R. A. Reconfiguração de sistemas de distribuição radiais utilizando o critério de queda de tensão. Revista Brasileira de Controle \& Automação - SBA, v. 11, n. 03, p. 150-159, 2000.

MEKKI, K. et al. Overview of Cellular LPWAN Technologies for loT Deployment: PerloT'18 - Second International Workshop on Mobile and Pervasive Internet of Things Overview, p. 197-202, 2018.

MEKONNEN, Y. et al. LTE and Wi-Fi Coexistence in Unlicensed Spectrum with Application to Smart Grid: A Review. 2018.

MINGYUE, Z. Measurements and Channel Characteristics of LV Power Line Communications Networks in China. 2006 IEEE International Symposium on Power Line Communications and Its Applications, n. 60402004, p. 212-216, 2006. 2017.

MUSCAS, C. et al. Fast Multi-area Approach for Distribution System State Estimation.

NAIR, K. K.; ABU-MAHFOUZ, A. M.; LEFOPHANE, S. Analysis of the Narrow Band Internet of Things (NB-loT) Technology. 2019.

NVIDIA CORPORATION. JETSON NANO User Guide. 2020. 
NVIDIA EMBEDDED. Máquinas Autônomas - Jetson Nano. Disponível em: $<$ https://www.nvidia.com/pt-br/autonomous-machines/embedded-systems/jetson-nano/>. Acesso em: 16 jul. 2020.

OSMAN, N. I.; ABBAS, E. B. Simulation and Modelling of LoRa and Sigfox Low Power Wide Area Network Technologies. p. 1-5, 2018.

OSORIO, A. E. et al. Evaluation of Wireless Network Based on ZigBee Technology Using XBee Modules. 2019.

PHUNG, C. V. et al. Enhancing REST HTTP with Random Linear Network Coding in Dynamic Edge Computing Environments. p. 435-440, 2019.

PHUNG, C. V.; DIZDAREVIC, J.; JUKAN, A. An Experimental Study of Network Coded REST HTTP in Dynamic IoT Systems. 2020.

PI, R. DATASHEET Raspberry Pi Compute Module (CM1) Raspberry Pi Compute Module 3 (CM3) Raspberry Pi Compute Module 3 Lite (CM3L). v. 3, n. October, p. 0-21, 2016. Disponível em: <https://www.raspberrypi.org/documentation/hardware/computemodule/RPICM-DATASHEET-V1_0.pdf\%0Ahttps://www.sparkfun.com/products/13825>.

POPLI, S.; JHA, R. K.; JAIN, S. A Survey on Energy Efficient Narrowband Internet of Things ( NBloT ): Architecture , Application and Challenges. IEEE Access, v. 7, p. 1673916776, 2020.

PRIMADIANTO, A.; LU, C. A Review on Distribution System State Estimation. v. 32, n. 5, p. 3875-3883, 2017.

RADHOUSH, S.; LIN, J. Distribution System State Estimation with Measurement Data Using Different Compression Methods. 2018 IEEE Texas Power and Energy Conference (TPEC), p. 1-6, 2018.

RAFAEL S. SILVA, FELIPE M. LABURU, M. C. de A. On the use of uPmu for State Estimation in Distribution Systems. In: 2017 IEEE Power \& Energy Society General Meeting (PESGM), Anais...2017.

RAMESH, L. et al. Ring Main Distribution State Estimation through Optimal. 2012.

ROLIM, F. B. B.; TRINDADE, F. C. L. Fast screening approach to estimate the hosting capacity of rooftop PV generators in electric power distribution systems. n. January 2018, p. 1-15, 2019. Disponível em: <https://doi.org/10.1002/etep.2740>.

ROSENBERG, C.; BHATTACHARYA, K. State Estimation in Power Distribution Systems Based on Ensemble Kalman Filtering. v. 33, n. 6, p. 6600-6610, 2018.

SACCHI, C. From LTE-A to LTE-M : a Futuristic Convergence between Terrestrial and Martian Mobile Communications. p. 0-4, 2019.

SANTOS, R. Z. S.; ORILLAZA, J. R. C. Distribution System State Estimator Using SCADA and -PMU Measurements. 2018 IEEE Innovative Smart Grid Technologies - Asia (ISGT Asia), p. 558-562, 2018.

SCHWEPPE, F. C.; WILDES, J. Power System Static-State Estimation, Part I: Exact Model. Transactions on Power Apparatus and Systems, v. PAS-89, n. 1, p. 120-125, 1970.

SHEN, D.; LIANG, H. Research on Distribution System State Estimation with Photovoltaic Generation. 2013 IEEE International Conference of IEEE Region 10 (TENCON 2013), p. 1-5, 2013.

SHIOBARA, T.; PALENSKY, P.; NISHI, H. Effective Metering Data Aggregation for Smart Grid Communication Infrastructure. IECON 2015 - 41st Annual Conference of the IEEE Industrial Electronics Society, p. 2136-2141, 2015.

SILVA, É. R. et al. Impact of the State Estimation in Different Scenarios and Topologies in a Power Distribution System. 2018 53rd International Universities Power Engineering Conference (UPEC), 2018. 

675, 2009.

SINGH, R.; PAL, B. C.; VINTER, R. B. System State Estimation. v. 24, n. 2, p. 668-

SOUSA, P. H. De et al. Sequential Method of State Estimation for Distribution Systems. Simpósio Brasileiro de Sistemas Elétricos (SBSE), p. 6-10, 2018.

TANTITHARANUKUL, N. et al. MQTT-Topics Management System for Sharing of Open Data. 2017 International Conference on Digital Arts, Media and Technology (ICDAMT), p. 62-65, 2017.

TELIT COMMUNICATIONS. Hardware User Guide. p. 1-93, 2017.

THINGSBOARD INC. ThingsBoard Open-source IoT Platform. Disponível em: <https://thingsboard.io/>. Acesso em: 10 jul. 2020.

UDUPA, H. N. et al. Power System Vertical Division State Estimation ( VDSE ) Application To Super Node Area. 2016 International Conference on Signal Processing, Communication, Power and Embedded System (SCOPES), p. 1311-1316, 2016.

VAN CUTSEM, T.; RIBBENS-PAVELLA, M. Critical Survey of Hierarchical Methods for State Estimation of Electric Power Systems. IEEE Transactions on Power Apparatus and Systems, v. PAS-102, n. 10, p. 3415-3424, 1983.

WAERESCH, D. et al. Field test of a linear three-phase low- voltage state estimation system based on smart meter data. 24th InternatioWAERESCH, D. et al. Field test of a linear three-phase low- voltage state estimation system based on smart meter data. 24th International Conference \& Exhibition on Electricity Distribution (CIRED), v. 2017, $\mathbf{n}$. June, p. 1773-1776, 2017. nal, v. 2017, n. June, p. 1773-1776, 2017.

WIBISONO, G. et al. Development of Advanced Metering Infrastructure Based on LoRa WAN in PLN Bali Toward Bali Eco Smart Grid. 2017 Saudi Arabia Smart Grid (SASG), p. 47, 2017.

XUE, L.; ZHIXIN, S. An Improved 6Lo WP AN Hierarchical Routing Protocol. 2015 11th International Conference on Heterogeneous Networking for Quality, Reliability, Security and Robustness (QSHINE), n. Qshine, p. 318-322, 2015.

YUEHAO, Y. et al. A Distribution Network State Estimation Method Based on Power User Electric Energy Data Acquisition System. 2016 China International Conference on Electricity Distribution (CICED), v. 2, n. Ciced, p. 1-4, 2016. 2019.

ZOURMAND, A. Internet of Things ( loT ) using LoRa technology. n. June, p. 324-330, 


\section{Apêndice A - Resultados do processo de estimação para a rede completa}

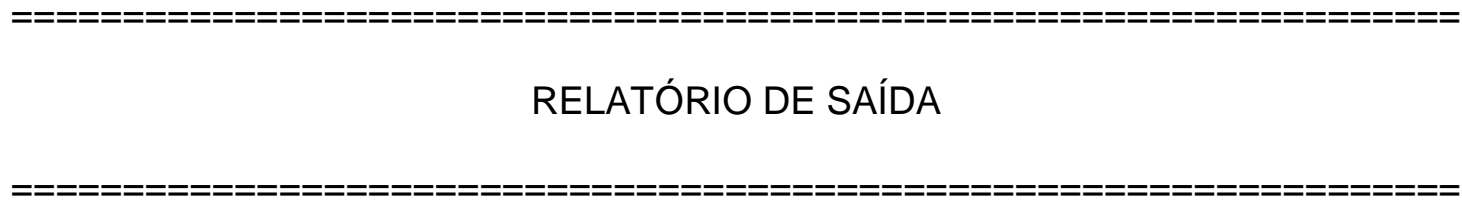

ESTIMADOR DE ESTADO SISTEMA TESTE

Número de Barras: 208

Número de Linhas: 207

Estimador de estado pelo método dos Mínimos Quadrados Ponderados (MQP)

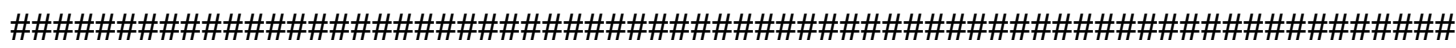
RESULTADOS DO ESTIMADOR NA ITERAÇÃO 1

\#\#\#\#\#\#\#\#\#\#\#\#\#\#\#\#\#\#\#\#\#\#\#\#\#\#\#\#\#\#\#\#\#\#\#\#\#\#\#\#\#\#\#\#\#\#\#\#\#\#\#\#\#\#\#\#\#\#\#

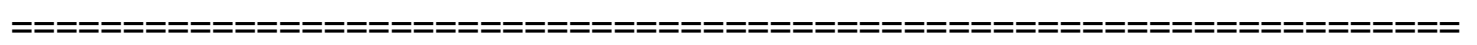

Barra Tensão (pu) Ângulo (ํ)

$\begin{array}{lll}1.0000000 & 1.0056469 & 0.0000000 \\ 2.0000000 & 1.0054995 & -0.0075582 \\ 3.0000000 & 1.0054812 & -0.0084454 \\ 4.0000000 & 1.0049994 & -0.0330408 \\ 5.0000000 & 1.0049904 & -0.0335333 \\ 6.0000000 & 1.0049721 & -0.0344212 \\ 7.0000000 & 1.0048724 & -0.0395480 \\ 8.0000000 & 1.0047348 & -0.0465669 \\ 9.0000000 & 1.0047348 & -0.0465670 \\ 10.0000000 & 1.0017539 & -0.1997573 \\ 11.0000000 & 0.9978203 & -0.4038992\end{array}$




\begin{tabular}{lll}
12.0000000 & 0.9978202 & -0.4039059 \\
13.0000000 & 0.9978200 & -0.4039179 \\
14.0000000 & 0.9978141 & -0.4039873 \\
15.0000000 & 0.9977990 & -0.4041660 \\
16.0000000 & 0.9972343 & -0.4345420 \\
17.0000000 & 0.9962149 & -0.4879577 \\
18.0000000 & 0.9953560 & -0.5330536 \\
\hline 19.0000000 & 0.9946108 & -0.5722441 \\
\hline 20.0000000 & 0.9946108 & -0.5722441 \\
\hline 21.0000000 & 0.9946108 & -0.5722441 \\
\hline 22.0000000 & 0.9946108 & -0.5722441 \\
\hline 23.0000000 & 0.9941054 & -0.5988649 \\
\hline 34.0000000 & 0.9935885 & -0.6261420 \\
\hline 35.0000000 & 0.9935885 & -0.6261422 \\
\hline 32.00
\end{tabular}




$$
\begin{aligned}
& \begin{array}{lll}
40.0000000 & 0.9908222 & -0.7727862
\end{array} \\
& \begin{array}{lll}
41.0000000 & 0.9908214 & -0.7727868
\end{array} \\
& \begin{array}{lll}
42.0000000 & 0.9908205 & -0.7727875
\end{array} \\
& \begin{array}{lll}
43.0000000 & 0.9908197 & -0.7727882
\end{array} \\
& \begin{array}{lll}
44.0000000 & 0.9908191 & -0.7727888
\end{array} \\
& \begin{array}{lll}
45.0000000 & 0.9908185 & -0.7727893
\end{array} \\
& \begin{array}{lll}
46.0000000 & 0.9908179 & -0.7727898
\end{array} \\
& \begin{array}{lll}
47.0000000 & 0.9908174 & -0.7727902
\end{array} \\
& \begin{array}{lll}
48.0000000 & 0.9908173 & -0.7727903
\end{array} \\
& \begin{array}{lll}
49.0000000 & 0.9908173 & -0.7727903
\end{array} \\
& 50.0000000 \quad 0.9908173 \quad-0.7727904 \\
& \begin{array}{lll}
51.0000000 & 0.9908172 & -0.7727904
\end{array} \\
& \begin{array}{lll}
52.0000000 & 0.9908172 & -0.7727904
\end{array} \\
& \begin{array}{lll}
53.0000000 & 0.9908170 & -0.7727906
\end{array} \\
& \begin{array}{lll}
54.0000000 & 0.9908169 & -0.7727907
\end{array} \\
& \begin{array}{lll}
55.0000000 & 0.9908168 & -0.7727907
\end{array} \\
& \begin{array}{lll}
56.0000000 & 0.9908167 & -0.7727908
\end{array} \\
& \begin{array}{lll}
57.0000000 & 0.9908167 & -0.7727909
\end{array} \\
& \begin{array}{lll}
58.0000000 & 0.9908166 & -0.7727909
\end{array} \\
& \begin{array}{lll}
59.0000000 & 0.9908166 & -0.7727910
\end{array} \\
& \begin{array}{lll}
60.0000000 & 0.9908166 & -0.7727910
\end{array} \\
& \begin{array}{lll}
61.0000000 & 0.9908171 & -0.7727905
\end{array} \\
& \begin{array}{lll}
62.0000000 & 0.9908171 & -0.7727905
\end{array} \\
& \begin{array}{lll}
63.0000000 & 0.9908170 & -0.7727906
\end{array} \\
& \begin{array}{lll}
64.0000000 & 0.9908170 & -0.7727906
\end{array} \\
& \begin{array}{lll}
65.0000000 & 0.9908169 & -0.7727906
\end{array} \\
& \begin{array}{lll}
66.0000000 & 0.9908169 & -0.7727907
\end{array} \\
& \begin{array}{lll}
67.0000000 & 0.9905948 & -0.7850155
\end{array}
\end{aligned}
$$




\begin{tabular}{|c|c|c|}
\hline 68.0000000 & 0.9903664 & -0.7972511 \\
\hline 69.0000000 & 0.9903664 & -0.7972511 \\
\hline 70.0000000 & 0.9903664 & -0.79725 \\
\hline 71.0000000 & 0.9903664 & -0.79725 \\
\hline 72.0000000 & 0.9903664 & -0.79725 \\
\hline 73.0000000 & 0.9899712 & -0.81833 \\
\hline 74.0000000 & 0.9896151 & -0.8373 \\
\hline 75.0000000 & 0.9892768 & -0.8554 \\
\hline 76.0000000 & 0.9889386 & -0.8735 \\
\hline 77.0000000 & 0.9889386 & -0.87 \\
\hline 78.0000000 & 0.9889386 & -0.87 \\
\hline 79.0000000 & 0.9889386 & -0.87 \\
\hline 80.0000000 & 0.9886036 & -0.89 \\
\hline 81.0000000 & 0.9882172 & -0.9123 \\
\hline 82.0000000 & 0.9876105 & -0.9204 \\
\hline 83.0000000 & 0.9875792 & -0.9208 \\
\hline 84.0000000 & 0.9875618 & -0.9211419 \\
\hline 85.0000000 & 0.9872155 & -0.92579 \\
\hline 86.0000000 & 0.9868262 & -0.93104 \\
\hline 87.0000000 & 0.9866704 & -0.93312 \\
\hline 88.0000000 & 0.9866704 & -0.9331 \\
\hline 89.0000000 & 0.9864653 & -0.9359 \\
\hline 90.0000000 & 0.9864551 & -0.93609 \\
\hline 91.0000000 & 0.9864540 & -0.936 \\
\hline 92.0000000 & 0.9864529 & -0.936 \\
\hline 93.0000000 & 0.9864395 & -0.93629 \\
\hline 94.0000000 & 0.9864224 & -0.93 \\
\hline 95.0000000 & 0.9861944 & -0.93 \\
\hline
\end{tabular}




\begin{tabular}{|c|c|c|}
\hline 96.0000000 & 0.9859253 & -0.9434785 \\
\hline 97.0000000 & 0.9856562 & -0.9472301 \\
\hline 98.0000000 & 0.9854344 & -0.9503770 \\
\hline 99.0000000 & 0.9852127 & -0.9535254 \\
\hline 00.0000000 & 0.9851219 & -0.9548102 \\
\hline 101.0000000 & 0.9850521 & -0.9558384 \\
\hline 102.0000000 & 0.9849645 & -0.9571314 \\
\hline 103.0000000 & 0.9848364 & -0.9590172 \\
\hline 104.0000000 & 0.9851219 & -0.9548102 \\
\hline 105.0000000 & 0.9850550 & -0.9557057 \\
\hline 106.0000000 & 0.9849487 & -0.9571426 \\
\hline 107.0000000 & 0.9848343 & -0.958 \\
\hline 108.0000000 & 0.9847188 & -0.9602450 \\
\hline 109.0000000 & 0.9846126 & -0.9616828 \\
\hline 110.0000000 & 0.9845274 & -0.9628 \\
\hline 111.0000000 & 0.9864957 & -0.9353962 \\
\hline 112.0000000 & 0.9862771 & -0.9382070 \\
\hline 113.0000000 & 0.9860622 & -0.9409799 \\
\hline 114.0000000 & 0.9858466 & -0.9437619 \\
\hline 115.0000000 & 0.9864224 & -0.9365154 \\
\hline 116.0000000 & 0.9864220 & -0.9365299 \\
\hline 117.0000000 & 0.9864208 & -0.9365728 \\
\hline 118.0000000 & 0.9864213 & -0.9365504 \\
\hline 119.0000000 & 0.9864205 & -0.9365809 \\
\hline 120.0000000 & 0.9856561 & -0.94723 \\
\hline 121.0000000 & 0.9856550 & -0.9472818 \\
\hline 122.0000000 & 0.9856459 & -0.9475 \\
\hline 123.0000000 & 0.9856484 & -0.94751 \\
\hline
\end{tabular}




\begin{tabular}{|c|c|c|}
\hline 24.0000000 & 0.9856376 & -0.9477443 \\
\hline 25.0000000 & 0.9856425 & -0.9477179 \\
\hline 26.0000000 & 0.9856298 & -0.9479492 \\
\hline 27.0000000 & 0.9856403 & -0.9477953 \\
\hline 00000 & 0.9856298 & -0.9479493 \\
\hline 129.0000000 & 0.9856393 & -0.9478049 \\
\hline 30.0000000 & 0.9856392 & -0.9478363 \\
\hline 31.0000000 & 0.9856396 & -0.9478220 \\
\hline 00000 & 0.9856387 & -0.9478193 \\
\hline 133.0000000 & 0.9848361 & -0.9590212 \\
\hline 134.0000000 & 0.9848327 & -0.959 \\
\hline 135.0000000 & 0.9848142 & -0.95 \\
\hline 136.0000000 & 0.9847889 & -0.96081 \\
\hline 37.0000000 & 049 & -0.9601 \\
\hline 138.0000000 & 0.9847476 & -0.9615003 \\
\hline 139.0000000 & 0.9847884 & -0.9608308 \\
\hline 40.0000000 & 0.9848045 & -0.9601870 \\
\hline 141.0000000 & 0.9847987 & -0.9602664 \\
\hline 142.0000000 & 0.9848005 & -0.9602503 \\
\hline 143.0000000 & 0.9847346 & -0.9616844 \\
\hline 144.0000000 & 0.9847885 & -0.9604140 \\
\hline 145.0000000 & 7966 & -0.96 \\
\hline 146.0000000 & 7220 & -0.9 \\
\hline 147.0000000 & 0.9847790 & -0.960552 \\
\hline 148.0000000 & 0.9847181 & -0.961906 \\
\hline 149.0000000 & 0.9847706 & -0.9606 \\
\hline 150.0000000 & 0.9847150 & -0.961936 \\
\hline 1.0 & 47656 & 96 \\
\hline
\end{tabular}




\begin{tabular}{lll}
152.0000000 & 0.9847131 & -0.9619558 \\
153.0000000 & 0.9847636 & -0.9607568 \\
154.0000000 & 0.9847120 & -0.9619666 \\
155.0000000 & 0.9847627 & -0.9607655 \\
156.0000000 & 0.9847629 & -0.9607677 \\
157.0000000 & 0.9847629 & -0.9607677 \\
158.0000000 & 0.9845272 & -0.9628317 \\
\hline 159.0000000 & 0.9845249 & -0.9629336 \\
\hline 160.0000000 & 0.9844987 & -0.9638662 \\
161.0000000 & 0.9845176 & -0.9631418 \\
\hline 162.0000000 & 0.9844839 & -0.9643934 \\
\hline 163.0000000 & 0.9845099 & -0.9633549 \\
\hline 174.0000000 & 0.9844811 & -0.9644251 \\
\hline 175.000
\end{tabular}




\begin{tabular}{|c|c|c|}
\hline 180.0000000 & 0.9844704 & -0.9645507 \\
\hline 81.0000000 & 0.9844704 & -0.964551 \\
\hline 82.0000000 & 0.9858461 & -0.943766 \\
\hline 83.0000000 & 0.9840641 & -1.0912576 \\
\hline 34.0000000 & 0.9840257 & -1.0926287 \\
\hline 185.0000000 & 0.9840152 & -1.0926337 \\
\hline 86.0000000 & 0.9839904 & -1.09 \\
\hline 87.0000000 & 0.9839991 & -1.0 \\
\hline 188.0000000 & 0.9839440 & -1.09 \\
\hline 189.0000000 & 0.9839932 & -1.0933306 \\
\hline 190.0000000 & 0.9839836 & $-1.0 s$ \\
\hline 191.0000000 & 0.9839989 & -1. \\
\hline 192.0000000 & 0.9839127 & -1.0951 \\
\hline 193.0000000 & 0.9839826 & -1.0937558 \\
\hline 194.0000000 & 0.9839540 & -1.0938400 \\
\hline 195.0000000 & 0.9839989 & -1.0930978 \\
\hline 196.0000000 & 0.9838974 & -1.0953220 \\
\hline 197.0000000 & 0.9839127 & -1.0951083 \\
\hline 198.0000000 & 0.9839127 & -1.0951084 \\
\hline 199.0000000 & 0.9839730 & 41 \\
\hline 200.0000000 & 0.9839989 & -1.0930978 \\
\hline 201.0000000 & 0.98 & -1.0 \\
\hline 202.0000000 & 0.9 & -1.05 \\
\hline 203.0000000 & 0.9839687 & -1.0942 \\
\hline 204.0000000 & 0.98 & -1.095 \\
\hline 205.0000000 & 0.9839699 & -1.094 \\
\hline 206.0000000 & 0.9839637 & $-1.0 \varsigma$ \\
\hline 7.0 & 60 & $.0 S$ \\
\hline
\end{tabular}




\section{$208.0000000 \quad 0.9839603 \quad-1.0945596$}

\section{RELATÓRIO DE CONVERGÊNCIA}

\section{Tolerância de Convergência: 0.0010}

\section{Iteração Mismatche}

$$
\begin{array}{ll}
0.0000000 & 1.0000000 \\
1.0000000 & 0.0189186 \\
2.0000000 & 0.0001997
\end{array}
$$

$\begin{array}{llll}1 & 2 & 1.00869 & 0.70221 \\ 2 & 3 & 1.00860 & 0.70195 \\ 3 & 4 & 1.00857 & 0.70189 \\ 4 & 5 & 1.00836 & 0.70109 \\ 5 & 6 & 1.00833 & 0.70105 \\ 6 & 7 & 1.00829 & 0.70099 \\ 7 & 8 & 1.00823 & 0.70080 \\ 8 & 9 & 0.00003 & 0.00003 \\ 8 & 10 & 1.00812 & 0.70053 \\ 10 & 11 & 1.00697 & 0.69573\end{array}$




$$
\begin{aligned}
& \begin{array}{llll}
11 & 12 & 0.01353 & 0.00960
\end{array} \\
& \begin{array}{llll}
11 & 16 & 0.99191 & 0.67980
\end{array} \\
& \begin{array}{llll}
12 & 13 & 0.01350 & 0.00957
\end{array} \\
& \begin{array}{llll}
13 & 14 & 0.01348 & 0.00954
\end{array} \\
& \begin{array}{llll}
14 & 15 & 0.01345 & 0.00951
\end{array} \\
& \begin{array}{llll}
16 & 17 & 0.99167 & 0.67884
\end{array} \\
& \begin{array}{llll}
17 & 18 & 0.99126 & 0.67719
\end{array} \\
& \begin{array}{llll}
18 & 19 & 0.99090 & 0.67580
\end{array} \\
& \begin{array}{llll}
19 & 20 & 0.00008 & 0.00009
\end{array} \\
& \begin{array}{llll}
19 & 23 & 0.99051 & 0.67450
\end{array} \\
& \begin{array}{llll}
20 & 21 & 0.00006 & 0.00006
\end{array} \\
& \begin{array}{llll}
21 & 22 & 0.00003 & 0.00003
\end{array} \\
& \begin{array}{llll}
23 & 24 & 0.99029 & 0.67367
\end{array} \\
& \begin{array}{llll}
24 & 25 & 0.00039 & 0.00030
\end{array} \\
& \begin{array}{llll}
24 & 29 & 0.98967 & 0.67252
\end{array} \\
& \begin{array}{llll}
25 & 26 & 0.00037 & 0.00027
\end{array} \\
& \begin{array}{llll}
26 & 27 & 0.00034 & 0.00024
\end{array} \\
& \begin{array}{llll}
27 & 28 & 0.00031 & 0.00021
\end{array} \\
& \begin{array}{llll}
29 & 30 & 0.98942 & 0.67155
\end{array} \\
& \begin{array}{llll}
30 & 31 & 0.98920 & 0.67069
\end{array} \\
& \begin{array}{llll}
31 & 32 & 0.98898 & 0.66987
\end{array} \\
& \begin{array}{llll}
32 & 33 & 0.98866 & 0.66859
\end{array} \\
& \begin{array}{llll}
33 & 34 & 0.98862 & 0.66853
\end{array} \\
& \begin{array}{llll}
34 & 35 & 0.98859 & 0.66849
\end{array} \\
& \begin{array}{llll}
35 & 67 & 0.98755 & 0.66700
\end{array} \\
& \begin{array}{llll}
35 & 36 & 0.00088 & 0.00091
\end{array}
\end{aligned}
$$




\begin{tabular}{|c|c|c|c|}
\hline 36 & 37 & 0.00085 & 0.00088 \\
\hline 37 & 38 & 0.00082 & 0.00085 \\
\hline 38 & 39 & 0.00079 & 0.00082 \\
\hline 39 & 40 & 0.00077 & 0.00079 \\
\hline 40 & 41 & 0.00074 & 0.00076 \\
\hline 41 & 42 & 0.00071 & 0.00073 \\
\hline 42 & 43 & 0.00068 & 0.00071 \\
\hline 43 & 44 & 0.00065 & 0.00068 \\
\hline 44 & 45 & 0.00062 & 0.00065 \\
\hline 45 & 46 & 0.00060 & 0.00062 \\
\hline 46 & 47 & 0.00057 & 0.00059 \\
\hline 47 & 48 & 0.00054 & 0.00056 \\
\hline 48 & 49 & 0.00051 & 0.00053 \\
\hline 49 & 50 & 0.00048 & 0.00050 \\
\hline 50 & 51 & 0.00045 & 0.00047 \\
\hline 51 & 52 & 0.00043 & 0.00044 \\
\hline 52 & 53 & 0.00023 & 0.00024 \\
\hline 52 & 61 & 0.00017 & 0.00018 \\
\hline 53 & 54 & 0.00020 & 0.00021 \\
\hline 54 & 55 & 0.00017 & 0.00018 \\
\hline 55 & 56 & 0.00014 & 0.00015 \\
\hline 56 & 57 & 0.00011 & 0.00012 \\
\hline 57 & 58 & 0.00009 & 0.00009 \\
\hline 58 & 59 & 0.00006 & 0.00006 \\
\hline 59 & 60 & 0.00003 & 0.00003 \\
\hline 61 & 62 & 0.00014 & 0.00015 \\
\hline
\end{tabular}




\begin{tabular}{|c|c|c|c|}
\hline 62 & 63 & 0.00011 & 0.00012 \\
\hline 63 & 64 & 0.00009 & 0.00009 \\
\hline 64 & 65 & 0.00006 & 0.00006 \\
\hline 65 & 66 & 0.00003 & 0.00003 \\
\hline 67 & 68 & 0.98744 & 0.66661 \\
\hline 68 & 69 & 0.00011 & 0.00012 \\
\hline 68 & 73 & 0.98721 & 0.66610 \\
\hline 69 & 70 & 0.00009 & 0.00009 \\
\hline 70 & 71 & 0.00006 & 0.00006 \\
\hline 71 & 72 & 0.00003 & 0.00003 \\
\hline 73 & 74 & 0.98704 & 0.66544 \\
\hline 74 & 75 & 0.98687 & 0.66484 \\
\hline 75 & 76 & 0.98672 & 0.66427 \\
\hline 76 & 77 & 0.00009 & 0.00009 \\
\hline 76 & 80 & 0.98647 & 0.66362 \\
\hline 77 & 78 & 0.00006 & 0.00006 \\
\hline 78 & 79 & 0.00003 & 0.00003 \\
\hline 80 & 81 & 0.98632 & 0.66305 \\
\hline 81 & 82 & 0.98615 & 0.66241 \\
\hline 82 & 83 & 0.98561 & 0.66183 \\
\hline 83 & 84 & 0.98556 & 0.66177 \\
\hline 84 & 85 & 0.98552 & 0.66173 \\
\hline 85 & 86 & 0.98519 & 0.66139 \\
\hline 86 & 87 & 0.98484 & 0.66100 \\
\hline 87 & 88 & 0.00003 & 0.00003 \\
\hline 87 & 89 & 0.56505 & 0.37366 \\
\hline
\end{tabular}




\begin{tabular}{|c|c|c|c|}
\hline 87 & 111 & 0.41960 & 0.28714 \\
\hline 89 & 90 & 0.03340 & 0.02290 \\
\hline 89 & 95 & 0.53152 & 0.35063 \\
\hline 90 & 91 & 0.03337 & 0.02287 \\
\hline 91 & 92 & 0.03335 & 0.02284 \\
\hline 92 & 93 & 0.03332 & 0.02281 \\
\hline 93 & 94 & 0.03329 & 0.02278 \\
\hline 95 & 96 & 0.53137 & 0.35047 \\
\hline 96 & 97 & 0.53122 & 0.35031 \\
\hline 97 & 98 & 0.43926 & 0.28717 \\
\hline 98 & 99 & 0.43915 & 0.28705 \\
\hline 99 & 100 & 0.43904 & 0.28694 \\
\hline 100 & 101 & 0.24761 & 0.15858 \\
\hline 100 & 104 & 0.00003 & 0.00003 \\
\hline 100 & 105 & 0.19134 & 0.12826 \\
\hline 101 & 102 & 0.24757 & 0.15854 \\
\hline 102 & 103 & 0.24752 & 0.15849 \\
\hline 105 & 106 & 0.19130 & 0.12822 \\
\hline 106 & 107 & 0.19125 & 0.12817 \\
\hline 107 & 108 & 0.19121 & 0.12812 \\
\hline 108 & 109 & 0.19116 & 0.12807 \\
\hline 109 & 110 & 0.19111 & 0.12802 \\
\hline 111 & 112 & 0.41951 & 0.28705 \\
\hline 112 & 113 & 0.41940 & 0.28693 \\
\hline 113 & 114 & 0.41929 & 0.28682 \\
\hline 94 & 115 & 0.01826 & 0.0 \\
\hline
\end{tabular}




$$
\begin{aligned}
& \begin{array}{llll}
115 & 116 & 0.01824 & 0.01178
\end{array} \\
& \begin{array}{llll}
116 & 117 & 0.00331 & 0.00207
\end{array} \\
& \begin{array}{llll}
116 & 118 & 0.00181 & 0.00136
\end{array} \\
& \begin{array}{llll}
117 & 119 & 0.00074 & 0.00050
\end{array} \\
& \begin{array}{llll}
97 & 120 & 0.05992 & 0.04146
\end{array} \\
& \begin{array}{llll}
120 & 121 & 0.05781 & 0.04019
\end{array} \\
& \begin{array}{llll}
121 & 122 & 0.02177 & 0.01767
\end{array} \\
& \begin{array}{llll}
121 & 123 & 0.01832 & 0.01169
\end{array} \\
& \begin{array}{llll}
122 & 124 & 0.01997 & 0.01629
\end{array} \\
& \begin{array}{llll}
123 & 125 & 0.01611 & 0.01033
\end{array} \\
& \begin{array}{llll}
124 & 126 & 0.01816 & 0.01492
\end{array} \\
& \begin{array}{llll}
125 & 127 & 0.01343 & 0.00870
\end{array} \\
& \begin{array}{llll}
126 & 128 & 0.00003 & 0.00003
\end{array} \\
& \begin{array}{llll}
127 & 129 & 0.00360 & 0.00274
\end{array} \\
& \begin{array}{llll}
127 & 130 & 0.00553 & 0.00333
\end{array} \\
& \begin{array}{llll}
127 & 131 & 0.00427 & 0.00260
\end{array} \\
& \begin{array}{llll}
129 & 132 & 0.00180 & 0.00137
\end{array} \\
& \begin{array}{llll}
103 & 133 & 0.17515 & 0.10691
\end{array} \\
& \begin{array}{llll}
133 & 134 & 0.17512 & 0.10688
\end{array} \\
& \begin{array}{llll}
134 & 135 & 0.04731 & 0.02973
\end{array} \\
& \begin{array}{llll}
134 & 136 & 0.11781 & 0.07108
\end{array} \\
& \begin{array}{llll}
135 & 137 & 0.04108 & 0.02597
\end{array} \\
& \begin{array}{llll}
136 & 138 & 0.11405 & 0.06853
\end{array} \\
& \begin{array}{llll}
136 & 139 & 0.00181 & 0.00137
\end{array} \\
& \begin{array}{llll}
137 & 140 & 0.00182 & 0.00136
\end{array} \\
& \begin{array}{llll}
137 & 141 & 0.02220 & 0.01436
\end{array}
\end{aligned}
$$




\begin{tabular}{|c|c|c|c|}
\hline 137 & 142 & 0.01703 & 0.01022 \\
\hline 138 & 143 & 0.02564 & 0.01678 \\
\hline 141 & 144 & 0.02104 & 0.01365 \\
\hline 142 & 145 & 0.00863 & 0.00520 \\
\hline 143 & 146 & 0.02384 & 0.01542 \\
\hline 144 & 147 & 0.01879 & 0.01216 \\
\hline 146 & 148 & 0.00720 & 0.00547 \\
\hline 147 & 149 & 0.01576 & 0.01033 \\
\hline 148 & 150 & 0.00541 & 0.00410 \\
\hline 149 & 151 & 0.00978 & 0.00674 \\
\hline 150 & 152 & 0.00361 & 0.00274 \\
\hline 151 & 153 & 0.00517 & 0.00370 \\
\hline 152 & 154 & 0.00181 & 0.00138 \\
\hline 153 & 155 & 0.00180 & 0.00136 \\
\hline 153 & 156 & 0.00158 & 0.00098 \\
\hline 156 & 157 & 0.00003 & 0.00003 \\
\hline 110 & 158 & 0.11227 & 0.07451 \\
\hline 158 & 159 & 0.11224 & 0.07448 \\
\hline 159 & 160 & 0.08372 & 0.05266 \\
\hline 159 & 161 & 0.02245 & 0.01725 \\
\hline 160 & 162 & 0.08191 & 0.05157 \\
\hline 161 & 163 & 0.01873 & 0.01470 \\
\hline 162 & 164 & 0.00869 & 0.00634 \\
\hline 162 & 165 & 0.06228 & 0.03792 \\
\hline 162 & 166 & 0.01091 & 0.00727 \\
\hline 163 & 167 & 0.01483 & 0.01 \\
\hline
\end{tabular}




$$
\begin{aligned}
& \begin{array}{llll}
164 & 168 & 0.00688 & 0.00498
\end{array} \\
& \begin{array}{llll}
165 & 169 & 0.05865 & 0.03567
\end{array} \\
& \begin{array}{llll}
166 & 170 & 0.00910 & 0.00591
\end{array} \\
& \begin{array}{llll}
167 & 171 & 0.00761 & 0.00609
\end{array} \\
& \begin{array}{llll}
167 & 172 & 0.00542 & 0.00408
\end{array} \\
& \begin{array}{llll}
168 & 173 & 0.00542 & 0.00410
\end{array} \\
& \begin{array}{llll}
170 & 174 & 0.00730 & 0.00453
\end{array} \\
& \begin{array}{llll}
171 & 175 & 0.00580 & 0.00474
\end{array} \\
& \begin{array}{llll}
172 & 176 & 0.00361 & 0.00271
\end{array} \\
& \begin{array}{llll}
173 & 177 & 0.00363 & 0.00275
\end{array} \\
& \begin{array}{llll}
174 & 178 & 0.00202 & 0.00137
\end{array} \\
& \begin{array}{llll}
176 & 179 & 0.00180 & 0.00136
\end{array} \\
& \begin{array}{llll}
177 & 180 & 0.00182 & 0.00139
\end{array} \\
& \begin{array}{llll}
180 & 181 & 0.00003 & 0.00003
\end{array} \\
& \begin{array}{llll}
114 & 182 & 0.25313 & 0.17814
\end{array} \\
& \begin{array}{llll}
182 & 183 & 0.25310 & 0.17811
\end{array} \\
& \begin{array}{llll}
183 & 184 & 0.10674 & 0.06700
\end{array} \\
& \begin{array}{llll}
183 & 185 & 0.11773 & 0.09141
\end{array} \\
& \begin{array}{llll}
184 & 186 & 0.09853 & 0.06207
\end{array} \\
& \begin{array}{llll}
185 & 187 & 0.11172 & 0.08683
\end{array} \\
& \begin{array}{llll}
186 & 188 & 0.09246 & 0.05756
\end{array} \\
& \begin{array}{llll}
187 & 189 & 0.03354 & 0.01862
\end{array} \\
& \begin{array}{llll}
187 & 190 & 0.07728 & 0.06762
\end{array} \\
& \begin{array}{llll}
187 & 191 & 0.00087 & 0.00056
\end{array} \\
& \begin{array}{llll}
188 & 192 & 0.08642 & 0.05304
\end{array} \\
& \begin{array}{llll}
189 & 193 & 0.03222 & 0.01781
\end{array}
\end{aligned}
$$




$\begin{array}{llll}190 & 194 & 0.06563 & 0.05890 \\ 191 & 195 & 0.00006 & 0.00006 \\ 192 & 196 & 0.08633 & 0.05295 \\ 192 & 197 & 0.00003 & 0.00003 \\ 192 & 198 & 0.00003 & 0.00003 \\ 193 & 199 & 0.03029 & 0.01665 \\ 195 & 200 & 0.00003 & 0.00003 \\ 196 & 201 & 0.01206 & 0.00904 \\ 199 & 202 & 0.01054 & 0.00632 \\ 199 & 203 & 0.01441 & 0.00628 \\ 201 & 204 & 0.00600 & 0.00453 \\ 202 & 205 & 0.00003 & 0.00003 \\ 203 & 206 & 0.01182 & 0.00472 \\ 206 & 207 & 0.00804 & 0.00243 \\ 207 & 208 & 0.00181 & -0.00133\end{array}$




\section{Apêndice B - Resultados do processo de estimação para a rede do transformador 1370.}

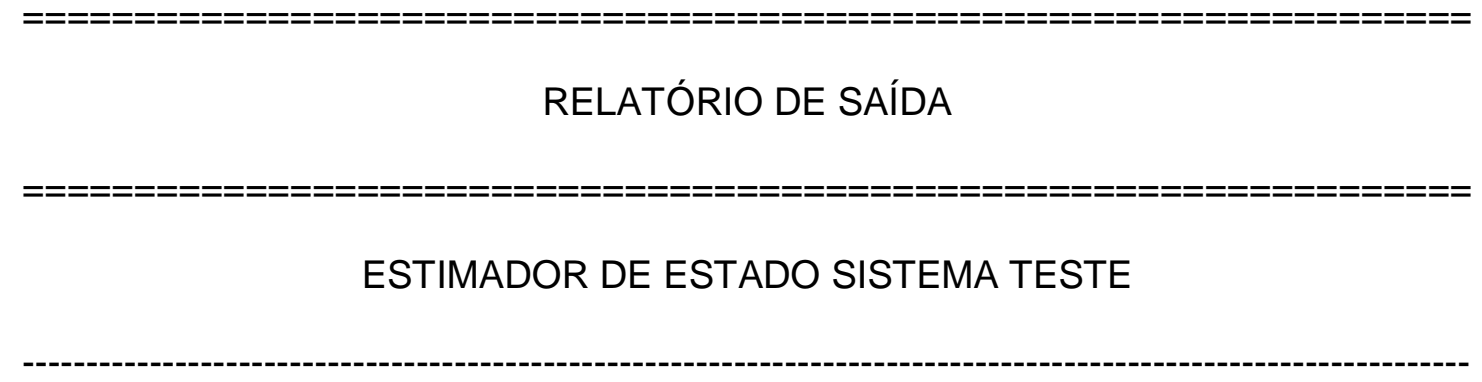

Número de Barras: 28

Número de Linhas: 27

Estimador de estado pelo método dos Mínimos Quadrados Ponderados

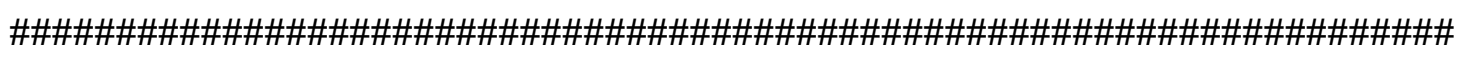
RESULTADOS DO ESTIMADOR NA ITERAÇÃO 1

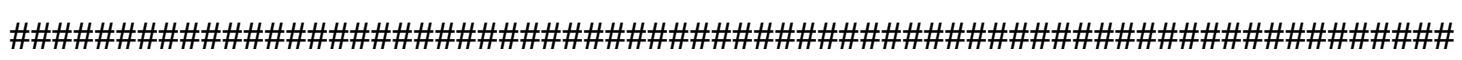

Barra Tensão (pu) Ângulo $(\stackrel{\circ}{)})$

$\begin{array}{lll}1.0000000 & 0.9858465 & 0.0000000 \\ 2.0000000 & 0.9858461 & -0.0000044 \\ 3.0000000 & 0.9840642 & -0.1474899 \\ 4.0000000 & 0.9840258 & -0.1488610 \\ 5.0000000 & 0.9840153 & -0.1488659 \\ 6.0000000 & 0.9839905 & -0.1501166 \\ 7.0000000 & 0.9839992 & -0.1493237 \\ 8.0000000 & 0.9839441 & -0.1508395 \\ 9.0000000 & 0.9839933 & -0.1495628 \\ 10.0000000 & 0.9839837 & -0.1496981 \\ 11.0000000 & 0.9839990 & -0.1493300\end{array}$




\begin{tabular}{lll}
12.0000000 & 0.9839128 & -0.1513409 \\
13.0000000 & 0.9839827 & -0.1499880 \\
14.0000000 & 0.9839541 & -0.1500722 \\
15.0000000 & 0.9839990 & -0.1493300 \\
16.0000000 & 0.9838975 & -0.1515543 \\
17.0000000 & 0.9839128 & -0.1513406 \\
18.0000000 & 0.9839128 & -0.1513407 \\
\hline 19.0000000 & 0.9839731 & -0.1503764 \\
\hline 20.0000000 & 0.9839990 & -0.1493301 \\
\hline 21.0000000 & 0.9838923 & -0.1516077 \\
\hline 22.0000000 & 0.9839700 & -0.1504949 \\
\hline 23.0000000 & 0.9839688 & -0.1504841 \\
\hline 24.0000000 & 0.9838901 & -0.1516302 \\
\hline 25.0000000 & 0.9839700 & -0.1504952 \\
\hline 26.0000000 & 0.9839638 & -0.1506208 \\
\hline 27.0000000 & 0.9839605 & -0.1507331 \\
\hline 28.0000000 & 0.9839604 & -0.1507919
\end{tabular}

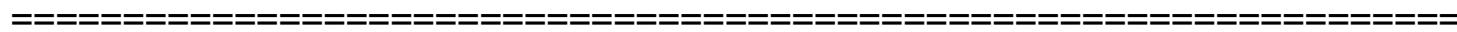

RELATÓRIO DE CONVERGÊNCIA

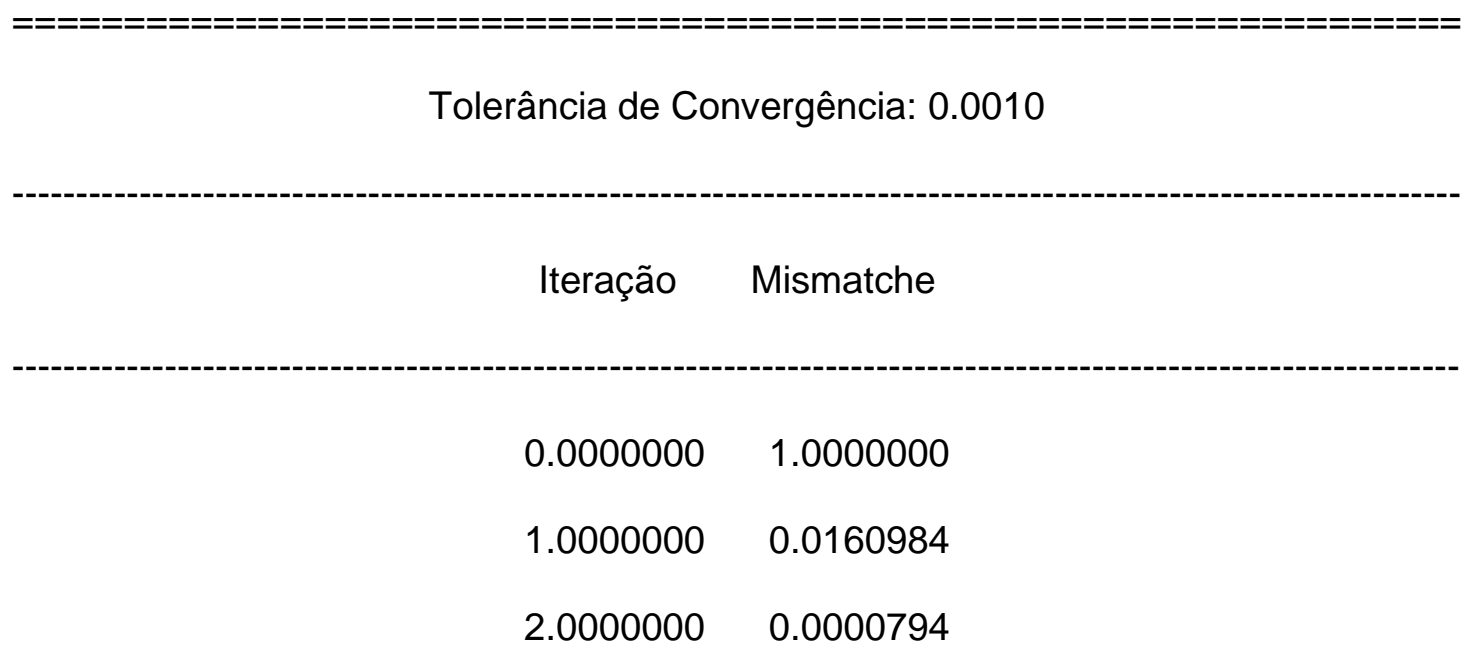


De Para Pkm Qkm

\begin{tabular}{|c|c|c|c|}
\hline 1 & 2 & 0.253116 & 0.178125 \\
\hline 2 & 3 & 0.253087 & 0.178096 \\
\hline 3 & 4 & 0.106739 & 0.066994 \\
\hline 3 & 5 & 0.117723 & 0.091406 \\
\hline 4 & 6 & 0.098531 & 0.062065 \\
\hline 5 & 7 & 0.111712 & 0.086827 \\
\hline 6 & 8 & 0.092459 & 0.057558 \\
\hline 7 & 9 & 0.033535 & 0.018615 \\
\hline 7 & 10 & 0.077281 & 0.067620 \\
\hline 7 & 11 & 0.000867 & 0.000560 \\
\hline 8 & 12 & 0.086419 & 0.053039 \\
\hline 9 & 13 & 0.032220 & 0.017806 \\
\hline 10 & 14 & 0.065632 & 0.058902 \\
\hline & 15 & 0.000057 & 0.000059 \\
\hline 12 & 16 & 0.086331 & 0.052949 \\
\hline & 17 & 0.000029 & 0.000029 \\
\hline & 18 & 0.000029 & 0.000029 \\
\hline & 19 & 0.030289 & 0.016645 \\
\hline & 20 & 0.000029 & 0.000029 \\
\hline 1 & 21 & 0.012063 & 0.009041 \\
\hline 1 & 22 & 0.010535 & 0.006319 \\
\hline 1 & 23 & 0.014408 & 0.006280 \\
\hline
\end{tabular}




$$
\begin{array}{llll}
21 & 24 & 0.005996 & 0.004530 \\
22 & 25 & 0.000029 & 0.000029 \\
23 & 26 & 0.011816 & 0.004717 \\
26 & 27 & 0.008044 & 0.002427 \\
27 & 28 & 0.001805 & -0.001335
\end{array}
$$




\section{Apêndice C - Resultados do processo de estimação para a rede primária com os valores de $P$ e $Q$ de cada transformador recebidos da plataforma embarcada.}

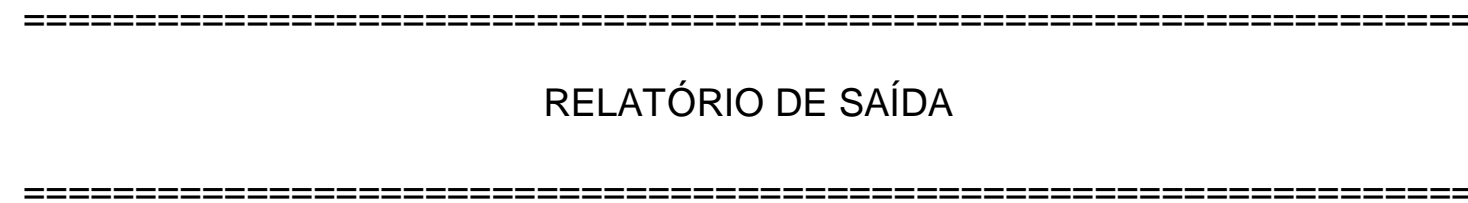

ESTIMADOR DE ESTADO SISTEMA TESTE

Número de Barras: 119

Número de Linhas: 118

Estimador de estado pelo método dos Mínimos Quadrados Ponderados

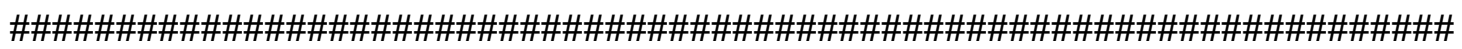
RESULTADOS DO ESTIMADOR NA ITERAÇÃO 1

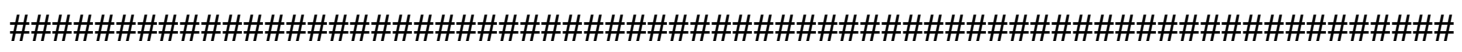

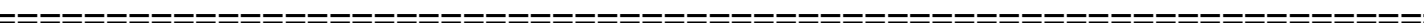

Barra Tensão (pu) Ângulo (oํ)

$\begin{array}{lll}1.0000000 & 1.0056390 & 0.0000000 \\ 2.0000000 & 1.0054916 & -0.0075563 \\ 3.0000000 & 1.0054733 & -0.0084427 \\ 4.0000000 & 1.0049917 & -0.0330055 \\ 5.0000000 & 1.0049827 & -0.0334971 \\ 6.0000000 & 1.0049644 & -0.0343829 \\ 7.0000000 & 1.0048648 & -0.0394947 \\ 8.0000000 & 1.0047272 & -0.0464891\end{array}$




\begin{tabular}{|c|c|c|}
\hline 9.0000000 & 1.0047272 & -0.0464928 \\
\hline 10.0000000 & 1.0017492 & -0.1989824 \\
\hline 11.0000000 & 0.9978198 & -0.4020841 \\
\hline 12.0000000 & 0.9978196 & -0.4020918 \\
\hline 13.0000000 & 0.9978194 & -0.4021053 \\
\hline 14.0000000 & 0.9978133 & -0.4021885 \\
\hline 15.0000000 & 0.9977979 & -0.4023849 \\
\hline 16.0000000 & 0.9972348 & -0.4324849 \\
\hline 17.0000000 & 0.9962171 & -0.4854493 \\
\hline 18.0000000 & 0.9953598 & -0.5301395 \\
\hline 19.0000000 & 0.9946161 & -0.5689556 \\
\hline 20.0000000 & 0.9946160 & -0.5689576 \\
\hline 21.0000000 & 0.9946160 & -0.5689586 \\
\hline 22.0000000 & 0.9946160 & -0.5689604 \\
\hline 23.0000000 & 0.9941119 & -0.5952638 \\
\hline 24.0000000 & 0.9935963 & -0.6222055 \\
\hline 25.0000000 & 0.9935963 & -0.6222068 \\
\hline 26.0000000 & 0.9935963 & -0.6222086 \\
\hline 27.0000000 & 0.9935955 & -0.6222411 \\
\hline 28.0000000 & 0.9935952 & -0.6222533 \\
\hline 29.0000000 & 0.9930094 & -0.6528321 \\
\hline 30.0000000 & 0.9924855 & -0.6802785 \\
\hline 31.0000000 & 0.9919891 & -0.7063066 \\
\hline 32.0000000 & 0.9912073 & -0.7472678 \\
\hline 33.0000000 & 0.9911895 & -0.7481525 \\
\hline 34.0000000 & 0.9911845 & -0.7484543 \\
\hline 35.0000000 & 0.9908405 & -0.7664666 \\
\hline 36.0000000 & 0.990840 & $-0.76647 \subseteq$ \\
\hline
\end{tabular}




\begin{tabular}{|c|c|c|}
\hline 37.0000000 & 0.9908399 & -0.7665020 \\
\hline 38.0000000 & 0.9908321 & -0.7669210 \\
\hline 9.0000000 & 0.9908318 & -0.7669351 \\
\hline 10.0000000 & 0.9908314 & -0.7669558 \\
\hline 1.0000000 & 0.9908246 & -0.7673266 \\
\hline 42.0000000 & 0.9908173 & -0.7677169 \\
\hline 43.0000000 & 0.9908104 & -0.7680917 \\
\hline 4.0000000 & 0.9908048 & -0.7683905 \\
\hline 5.0000000 & 0.9907995 & $-0.7 €$ \\
\hline 6.0000000 & 0.9907945 & -0.76 \\
\hline 7.0000000 & 0.9907896 & -0.7692086 \\
\hline 48.0000000 & 0.9907890 & -0.7692433 \\
\hline 49.0000000 & 0.9907889 & -0.7692485 \\
\hline 50.0000000 & 0.9907887 & -0.7692575 \\
\hline 51.0000000 & 0.9907884 & -0.7692732 \\
\hline 52.0000000 & 0.9907881 & -0.7692926 \\
\hline 53.0000000 & 0.9907868 & -0.7693612 \\
\hline 54.0000000 & 0.9907858 & -0.7694159 \\
\hline 55.0000000 & 0.9907849 & -0.7694643 \\
\hline 56.0000000 & 0.9907841 & -0.7695059 \\
\hline 57.0000000 & 0.9907835 & 5391 \\
\hline 58.0000000 & 0.9907831 & -0.7695625 \\
\hline 59.0000000 & 0.9907828 & $-0.7 €$ \\
\hline 60.0000000 & 0.9907827 & -0 . \\
\hline 61.0000000 & 0.9907877 & -0 . \\
\hline 62.0000000 & 0.9907870 & -0.7 \\
\hline 63.0000000 & 0.9907865 & -0.7693787 \\
\hline 000 & 0.990 & -0 \\
\hline
\end{tabular}




\begin{tabular}{|c|c|c|}
\hline 65.0000000 & 0.9907859 & -0.7694085 \\
\hline 66.0000000 & 0.9907859 & -0.7694111 \\
\hline 67.0000000 & 0.9906139 & -0.7782585 \\
\hline 68.0000000 & 0.9903873 & -0.7900488 \\
\hline 69.0000000 & 0.9903873 & -0.7900506 \\
\hline 70.0000000 & 0.9903872 & -0.7900522 \\
\hline 71.0000000 & 0.9903872 & -0.7900525 \\
\hline 72.0000000 & 0.9903872 & -0.7900541 \\
\hline 73.0000000 & 0.9899955 & -0.8103083 \\
\hline 74.0000000 & 0.9896424 & -0.8285608 \\
\hline 75.0000000 & 0.9893071 & -0.8459495 \\
\hline 76.0000000 & 0.9889719 & -0.8633395 \\
\hline 77.0000000 & 0.9889718 & -0.8633415 \\
\hline 78.0000000 & 0.9889718 & -0.8633426 \\
\hline 79.0000000 & 0.9889717 & -0.8633487 \\
\hline 80.0000000 & 0.9886399 & -0.8805712 \\
\hline 81.0000000 & 0.9882572 & -0.9003810 \\
\hline 82.0000000 & 0.9876636 & -0.9076834 \\
\hline 83.0000000 & 0.9876329 & -0.9080979 \\
\hline 84.0000000 & 0.9876160 & -0.9083217 \\
\hline 85.0000000 & 0.9872774 & -0.9124926 \\
\hline 86.0000000 & 0.9868968 & -0.9171916 \\
\hline 87.0000000 & 0.9867446 & -0.9190507 \\
\hline 88.0000000 & 0.9867446 & -0.9190535 \\
\hline 89.0000000 & 0.9865485 & -0.9213263 \\
\hline 90.0000000 & 0.9865377 & -0.9214873 \\
\hline 91.0000000 & 0.9865366 & -0.9215058 \\
\hline 92.0000000 & 0.986535 & -0.92 \\
\hline
\end{tabular}




\begin{tabular}{|c|c|c|}
\hline 93.0000000 & 0.9865218 & -0.9217149 \\
\hline 94.0000000 & 0.9865044 & $-0.921952 c$ \\
\hline 95.0000000 & 0.9862910 & -0.924254 \\
\hline 96.0000000 & 0.9860355 & -0.9271590 \\
\hline 97.0000000 & 0.9857801 & 0.9300571 \\
\hline 98.0000000 & 0.9855563 & 0.933 \\
\hline 99.0000000 & 0.98 & 935 \\
\hline 00.0000000 & 0.98 & -0 . \\
\hline 01.0000000 & 0.9851710 & -0.9 \\
\hline 102.0000000 & 0.985 & -0 \\
\hline 03.0000000 & 0.98 & -0.9 \\
\hline 104.0000000 & 0.98 & $-0.937 c$ \\
\hline 105.0000000 & 0.98 & -0.9388 \\
\hline 106.0000000 & 0.9850663 & -0.9403492 \\
\hline 07.0000000 & 0.9849511 & -0.9 \\
\hline 08.0000000 & 0.9848350 & $-0.9<$ \\
\hline 109.0000000 & 0.9847283 & -0.9450043 \\
\hline 10.0000000 & 0.9846428 & -0.9461653 \\
\hline 111.0000000 & 0.9865694 & -0.92 \\
\hline 112.0000000 & 0.9863503 & -0.924196 \\
\hline 113.0000000 & 0.98 & -0.9 \\
\hline 114.0000000 & 59190 & -0.9 \\
\hline 115.0000000 & 0.9865044 & -0.92195 \\
\hline 116.0000000 & 0.9857801 & -0.9300 \\
\hline 117.0000000 & 0.9849544 & -0.942186 \\
\hline 118.0000000 & 0.9846427 & -0.946167 \\
\hline 19 & 186 & -0 \\
\hline
\end{tabular}




\section{RELATÓRIO DE CONVERGÊNCIA}

Tolerância de Convergência: 0.0010

Iteração Mismatche

$\begin{array}{ll}0.0000000 & 1.0000000 \\ 1.0000000 & 0.0163758 \\ 2.0000000 & 0.0001516\end{array}$

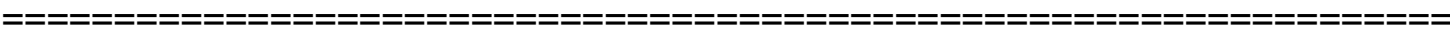

DADOS DE FLUXO POTÊNCIA ATIVA E REATIVA

De Para Pkm Qkm

$\begin{array}{cccc}1 & 2 & 1.00846 & 0.70221 \\ 2 & 3 & 1.00792 & 0.70195 \\ 3 & 4 & 1.00744 & 0.70189 \\ 4 & 5 & 1.00678 & 0.70109 \\ 5 & 6 & 1.00629 & 0.70104 \\ 6 & 7 & 1.00581 & 0.70099 \\ 7 & 8 & 1.00529 & 0.70080 \\ 8 & 9 & 0.00048 & 0.00003 \\ 8 & 10 & 1.00428 & 0.70052 \\ 10 & 11 & 1.00267 & 0.69575 \\ 11 & 12 & 0.01535 & 0.00961 \\ 11 & 16 & 0.98536 & 0.67984\end{array}$




$$
\begin{aligned}
& \begin{array}{llll}
12 & 13 & 0.01487 & 0.00957
\end{array} \\
& \begin{array}{llll}
13 & 14 & 0.01438 & 0.00954
\end{array} \\
& \begin{array}{llll}
14 & 15 & 0.01390 & 0.00951
\end{array} \\
& \begin{array}{llll}
16 & 17 & 0.98466 & 0.67888
\end{array} \\
& \begin{array}{llll}
17 & 18 & 0.98379 & 0.67725
\end{array} \\
& \begin{array}{llll}
18 & 19 & 0.98299 & 0.67587
\end{array} \\
& \begin{array}{llll}
19 & 20 & 0.00145 & 0.00010
\end{array} \\
& \begin{array}{llll}
19 & 23 & 0.98078 & 0.67457
\end{array} \\
& \begin{array}{llll}
20 & 21 & 0.00097 & 0.00006
\end{array} \\
& \begin{array}{llll}
21 & 22 & 0.00048 & 0.00003
\end{array} \\
& \begin{array}{llll}
23 & 24 & 0.98011 & 0.67374
\end{array} \\
& \begin{array}{llll}
24 & 25 & 0.00222 & 0.00031
\end{array} \\
& \begin{array}{llll}
24 & 29 & 0.97722 & 0.67259
\end{array} \\
& \begin{array}{llll}
25 & 26 & 0.00173 & 0.00028
\end{array} \\
& \begin{array}{llll}
26 & 27 & 0.00125 & 0.00025
\end{array} \\
& \begin{array}{llll}
27 & 28 & 0.00077 & 0.00022
\end{array} \\
& \begin{array}{llll}
29 & 30 & 0.97651 & 0.67164
\end{array} \\
& \begin{array}{llll}
30 & 31 & 0.97584 & 0.67078
\end{array} \\
& \begin{array}{llll}
31 & 32 & 0.97517 & 0.66997
\end{array} \\
& \begin{array}{llll}
32 & 33 & 0.97439 & 0.66872
\end{array} \\
& \begin{array}{llll}
33 & 34 & 0.97390 & 0.66865
\end{array} \\
& \begin{array}{llll}
34 & 35 & 0.97342 & 0.66861
\end{array} \\
& \begin{array}{llll}
35 & 67 & 0.95779 & 0.66702
\end{array} \\
& \begin{array}{llll}
35 & 36 & 0.01502 & 0.00103
\end{array} \\
& \begin{array}{llll}
36 & 37 & 0.01453 & 0.00099
\end{array} \\
& \begin{array}{llll}
37 & 38 & 0.01405 & 0.00096
\end{array} \\
& \begin{array}{llll}
38 & 39 & 0.01356 & 0.00093
\end{array} \\
& \begin{array}{llll}
39 & 40 & 0.01308 & 0.00089
\end{array}
\end{aligned}
$$




\begin{tabular}{|c|c|c|c|}
\hline 40 & 41 & 0.01259 & 0.00086 \\
\hline 41 & 42 & 0.01211 & 0.00083 \\
\hline 42 & 43 & 0.01163 & 0.00079 \\
\hline 43 & 44 & 0.01114 & 0.00076 \\
\hline 44 & 45 & 0.01066 & 0.00073 \\
\hline 45 & 46 & 0.01017 & 0.00069 \\
\hline 46 & 47 & 0.00969 & 0.00066 \\
\hline 47 & 48 & 0.00920 & 0.00063 \\
\hline 48 & 49 & 0.00872 & 0.00060 \\
\hline 49 & 50 & 0.00823 & 0.00056 \\
\hline 50 & 51 & 0.00775 & 0.00053 \\
\hline 51 & 52 & 0.00727 & 0.00050 \\
\hline 52 & 53 & 0.00388 & 0.00026 \\
\hline 52 & 61 & 0.00291 & 0.00020 \\
\hline 53 & 54 & 0.00339 & 0.00023 \\
\hline 54 & 55 & 0.00291 & 0.00020 \\
\hline 55 & 56 & 0.00242 & 0.00017 \\
\hline 56 & 57 & 0.00194 & 0.00013 \\
\hline 57 & 58 & 0.00145 & 0.00010 \\
\hline 58 & 59 & 0.00097 & 0.00007 \\
\hline 59 & 60 & 0.00048 & 0.00003 \\
\hline 61 & 62 & 0.00242 & 0.00017 \\
\hline 62 & 63 & 0.00194 & 0.00013 \\
\hline 63 & 64 & 0.00145 & 0.00010 \\
\hline 64 & 65 & 0.00097 & 0.00007 \\
\hline 65 & 66 & 0.00048 & 0.00003 \\
\hline 67 & 68 & 0.95722 & 0.66663 \\
\hline 68 & 69 & 0.00194 & 0.00013 \\
\hline
\end{tabular}




$$
\begin{aligned}
& \begin{array}{llll}
68 & 73 & 0.95472 & 0.66612
\end{array} \\
& \begin{array}{llll}
69 & 70 & 0.00145 & 0.00010
\end{array} \\
& \begin{array}{llll}
70 & 71 & 0.00097 & 0.00007
\end{array} \\
& \begin{array}{llll}
71 & 72 & 0.00048 & 0.00003
\end{array} \\
& \begin{array}{llll}
73 & 74 & 0.95409 & 0.66548
\end{array} \\
& \begin{array}{llll}
74 & 75 & 0.95348 & 0.66491
\end{array} \\
& \begin{array}{llll}
75 & 76 & 0.95287 & 0.66436
\end{array} \\
& \begin{array}{llll}
76 & 77 & 0.00145 & 0.00010
\end{array} \\
& \begin{array}{llll}
76 & 80 & 0.95081 & 0.66371
\end{array} \\
& \begin{array}{llll}
77 & 78 & 0.00097 & 0.00007
\end{array} \\
& \begin{array}{llll}
78 & 79 & 0.00048 & 0.00003
\end{array} \\
& \begin{array}{llll}
80 & 81 & 0.95020 & 0.66317
\end{array} \\
& \begin{array}{llll}
81 & 82 & 0.94959 & 0.66255
\end{array} \\
& \begin{array}{llll}
82 & 83 & 0.94861 & 0.66200
\end{array} \\
& \begin{array}{llll}
83 & 84 & 0.94810 & 0.66194
\end{array} \\
& \begin{array}{llll}
84 & 85 & 0.94760 & 0.66189
\end{array} \\
& \begin{array}{llll}
85 & 86 & 0.94684 & 0.66156
\end{array} \\
& \begin{array}{llll}
86 & 87 & 0.94605 & 0.66119
\end{array} \\
& \begin{array}{llll}
87 & 88 & 0.00049 & 0.00003
\end{array} \\
& \begin{array}{llll}
87 & 89 & 0.52305 & 0.37381
\end{array} \\
& \begin{array}{llll}
87 & 111 & 0.42190 & 0.28718
\end{array} \\
& \begin{array}{llll}
89 & 90 & 0.03616 & 0.02294
\end{array} \\
& \begin{array}{llll}
89 & 95 & 0.48631 & 0.35074
\end{array} \\
& \begin{array}{llll}
90 & 91 & 0.03567 & 0.02291
\end{array} \\
& \begin{array}{llll}
91 & 92 & 0.03519 & 0.02287
\end{array} \\
& \begin{array}{llll}
92 & 93 & 0.03470 & 0.02284
\end{array} \\
& \begin{array}{llll}
93 & 94 & 0.03422 & 0.02280
\end{array} \\
& \begin{array}{llll}
95 & 96 & 0.48572 & 0.35059
\end{array}
\end{aligned}
$$




\begin{tabular}{rrrr}
96 & 97 & 0.48512 & 0.35044 \\
97 & 98 & 0.44617 & 0.28729 \\
98 & 99 & 0.44560 & 0.28716 \\
99 & 100 & 0.44503 & 0.28704 \\
100 & 101 & 0.24945 & 0.15861 \\
100 & 104 & 0.00049 & 0.00003 \\
100 & 105 & 0.19457 & 0.12832 \\
101 & 102 & 0.24895 & 0.15856 \\
102 & 103 & 0.24845 & 0.15851 \\
105 & 106 & 0.19407 & 0.12827 \\
106 & 107 & 0.19356 & 0.12822 \\
107 & 108 & 0.19306 & 0.12816 \\
\hline 108 & 109 & 0.19255 & 0.12810 \\
\hline 109 & 110 & 0.19204 & 0.12805 \\
111 & 112 & 0.42135 & 0.28708 \\
112 & 113 & 0.42079 & 0.28696 \\
113 & 114 & 0.42022 & 0.28685 \\
94 & 115 & 0.01873 & 0.01183 \\
114 & 116 & 0.00648 & 0.04148 \\
\hline 103 & 117 & 0.17562 & 0.10693 \\
\hline 118 & 0.11274 & 0.07453 \\
\hline 19 & 0.25360 & 0.17816
\end{tabular}

